https://doi.org/10.15407/ujpe65.7.557

O. SHPENIK, ${ }^{1}$ A. ZAVILOPUlO, ${ }^{1}$ E. REMETA, ${ }^{1}$ S. DEMES,${ }^{2}$ M. ERDEVDY ${ }^{1}$

${ }^{1}$ Institute of Electron Physics, Nat. Acad. of Sci. of Ukraine

(21, Universytets'ka Str., Uzhgorod 88017, Ukraine)

2 Institute for Nuclear Research (MTA Atomki), Hungarian Academy of Sciences

(18/c Bem Sq., Debrecen 4026, Hungary)

\title{
INELASTIC PROCESSES \\ OF ELECTRON INTERACTION WITH CHALCOGENS IN THE GASEOUS PHASE
}

Complex research of elementary pair collision processes occurring when low-energy (0-70 eV) electrons pass through chalcogen ( $S, S e, T e)$ vapor has been carried out in the evaporation temperature intervals of those elements $(T=320 \div 700 \mathrm{~K}$ for sulfur, $420 \div 490 \mathrm{~K}$ for selenium, and $400 \div 600 \mathrm{~K}$ for tellurium). The vapor compositions of indicated elements are studied using the mass spectroscopy method. The radiation spectra are analyzed in the wavelength interval from 200 to $600 \mathrm{~nm}$ with the help of optical spectroscopy. Using highly monoenergetic electron beams, the total (integral) formation cross-sections for positive and negative $S, S e$, and Te ions are measured. It is found that, under the experimental conditions, the main components of chalcogen vapor are molecules containing 2 to 8 atoms. At the energies of bombarding electrons below $10 \mathrm{eV}$, the emission spectra mainly consist of bands of diatomic molecules, and, at higher energies $(E>15 \mathrm{eV})$, there appear separate atomic and ionic lines. At $E=50 \mathrm{eV}$, the lines of singly charged ions are the most intense ones. It is shown that the most effective reaction channel is the interaction of electrons with diatomic molecules of indicated elements, whereas other processes are mainly associated with the decay of polyatomic molecules. The excitation and ionization thresholds for interaction products are found by analyzing the energy dependences of process characteristics. Specific features are also observed in the energy dependences of the excitation and ionization functions. Doubly charged ions of diatomic sulfur molecules, as well as selenium and tellurium atoms, are revealed for the first time. The appearance of triply charged ions of diatomic sulfur molecules is also detected. The main contribution to the total (integral) effective ionization cross-section of both positive and negative ions is proved to be made by the interaction processes of electrons with diatomic molecules $\mathrm{S}_{2}, \mathrm{Se}_{2}$, and $\mathrm{Te}_{2}$. Besides the experimental research, a detailed theoretical study is carried out. Calculations with a theoretical analysis of their results are performed for the structural characteristics of homoatomic sulfur, $S_{n}$, selenium, $S e_{n}$, and tellurium, Te $e_{n}$, molecules with $n=2 \div 8$; namely, interatomic distances, ionization potentials, electron affinity energies, and dissociation energies. The energy characteristics are applied to calculate the appearance energies for singly and doubly charged ionic fragments of those molecules at the dissociative ionization. The obtained results are carefully compared with the available experimental and theoretical data.

Ke ywords: chalcogens, mass spectrometry method, ionic fragments, dissociative ionization, optical spectroscopy method.

(C) O. SHPENIK, A. ZAVILOPULO, E. REMETA,

S. DEMES, M. ERDEVDY, 2020 


\section{Introduction}

Elementary processes of pair collisions (such as elastic scattering, excitation, and ionization) of low-energy electrons with atoms and molecules have been intensively studied during the last decades [1]. Our group systematically researched those processes in the case of electron interaction with atoms of alkaline and alkaline earth elements, some atoms from the third and fourth groups of the periodic table of elements, carbon gases, and atmospheric gas molecules $\mathrm{H}_{2}, \mathrm{~N}_{2}$, $\mathrm{O}_{2}$, and $\mathrm{CO}_{2}$ [2-4]. On the basis of those studies, we have determined the corresponding effective excitation and ionization cross-sections and their energy dependences. We also revealed the mechanisms of particle interaction: resonances, autoionization, interaction effects after collisions, the role of cascade transitions in the excitation of atoms and molecules, and so forth. However, it is paradoxical, but the information concerning the interaction of controlledenergy electrons with atoms, molecules, and clusters of chalcogens (sulfur, selenium, and tellurium) is almost absent.

Nevertheless, the study of elementary processes occurring, when electrons inelastically interact with elements of the chalcogen group, is undoubtedly challenging and has practical importance owing to the unique properties of chalcogens and their wide applications to various domains of science and technology. Besides oxygen and polonium, this group of elements includes sulfur, selenium, and tellurium. Each of those elements has a variety of properties, with the presence of allotropic modifications being inherent to all of them. The electron shells of chalcogen atoms have the configuration $n s^{2} n p^{4}$. As the atomic number grows, the covalent and ionic radii of the atoms increase, whereas the ionization energy of the atoms and the dissociation energy of molecules decrease. Molecules including more than three atoms can be classified to cluster compounds. In many aspects, they comprise a non-thoroughly researched state of matter: something located between atoms and molecules, on the one hand, and the solid state, on the other hand. Chalcogen atoms easily form clusters, which can stay in the gaseous, liquid, amorphous, or solid phases.

Under normal conditions, sulfur forms eight-atom ring molecules, in which the bonds in the ring begin to break, as the temperature increases, so that the molecule transforms into an open chain. In other words, the structure of a sulfur molecule depends on the temperature, and this fact is responsible for the existence of allotropic modifications. Sulfur molecules (clusters) are diverse in their structural properties. The number of sulfur allotropic modifications observed in all phase states is the largest among chalcogens. It should be emphasized that sulfur is one of the most dominant elements in the chalcogen group. The radio frequencies of chalcogens are registered in the interstellar space, various star sources, and comets [5].

In the gaseous phase, the atomic composition of all chalcogens strongly depends on the vapor temperature. For example, saturated sulfur vapor at $384 \mathrm{~K}$ contains $\mathrm{S}_{n}$ molecules (with $n=2 \div 8$ ), the fractions of which substantially change with the temperature [6]. Note that the experimental determination of the appearance energy for $\mathrm{S}_{n}^{+}$ions $(n=2 \div 8)$ at the interaction of sulfur with electrons was dealt with in works [7-9]. However, no comprehensive analysis of dissociative ionization channels was made in the cited works, first of all, because of the unknown composition and state of the neutral reaction products.

As concerning the study of the processes of elastic electron scattering by sulfur, they have been analyzed only with the help of theoretical methods applied to atomic targets [10-13]. Only work [14] contains the calculation of differential cross-sections of electron scattering by the $\mathrm{S}_{3}$ molecule in the framework of the $R$-matrix method.

Owing to its versatile properties, sulfur is a component of some amino acids (cysteine, methionine), vitamins (biotin, thiamine), and enzymes [15], whereas the redox reactions of sulfur are an energy source in chemosynthesis. It is important to emphasize that sulfur enters the composition of the atmosphere of some cosmic objects, being a very widespread element in the Universe and in the interstellar space [5]. Natural sulfur has more than 20 isotopes, whose lifetimes vary from $10 \mathrm{~ns}$ to $200 \mathrm{~min}$, and four stable isotopes - these are ${ }^{32} \mathrm{~S}(95.084 \%),{ }^{33} \mathrm{~S}(0.74 \%)$, ${ }^{34} \mathrm{~S}(4.16 \%)$, and ${ }^{36} \mathrm{~S}(0.016 \%)$ - which can be well resolved using a mass spectrometer. In the ground state, sulfur atoms have an electronic configuration of the type [Ne] $3 s^{2} 3 p^{4}$, where two $p$-electrons remain unpaired. However, the molecular orbitals in sulfur compounds do not completely reproduce the electron shells of inert gases, being only similar to them.

Selenium, analogously to sulfur, changes its properties depending on the external conditions occurring 
at its production. There are several allotropic modifications of selenium. These is gray selenium $(\gamma$-Se or "metallic selenium"), which is the most stable modification with a hexagonal crystal lattice; red crystalline selenium, which has three monoclinic modifications: orange-red $(\alpha$-Se), dark red $(\beta$-Se), and red amorphous $(\gamma$-Se) selenium; and black vitreous selenium [16]. Selenium is a component of active centers of some proteins by entering the selenocysteine amino acid [17]. As was already mentioned, chalcogen atoms easily form clusters. For instance, selenium clusters are characterized by the presence of $\mathrm{Se}_{n}$ chains and rings with various sizes $(n=1 \div 25)$. It is known [18] that natural selenium has six stable isotopes: ${ }^{74} \mathrm{Se}$ $(0.87 \mathrm{wt} \%),{ }^{76} \mathrm{Se}(9.02 \mathrm{wt} \%),{ }^{77} \mathrm{Se}(7.58 \mathrm{wt} \%),{ }^{78} \mathrm{Se}$ (23.52 wt\%), ${ }^{80}$ Se (49.82 wt\%), and ${ }^{82} \mathrm{Se}(9.19 \mathrm{wt} \%)$.

Tellurium, in comparison with sulfur and selenium, is chemically less active. It has strongly expressed metallic properties. Its crystalline lattice is hexagonal, and the structure consists of parallel helical chains. The outer electron shell of a tellurium atom has the configuration $5 s^{2} 5 p^{4}$. At chemical interactions, the tellurium atom either gives up its valence electrons and becomes a positive ion, or takes an electron from another atom, thus turning into a negative ion. There are eight tellurium isotopes in the Nature, five of which are stable, and the others are radioactive. The stable isotopes comprise only $33.3 \%$ of the total amount of tellurium found in the Nature, which is associated with an extremely long half-life of natural tellurium radioactive isotopes: their lifetimes extend from $6 \times 10^{14}$ to $2.2 \times 10^{24}$ years, with the ${ }^{128} \mathrm{Te}$ isotope possessing the longest half-life among all known radionuclides [19]. Tellurium compounds demonstrate chemical properties that are different from those of sulfur and selenium compounds. This fact is explained by the specific structure of tellurium compounds and the weak electronegativity of tellurium. On the other hand, tellurium can substitute sulfur or selenium in compounds by means of nonspecific metabolic ways [20]. Note that, unlike the cases of sulfur and selenium, the cyclic structure of tellurium molecules allows the appearance of very large $\mathrm{Te}_{n}$ clusters with $n_{\max }=56$.

As concerning the theoretical studies of elementary processes with the participation of chalcogens, the corresponding complicated and accurate methods have been developed in this domain. Nevertheless, a complete description of the course of those pro- cesses often remains unknown because of their extremely complicated character $[21,22]$. Especially difficult are studies of the interaction between lowenergy electrons, whose energy is up to several hundredths of one electronvolt, and chalcogen molecular targets. In those processes, the incident electron invokes a number of changes in the molecule in the course of collisions. In particular, it excites the molecular rotational, vibrational, and electronic states one after another. At the energies above the ionization threshold, the electron can give rise to the ionization of the molecule including its dissociative ionization (DI) [23]. Such processes are very complicated and are often interrelated. Therefore, it is clear that a good quantitative and qualitative theoretical description of the electron collisions with chalcogen atoms and molecules is a non-trivial task even at the current development stage of the computer calculation technology.

It is important that, by theoretically studying the separate fragmentation channels, it is possible to determine the total energy balance between the parent molecule and its final fragments, which are the products of the DI process. This method often turns out the only possible way to provide the most complete pattern of the fragmentation, including the description of the state parameters of emerging neutral and ionic reaction products. A theoretical analysis of the threshold energies for the appearance of a particular ionic fragment in various channels is very useful for the interpretation of experimental results, when it is impossible to measure the characteristics of neutral reaction products. At the same time, a probabilistic description of DI through that or another channel is a too complicated problem, which is practically unsolvable in the framework of theoretical approaches from the first principles [24].

Hence, from the viewpoint of fundamental knowledge, there is no doubt in the relevance and importance of the study of elementary interaction processes between low-energy electrons and chalcogens in the gaseous phase [25-27].

It should be noted that the data presented in this work have wide areas of practical application and can be used both in materials science and to analyze physical and chemical processes both in complex semiconductors containing chalcogen atoms and in chalcogenide glasses (non-crystalline solids). For instance, the active elements of functional electronic 
devices are complex semiconductor chalcogenides, namely, 3D crystals $\left(\mathrm{Pb}_{y} \mathrm{Sn}_{1-y}\right)_{2} \mathrm{P}_{2}\left(\mathrm{Se}_{x} \mathrm{~S}_{1-x}\right)_{6}$ (ferroelectric solid solutions), $\mathrm{Sn}_{2} \mathrm{P}_{2} \mathrm{~S}_{6}, \mathrm{Sn}_{2} \mathrm{P}_{2} \mathrm{Se}_{6}$, and $\mathrm{Pb}_{2} \mathrm{P}_{2} \mathrm{~S}_{6}$, and layered $2 \mathrm{D}$ crystals $\mathrm{CuInP}_{2}\left(\mathrm{Se}_{x} \mathrm{~S}_{1-x}\right)_{6}$, $\mathrm{CuCrP}_{2} \mathrm{~S}_{6}$, and $\mathrm{Cd}_{2} \mathrm{P}_{2} \mathrm{Se}_{6}$. The $3 \mathrm{D}$ crystals of the $\mathrm{Sn}_{2} \mathrm{P}_{2} \mathrm{~S}_{6}$ type and the $\mathrm{CuInP} \mathrm{P}_{2} \mathrm{~S}_{6}$ layered crystals are applied as major components of electronic devices. Those crystals serve as a basis to develop novel memory devices and to create diodes, transistors, and highspeed microchips with long-term information storage. By their properties, $\mathrm{Li}_{2} \mathrm{FeP}_{2} \mathrm{~S}_{6}$ and $\mathrm{Li}_{2} \mathrm{NiP}_{2} \mathrm{~S}_{6}$ crystals have a great potential to be applied, when developing and fabricating high-capacity solid-state batteries. On the basis of superionic compounds like $\mathrm{Cu}_{6} \mathrm{PS}_{5} \mathrm{I}, \mathrm{Cu}_{6} \mathrm{PSe}_{5} \mathrm{I}$, and $\mathrm{Cu}_{7} \mathrm{GeS}_{5} \mathrm{I}$, thin but highly conductive crystalline films were obtained, which can be successfully used in the development and production of solid-state electrolytic energy sources.

Mercury chalcogenide crystals $\mathrm{Hg}_{3} \mathrm{X}_{2} Y_{2}$ (where $X=\mathrm{S}$, Se, Te, and $Y=\mathrm{F}, \mathrm{Cl}, \mathrm{Br}, \mathrm{I})$ possess attractive physicochemical properties, being very interesting substances for researches in solid state physics and chemistry. Those crystals have a considerable optical activity, high refractive indices, a wide transparency interval in the visible and infrared spectral regions, and good photoconductivity. This circumstance makes their practical application promising in the field of optoelectronic and acoustic-optical devices, as well as in nanomaterials.

Wide-gap chalcogenide glasses of the Ge-As-S system (c- $\mathrm{As}_{2} \mathrm{~S}_{3}, c-\mathrm{Ge}_{2} \mathrm{~S}_{3}, \mathrm{As}-\mathrm{S}, \mathrm{As}_{2} \mathrm{~S}_{3}-\mathrm{GeS}_{2}, \mathrm{Ge}-\mathrm{S}$ ) with a high thermal conductivity are widely used in radiation optics and photonics and in the production of optical coatings.

The aim of this review is to present the results of a comprehensive experimental study of the inelastic collision processes of low-energy electrons with sulfur, selenium, and tellurium in the gaseous phase, as well as the results of a theoretical analysis concerning the appearance energies of ionic fragments from chalcogen clusters.

\section{Experimental Part}

In our work, we used three experimental installations for the comprehensive study of elementary processes of interaction between low-energy electrons and chalcogens in the gaseous phase: (i) with a monopole mass spectrometer $[28,29]$, (ii) with a hypocycloidal electron spectrometer [30], and (iii) an installation for optical researches in a spectral interval of 200-590 nm [31]. Sulfur, selenium, and tellurium with a purity grade of $99 \%$ were used as working substances. Before the experiment, they were additionally purified by the distillation in a special vacuum chamber.

\subsection{Installation with a monopole mass spectrometer (IMMS)}

This installation included a vacuum chamber connected to a turbo-molecular pump with a residual gas pumping rate of $500 \mathrm{l} / \mathrm{s}$ and a system of gas control and inlet. The latter was used to calibrate the scales of ionic masses and electron energies. In the vacuum chamber, there were arranged a monopole mass spectrometer (MMS), a manometric tube, andat an angle of $90^{\circ}$ with respect to the electron motion direction-an effusion beam source of the researched substance. The residual gas pressure in the vacuum chamber was $2 \times 10^{-5} \mathrm{~Pa}$ after heating the chamber for $24 \mathrm{~h}$ and $8 \times 10^{-5} \mathrm{~Pa}$ in the operating mode [25]. The choice of a monopole mass spectrometer MX7304A with a modernized ion source [32] as an analytical device was associated with its compactness and a possibility to be used not only to study gaseous objects, but also substances in the condensed state.

A schematic diagram of the experiment is shown in Fig. 1. A beam of examined molecules was formed with the help of a multichannel source of the effusion type (with a concentration of molecules in the beam of an order of $\left.10^{10}-10^{11} \mathrm{~cm}^{-3}\right)(11)$. The beam was directed to an ion source with electron ionization (10), which operated in the electron current stabilization mode and made it possible to obtain electron beams with a fixed energy from 3 to $70 \mathrm{eV}$ and a current from 0.05 to $0.5 \mathrm{~mA}$. The corresponding electron energy spread was $\Delta E_{1 / 2}=250 \mathrm{meV}$, where $\Delta E_{1 / 2}$ is the total width of the electron energy distribution at the half-height of its maximum. In order to calibrate the mass and energy scales, we used a special gas inlet system $(6)$. This allowed us to calibrate the mass scale according to the isotopes of the $\mathrm{Ar}, \mathrm{Kr}$, and $\mathrm{Xe}$ atoms and to determine the energy scale according to the initial section in the energy dependences of the effective ionization cross-sections of a $\mathrm{Kr}$ atom and an $\mathrm{N}_{2}$ molecule.

The experiment was performed in two stages. At the first stage, the mass spectra of sulfur, selenium, and tellurium were studied at various temperatures. At the second stage, the energy dependences of the

ISSN 2071-0194. Ukr. J. Phys. 2020. Vol. 65, No. 7 
relative cross-sections of the complete and dissociative ionizations were measured in the electron energy interval from 5 to $70 \mathrm{eV}$. This procedure made it possible to obtain the mass spectra of the examined substances and the ionization functions of their atoms and molecules, as well as the functions of the dissociative ionization of molecular fragments, all measurements being performed under identical experimental conditions. The registration and processing of the experimental results were carried out in the automatic mode making use of special computer programs, which were described in our publications [25-29].

\subsection{Installation with a hypocycloidal electron spectrometer (IHES)}

The schematic diagram of a hypocycloidal electron spectrometer (HES) is shown in Fig. 2, and the detailed description of its design and the principle of its operation are given in work [16].

When measuring positive and negative ions, the electron currents in the beam were 25 and $40 \mathrm{nA}$, respectively. The energy homogeneity of the electrons in the beam was $\Delta E_{1 / 2}=0.11 \mathrm{eV}$. The magnitude of $\Delta E_{1 / 2}$ was found by differentiating the initial section in the current-voltage characteristic of the electron beam measured at collector F1 (see Fig. 2). A complete collection of ions was provided by supplying a potential of $-1.5 \mathrm{~V}$ (for positive ions) or $+1.5 \mathrm{~V}$ (for negative ions) to the ion detector with respect to the collision chamber.

The electron energy was controlled by the potential difference applied between the cathode and the collision chamber. The increment of the electron energy scanning was chosen to equal $50 \mathrm{meV}$ for positive ions and $20 \mathrm{meV}$ for negative ones. The vacuum in the working chamber was not worse than $2 \times 10^{-4} \mathrm{~Pa}$. The HES was embedded into a uniform magnetic field created by a pair of Helmholtz coils $210 \mathrm{~mm}$ in diameter. The registration of signals and the measurements were carried out in the automatic mode with the help of a PC software developed by us. This program allowed the process of energy dependence measurement to be carried out in the real-time mode. Note that, in this experiment, the electron analyzer was used to determine the electron energy distribution $\left(\Delta E_{1 / 2}\right)$.

\subsection{Installation for optical researches}

An automated installation for studying the inelastic excitation processes using the optical method

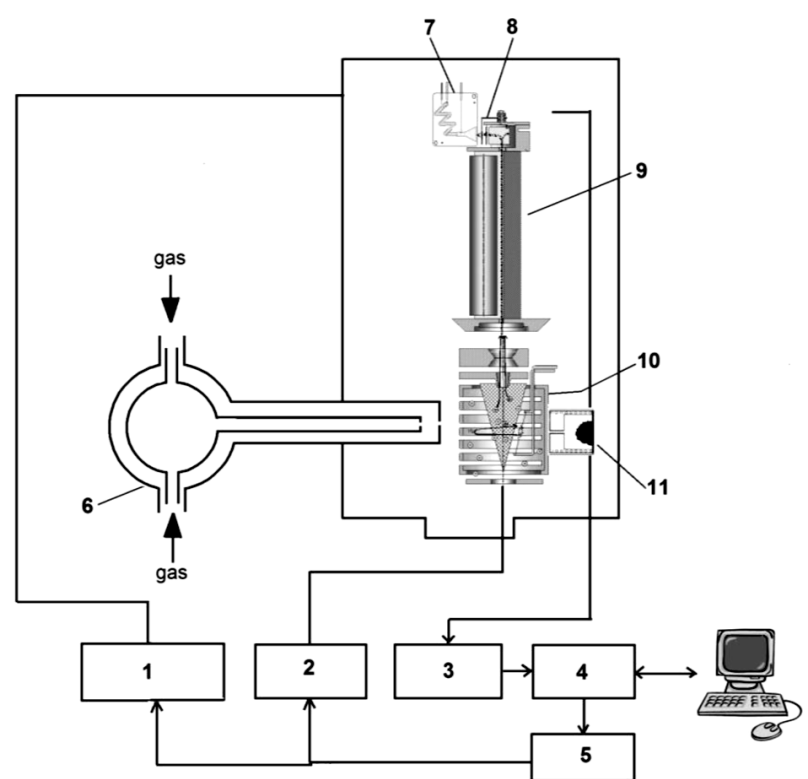

Fig. 1. Schematic diagram of the experiment with a mass spectrometer: (1) mass-spectrometer control unit, (2) power supply unit, (3) registration system, $(4,5)$ interfaces and digital-to-analog converters, (6) inlet system of $\mathrm{Ar}, \mathrm{Kr}, \mathrm{Xe}$, and $\mathrm{N}_{2}$ calibration gases, $(7,8) \mathrm{KEU}$ and ion collector (Faraday cylinder), (9) mass-analyzer electrodes, (10) ion source, (11) effusive source of the examined substance

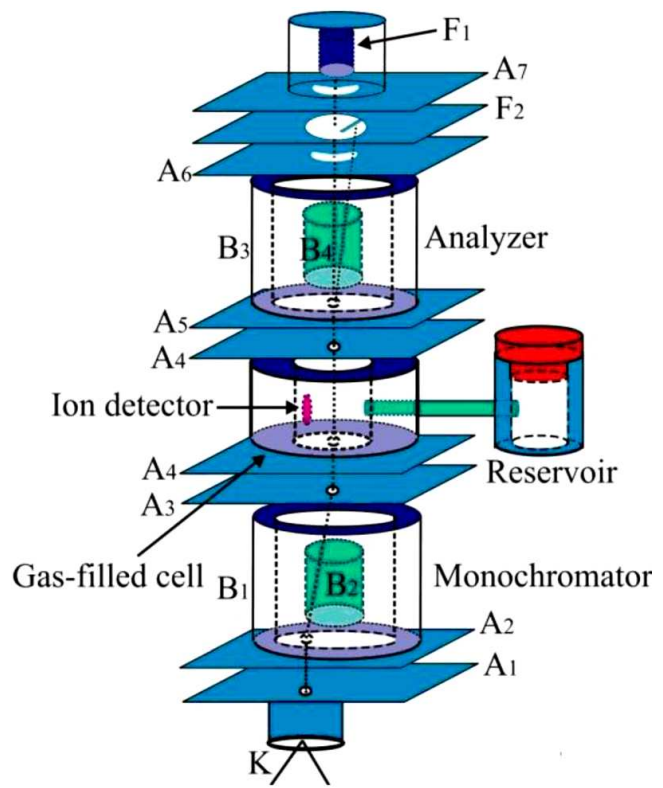

Fig. 2. Schematic diagram of a hypocycloidal electron spectrometer: ( $A 1$ to $A 7$ ) electron beam forming electrodes, (B1 to $B 4$ ) electrodes of cylindrical capacitors, (F1 and F2) collectors of primary beam and scattered electrons 
included a high-transmission diffraction monochromator and a vacuum chamber. In the latter, a 4electrode electron gun was arranged, which created an electron beam about $1.5 \mathrm{~mm}$ in diameter. The beam passed through a cell filled with substance vapor. The current stability of electrons with an energy of 3-50 eV after the collision cell was not worse than $3 \%$. The energy homogeneity $\Delta E_{1 / 2}$ of electrons in the beam was 0.2 and $0.6 \mathrm{eV}$ at currents of 10 and $20 \mu \mathrm{A}$, respectively.

The vapor of the examined substance was inlet into the cell from a separate resistively heating tank through a thin-walled tube, which allowed the temperatures of the collision chamber and the unit of electron-optical system to be maintained $20-30{ }^{\circ} \mathrm{C}$ higher than the tank heating temperature. This design prevented the condensation of the researched substance on the electrodes of the electron-optical system during long-term experiments. The vacuum chamber was pumped out by means of a steam-oil pump (at a rate of $500 \mathrm{l} / \mathrm{s}$ ). The residual gas pressure in the vacuum chamber during the measurements did not exceed $10^{-4} \mathrm{~Pa}$.

The radiation emitted at the collisions of electrons with the vapor of studied elements was led out through quartz windows available in both the collision cell and the vacuum chamber, focused with the help of a two-lens condenser onto the input slit of an MDR-2 monochromator (with a diffraction grating of 1200 lines $/ \mathrm{mm}$ and an inverse dispersion of $2 \mathrm{~nm} / \mathrm{mm}$ ), and detected by means of a photoelectronic multiplier FEU-106. One-photoelectron pulses produced by the latter were pre-amplified and shaped by a wide-band amplifier-discriminator. Then they were directed to a pulse counter and accumulated in the PC memory. Depending on the radiation intensity, the signals were accumulated at every measurement point with an exposure time from 10 to $60 \mathrm{~s}$, which provided the measurement accuracy at a level of $5-10 \%$.

Special computer programs developed by us to control the experiment made it possible to register the emission spectral lines or bands of the studied elements in the automated mode, at fixed energies of bombarding electrons, and at a given drum rotation step of the diffraction grating in the monochromator. They also allowed us to measure the energy dependences of the intensities of separate spectral lines, bands, and certain spectral sections, i.e., the op- tical excitation functions (OEFs). When measuring the OEFs, the increment of the energy of bombarding electrons was set fixed within an interval from $2.5 \mathrm{meV}$ to $2 \mathrm{eV}$.

\section{Results and Their Discussion}

\subsection{Mass spectra}

Sulfur, selenium and tellurium mass spectra were measured at various energies of ionizing electrons, in a wide range of substance evaporation temperatures, and in an interval of mass numbers that was restricted only by the technical parameters of the mass spectrometer [32]. The measurement procedure consisted in the accumulation of multiple useful signals, so that the relative error did not exceed $0.5-1.5 \%$. The mass spectrometry method was applied to study the composition of vapors in a temperature interval of 320 $600 \mathrm{~K}$ for sulfur, 420-480 K for selenium, and 400$600 \mathrm{~K}$ for tellurium.

Figure 3 demonstrates the mass spectra of the examined substances registered at a temperature of $510 \mathrm{~K}$ for sulfur, $470 \mathrm{~K}$ for selenium, and $600 \mathrm{~K}$ for tellurium. As one can see, a common feature of those mass spectra is the presence of peak groups, one of which has a high intensity, and the others, satellites, belong to the isotopes of researched elements. There are four stable isotopes for sulfur, six for selenium, and eight for tellurium. That is why the number of satellite mass peaks increases in the mass spectra from sulfur to tellurium.

As follows from Fig. 3, all examined substances in the gaseous phase exist in both the atomic and molecular forms. The formation of monocations from chalcogen molecules $M_{n}$ with $n=2 \div 8$ under the electron impact action can occur according to the following scenarios: direct ionization of the molecule,

$M_{n}+\mathrm{e}^{-} \rightarrow \mathrm{M}_{n}^{+}+2 \mathrm{e}^{-}$

or its dissociative ionization,

$\mathrm{M}_{n}+\mathrm{e}^{-} \rightarrow \mathrm{M}^{+}+M_{n-1}+2 \mathrm{e}^{-}$.

The formation of a doubly charged $M^{2+}$ ion occurs similarly: in the processes of direct atomic ionization

$\mathrm{M}+\mathrm{e}^{-} \rightarrow \mathrm{M}^{2+}+3 \mathrm{e}^{-}$

or dissociative ionization of a diatomic molecule,

$\mathrm{M}_{2}+\mathrm{e}^{-} \rightarrow \mathrm{M}^{2+}+M+3 \mathrm{e}^{-}$.

ISSN 2071-0194. Ukr. J. Phys. 2020. Vol. 65, No. 7 
The intensities of the peaks in the groups of $\mathrm{M}^{2+}$, $\mathrm{M}^{+}$, and $\mathrm{M}_{n}^{+}$ions, according to schemes (1)-(4), must be different (see Fig. 3) and can depend on both the effective cross-section of the elementary process and the specimen evaporation temperature.

\subsubsection{Sulfur}

Sulfur mass spectra were measured in a mass number interval of 10-280 a.m.u. at various electron energies. Figure 3, a demonstrates a typical mass spectrum of sulfur. It includes nine groups of mass lines. Each group has a major peak, i.e., the largest among the others, and its satellites with lower intensities corresponding to sulfur isotopes with different masses. At a temperature of $510 \mathrm{~K}$, the most intense peaks in the groups are the peaks corresponding to the ${ }^{32} \mathrm{~S}^{+},{ }^{64} \mathrm{~S}_{2}^{+}$, and ${ }^{256} \mathrm{~S}_{8}^{+}$ions. The intensity of the atomic ion peak equals $33.7 \%$, and that of the molecular ion $\mathrm{S}_{8}^{+}$is $59.3 \%$, whereas the peak intensities of other ions $\left(\mathrm{S}_{3}^{+}, \mathrm{S}_{4}^{+}, \mathrm{S}_{5}^{+}, \mathrm{S}_{6}^{+}\right.$, and $\left.\mathrm{S}_{7}^{+}\right)$are lower than the intensity of the $\mathrm{S}_{2}^{+}$molecular peak. It is most likely that the $\mathrm{S}_{2}^{+}$and $\mathrm{S}^{+}$ions mainly appear owing to the dissociative ionization of $\mathrm{S}_{8}$ molecules, because, according to the results of work [6], these molecules have the highest concentration at temperatures of $480-540 \mathrm{~K}$.

In Table 1 , the relative intensities of ion peaks normalized by the peak intensity of the molecular ion $\mathrm{S}_{2}^{+}$are compared. The obtained data are in good agreement with those taken from the NIST database [18]. As concerning the data obtained by other authors [33, 34], there is a considerable discrepancy among the efficiencies of formation of certain ions for some mass peaks. The origin of this discrepancy may probably be associated with different temperature modes of sulfur evaporation and different methods used to produce sulfur ions. As one can see from Fig. 3, a, the peaks corresponding to the isotopes of sulfur atoms and molecules are clearly identified in the mass spectrum. Attention is attracted by the intensity ratio between the isotope and main peaks (see Table 1). For instance, the amplitude of the ${ }^{34} \mathrm{~S}^{+}$isotope peak comprises $5.1 \%$ of the main ${ }^{32} \mathrm{~S}^{+}$peak amplitude, whereas, for other peaks, this value increases with the growth of the number of sulfur atoms in the molecule. In particular, the intensity of the ${ }^{66} \mathrm{~S}_{2}^{+}$isotope peak amounts to $10.2 \%$ of the intensity of the ${ }^{66} \mathrm{~S}_{2}^{+}$peak, which is twice as much as in the previous case. As the mass numbers grow, the peak inten-
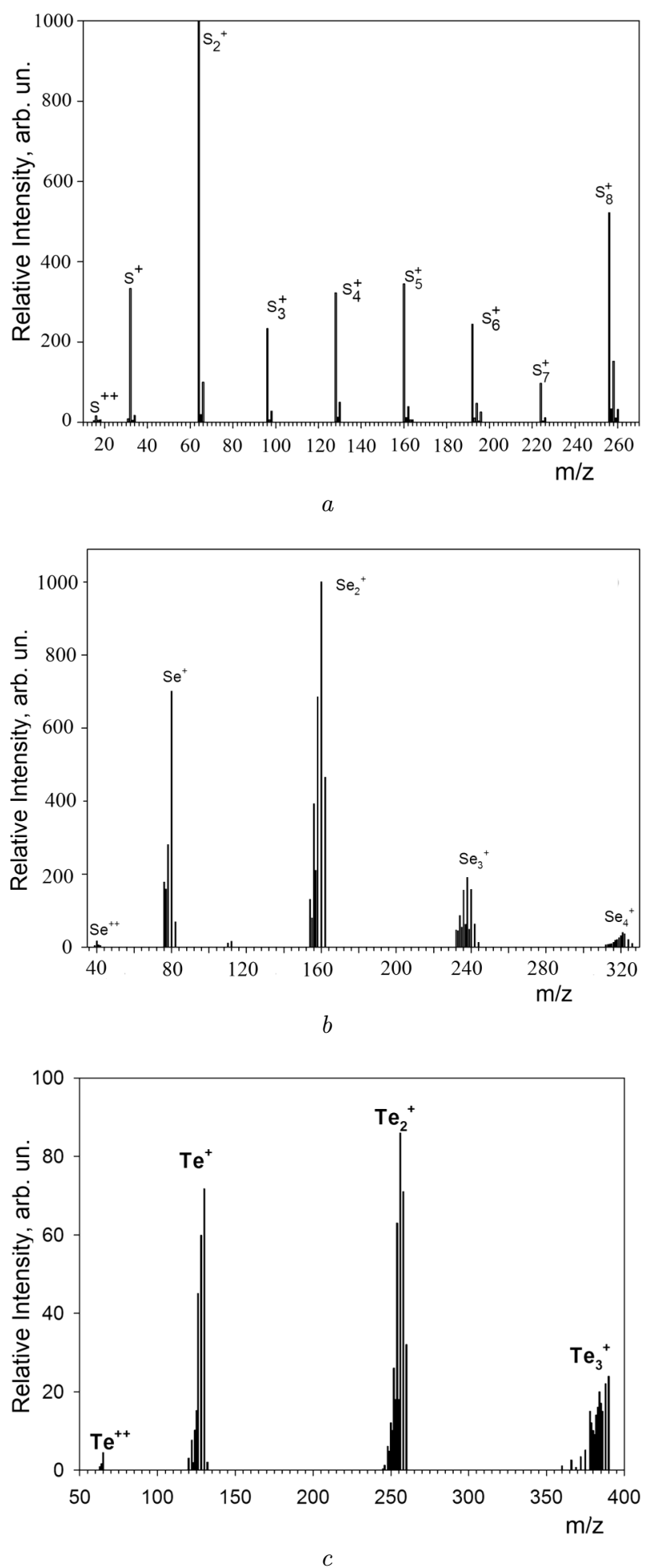

Fig. 3. Mass spectra of sulfur $(a)$, selenium $(b)$, and tellurium (c). The energy of ionizing electrons $E=70 \mathrm{eV}$ 
Table 1. Relative formation intensities of atomic and molecular sulfur ions at an electron energy of $70 \mathrm{eV}$ and the results from other works

\begin{tabular}{|c|c|c|c|c|c|c|c|c|c|}
\hline \multirow{3}{*}{ Ion } & \multirow{3}{*}{$\begin{array}{l}m / z \\
\text { a.m.u. }\end{array}$} & \multicolumn{8}{|c|}{ Relative intensity of ion formation, $\%$} \\
\hline & & \multicolumn{5}{|c|}{ Electron-impact formation } & \multirow{2}{*}{$\begin{array}{c}\begin{array}{c}\text { Photon-induced } \\
\text { formation }\end{array} \\
{[40]}\end{array}$} & \multicolumn{2}{|c|}{$\begin{array}{l}\text { Photon-induced negative ions, } \\
\text { photon-induced formation }\end{array}$} \\
\hline & & Our data & {$[18]$} & {$[33]$} & {$[34]$} & Intensity ratio, $\%$ & & Ion & {$[40]$} \\
\hline $\mathrm{S}^{+}$ & $\begin{array}{l}32 \\
34\end{array}$ & $\begin{array}{c}33.3 \\
1.7\end{array}$ & $\begin{array}{c}33.1 \\
1.2\end{array}$ & $\begin{array}{c}10.2 \\
-\end{array}$ & $\begin{array}{c}13.5 \\
-\end{array}$ & ${ }^{32} \mathrm{~S}^{+} /{ }^{34} \mathrm{~S}^{+}=5.1$ & - & $\mathrm{S}^{-}$ & 100 \\
\hline $\mathrm{S}_{2}^{+}$ & $\begin{array}{l}64 \\
66\end{array}$ & $\begin{array}{l}100 \\
10.3\end{array}$ & $\begin{array}{c}100 \\
10.8\end{array}$ & $\begin{array}{c}100 \\
79\end{array}$ & $\begin{array}{c}100 \\
-\end{array}$ & ${ }^{64} \mathrm{~S}_{2}^{+} /{ }^{66} \mathrm{~S}_{2}^{+}=10.3$ & 100 & $\mathrm{~S}_{2}^{-}$ & 97 \\
\hline $\mathrm{S}_{3}^{+}$ & $\begin{array}{l}96 \\
98\end{array}$ & $\begin{array}{c}23.4 \\
2.8\end{array}$ & $\begin{array}{c}21.1 \\
3.1\end{array}$ & $\begin{array}{c}23.1 \\
4.8\end{array}$ & $\begin{array}{l}4.7 \\
-\end{array}$ & ${ }^{96} \mathrm{~S}_{3}^{+} /{ }^{98} \mathrm{~S}_{3}^{+}=11.96$ & 8 & $\mathrm{~S}_{3}^{-}$ & 88 \\
\hline $\mathrm{S}_{4}^{+}$ & $\begin{array}{l}128 \\
130\end{array}$ & $\begin{array}{c}45.6 \\
7.5\end{array}$ & $\begin{array}{l}52.0 \\
10.2\end{array}$ & $\begin{array}{c}48.2 \\
5.4\end{array}$ & $\begin{array}{l}8.0 \\
-\end{array}$ & ${ }^{128} \mathrm{~S}_{4}^{+} /{ }^{130} \mathrm{~S}_{4}^{+}=16.5$ & 6 & $\mathrm{~S}_{4}^{-}$ & 8 \\
\hline $\mathrm{S}_{5}^{+}$ & $\begin{array}{l}160 \\
162\end{array}$ & $\begin{array}{c}47.7 \\
4.9\end{array}$ & $\begin{array}{l}53.1 \\
10.2\end{array}$ & $\begin{array}{c}23.2 \\
6.5\end{array}$ & $\begin{array}{c}5.2 \\
-\end{array}$ & ${ }^{160} \mathrm{~S}_{5}^{+} /{ }^{162} \mathrm{~S}_{5}^{+}=10.2$ & 11 & $\mathrm{~S}_{5}^{-}$ & 2 \\
\hline $\mathrm{S}_{6}^{+}$ & $\begin{array}{l}192 \\
194\end{array}$ & $\begin{array}{c}34.9 \\
5.4\end{array}$ & $\begin{array}{l}41.0 \\
10.5\end{array}$ & $\begin{array}{c}12.1 \\
4\end{array}$ & $\begin{array}{l}3.2 \\
-\end{array}$ & ${ }^{192} \mathrm{~S}_{6}^{+} /{ }^{194} \mathrm{~S}_{6}^{+}=15.7$ & 2 & & \\
\hline $\mathrm{S}_{7}^{+}$ & $\begin{array}{l}224 \\
226\end{array}$ & $\begin{array}{c}17.5 \\
4.8\end{array}$ & $\begin{array}{c}18.0 \\
5.4\end{array}$ & $\begin{array}{l}2.1 \\
1.1\end{array}$ & $\begin{array}{c}0.3 \\
-\end{array}$ & ${ }^{224} \mathrm{~S}_{7}^{+} /{ }^{226} \mathrm{~S}_{7}^{+}=27.4$ & 3 & & \\
\hline $\mathrm{S}_{8}^{+}$ & $\begin{array}{l}256 \\
258\end{array}$ & $\begin{array}{l}59.3 \\
22.2\end{array}$ & $\begin{array}{l}70.0 \\
25.2\end{array}$ & $\begin{array}{l}59.2 \\
18.3\end{array}$ & $\begin{array}{c}5.4 \\
-\end{array}$ & ${ }^{256} \mathrm{~S}_{8}^{+} /{ }^{258} \mathrm{~S}_{8}^{+}=37.2$ & 4 & & \\
\hline $\mathrm{S}^{2+}$ & 16 & 1.6 & - & - & - & - & & & \\
\hline $\mathrm{S}_{2}^{+} / \mathrm{S}^{+}$ & - & 3.00 & 3.02 & 9.82 & 7.42 & - & - & $\mathrm{S}_{2}^{-} / \mathrm{S}^{-}$ & 0.97 \\
\hline
\end{tabular}

sity ratio between the satellite molecular ions and the main one changes from $12 \%$ to $37 \%$.

For the sake of comparison between the efficiencies of sulfur formation and fragmentation in the course of photoionization, the data from work [40] concerning the photo-induced formation of positive and negative ions are quoted in Table 1 . This process occurs according to the scheme

$\mathrm{A}_{n}+h \nu \rightarrow \mathrm{A}^{+}+\mathrm{A}^{-}+\mathrm{A}_{n-2}$.

The analysis of the data given in Table 1 demonstrates that the photoionization efficiency differs from the electron-impact ionization efficiency. Namely, there is no peak in the mass spectrum of positive ions corresponding to the $\mathrm{S}^{+}$atomic ion, and the most intense peak belongs to the $\mathrm{S}_{2}^{+}$molecular ion, as it already was in the mass spectrum for the electron-impact ionization.

In the mass spectrum of negative ions, the intensities of the peaks corresponding to the formation of the $\mathrm{S}^{-}$and $\mathrm{S}_{2}^{-}$ions are maximum and almost identical (Table 1). Therefore, the different formation efficiencies of sulfur ions at the interaction with electrons or photons confirm that the processes of direct and dissociative ionizations occur in different ways.

Note that the analysis of the intensity ratio $\mathrm{S}_{\mathbf{2}}^{+} / \mathrm{S}^{+}$ (see Table 1) makes it possible to assume that the $\mathrm{S}_{2}^{+}$ ion is formed according to the scheme

$\mathrm{S}_{6}+\mathrm{e}^{-} \rightarrow \mathrm{S}_{2}^{+}+\mathrm{S}_{4}+2 \mathrm{e}^{-}$

whereas the formation of the monocation $\mathrm{S}^{+}$occurs through more complicated ways:

- either through direct ionization of the sulfur atom,

$\mathrm{S}+\mathrm{e}^{-} \rightarrow \mathrm{S}^{+}+2 \mathrm{e}^{-}$

- or through dissociative ionization of the molecule,

$\mathrm{S}_{n}+\mathrm{e}^{-} \rightarrow \mathrm{S}^{+}+\mathrm{S}_{n-1}+2 \mathrm{e}^{-}$.

ISSN 2071-0194. Ukr. J. Phys. 2020. Vol. 65, No. 7 
This assumption explains a substantial difference between the appearance of positive and negative atomic sulfur ions under the action of electron and photon impacts. In the former case, dissociation (6) is the main formation channel; in the latter case, this is the direct ionization of a sulfur atom, as is evidenced by the value of the $\mathrm{S}_{2}^{-} / \mathrm{S}^{-}$intensity ratio, which is equal to unity. Attention is drawn by the difference between the $\mathrm{S}_{2}^{+} / \mathrm{S}^{+}$intensity ratios for our data and the data of work [18], on the one hand, and the data of works $[33,34]$, on the other hand. This difference can be explained by different experimental conditions.

Note that our mass spectrum (Fig. 3,a) also contains a peak of the doubly charged sulfur ion $\mathrm{S}^{++}$ $(m / z=16)$. Our experimental temperature dependences of the formation of various molecular and atomic sulfur ions in the gaseous phase showed that the relative intensities of the corresponding ion peaks strongly depend on the source temperature.

\subsubsection{Selenium}

Selenium mass spectra were measured in the mass interval from 10 to 340 a.m.u. As was in the case of sulfur, the peaks of $\mathrm{Se}_{n}^{+}$molecular ions with the number of atoms $n=2 \div 8$ were observed in the selenium mass spectrum. In work [35], where the temperature dependence of the molar fraction of a selenium vapor during the evaporation was studied, it was found that, up to a temperature of $800 \mathrm{~K}, \mathrm{Se}_{6}$ molecules dominated in a selenium vapor, whereas the diatomic molecule $\mathrm{Se}_{2}$ had the highest concentration at higher temperatures, i.e., the process of thermal dissociation took place.

The mass spectrum of a selenium vapor at $T=$ $470 \mathrm{~K}$ is shown in Fig. 3, b. Obviously, this mass spectrum contains the peaks of the doubly, $\mathrm{Se}^{++}$, and singly, $\mathrm{Se}^{+}$, charged atomic ions, as well as the peaks of the $\mathrm{Se}_{2}^{+}, \mathrm{Se}_{3}^{+}$, and $\mathrm{Se}_{4}^{+}$molecular ions. Among them, the $\mathrm{Se}_{2}^{+}$peak has the maximum intensity, which is typical of selenium mass spectra measured using the electron impact method [36]. It should be noted that if positive selenium ions are produced by the photon impact, the maximum intensity in the mass spectrum belongs to the $\mathrm{Se}_{6}^{+}$ion [37]. This specific feature in the distribution of the peak intensities of selenium ions as compared with the results obtained by the electron impact is explained by the fact that photons with lower energy $(10 \mathrm{eV})$ were used for the photoionization, so that the fragmen- tation of $\mathrm{Se}_{6}$ molecules under the action of photons occurred less intensively than in the case of electronimpact ionization. This circumstance allows us to assert that the high peak intensity of the $\mathrm{Se}_{6}^{+}$ions in our mass spectrum is a result of the fragmentation of the $\mathrm{Se}_{6}$ molecule, but the molecular ion of the latter was not observed due to technical limitations of the mass spectrometer.

In Table 2, the relative appearance intensities of the atomic and molecular selenium ions are shown and compared with the results of other studies. From the presented data, one can see that, as was in the case of sulfur, the formation of the $\mathrm{Se}_{2}^{+}$ion is the most effective. As concerning the appearance intensities of remaining ions, we can observe certain discrepancies among the results of different authors. A group of low-intensity peaks at about 40 a.m.u. corresponds to the doubly charged selenium ion $\mathrm{Se}^{++}$and its isotopes. The low peak intensity of this ion testifies that an electron energy of $70 \mathrm{eV}$ is most probably not sufficient for its effective formation.

Six stable isotopes of selenium atom and molecules are also observed in the mass spectrum, and their peaks are well distinguished against the peaks of the main ion. In Table 2, the intensity ratios between the main peaks and the isotopic ones nearest to them are quoted. For instance, the value of the ${ }^{78} \mathrm{Se}^{+}$atomic isotope peak equals $39.7 \%$ of the main ${ }^{80} \mathrm{Se}^{+}$peak, and the intensity of the ${ }^{158} \mathrm{Se}_{2}^{+}$molecular isotope peak equals $85.6 \%$ of the ${ }^{160} \mathrm{Se}_{2}^{+}$peak, i.e., twice as high as in the previous case. It is important to note that a redistribution of the peak intensity between the main and satellite peaks is observed for molecular ions with $n>2$. In particular, the intensity of the ${ }^{238} \mathrm{Se}_{3}^{+}$ molecular ion peak becomes higher, so that the main ${ }^{240} \mathrm{Se}_{3}^{+}$peak becomes equal to $82.6 \%$ of it. The same situation takes place for molecular ions with $n=5$ and 8 [18], for which the relative intensity of the nearest satellite ion peak with respect to the main peak decreases as the number of atoms grows, whereas the number of peaks increases. It should be noted that this phenomenon is not observed in the case of sulfur.

From the data taken from work [40] and presented in Table 2, one can see that there are substantial differences between the mass spectra of positive and negative selenium ions that emerge owing to the interaction of particles with photons. For instance, the mass spectrum of positive ions demonstrates the presence of atomic $\mathrm{Se}^{+}$and molecular $\mathrm{Se}_{n}^{+}$ions. The intensities 
Table 2. Relative formation intensities of atomic and molecular selenium ions at an electron energy of $70 \mathrm{eV}$ and the results of other works

\begin{tabular}{|c|c|c|c|c|c|c|c|c|c|}
\hline \multirow{3}{*}{ Ion } & \multirow{3}{*}{$\begin{array}{l}m / z \\
\text { a.m.u. }\end{array}$} & \multicolumn{8}{|c|}{ Relative intensity of ion formation, $\%$} \\
\hline & & \multicolumn{5}{|c|}{ Electron-impact formation } & \multirow{2}{*}{$\begin{array}{c}\begin{array}{c}\text { Photon-induced } \\
\text { formation }\end{array} \\
{[40]}\end{array}$} & \multicolumn{2}{|c|}{$\begin{array}{l}\text { Photon-induced negative ions, } \\
\text { electron-impact formation }\end{array}$} \\
\hline & & Our data & {$[18]$} & {$[38]$} & {$[39]$} & Intensity ratio, $\%$ & & Ion & {$[40]$} \\
\hline $\mathrm{Se}^{+}$ & $\begin{array}{l}80 \\
78\end{array}$ & $\begin{array}{l}70.1 \\
28.9\end{array}$ & $\begin{array}{l}69.5 \\
33.5\end{array}$ & $\begin{array}{c}34.9 \\
-\end{array}$ & 19.5 & ${ }^{80} \mathrm{Se}^{+} /{ }^{78} \mathrm{Se}^{+}=41.2$ & 6 & $\mathrm{Se}^{-}$ & 61 \\
\hline $\mathrm{Se}_{2}^{+}$ & $\begin{array}{l}160 \\
158\end{array}$ & $\begin{array}{l}100 \\
78.5\end{array}$ & $\begin{array}{l}100 \\
87.5\end{array}$ & $\begin{array}{c}100 \\
-\end{array}$ & $\begin{array}{c}100 \\
-\end{array}$ & ${ }^{160} \mathrm{Se}_{2}^{+} /{ }^{158} \mathrm{Se}_{2}^{+}=78.5$ & 100 & $\mathrm{Se}_{2}^{-}$ & 100 \\
\hline $\mathrm{Se}_{3}^{+}$ & $\begin{array}{l}240 \\
238\end{array}$ & $\begin{array}{c}15.9 \\
19\end{array}$ & $\begin{array}{l}15.7 \\
18.6\end{array}$ & $\begin{array}{c}31.2 \\
-\end{array}$ & $\begin{array}{c}23.2 \\
-\end{array}$ & ${ }^{238} \mathrm{Se}_{3}^{+} /{ }^{240} \mathrm{Se}_{3}^{+}=83.6$ & 4 & $\mathrm{Se}_{3}^{-}$ & 19 \\
\hline $\mathrm{Se}_{4}^{+}$ & $\begin{array}{l}320 \\
318\end{array}$ & $\begin{array}{l}5.5 \\
7.3\end{array}$ & $\begin{array}{l}5.4 \\
7.3\end{array}$ & $\begin{array}{c}16.2 \\
-\end{array}$ & $\begin{array}{c}14.4 \\
-\end{array}$ & ${ }^{318} \mathrm{Se}_{4}^{+} /{ }^{320} \mathrm{Se}_{4}^{+}=75.3$ & 2 & $\mathrm{Se}_{4}^{-}$ & 4 \\
\hline $\mathrm{Se}_{5}^{+}$ & $\begin{array}{l}400 \\
398\end{array}$ & - & $\begin{array}{l}11.1 \\
15.7\end{array}$ & $\begin{array}{c}16.2 \\
-\end{array}$ & $\begin{array}{c}14.4 \\
-\end{array}$ & ${ }^{398} \mathrm{Se}_{4}^{+} /{ }^{400} \mathrm{Se}_{4}^{+}=70.7$ & 4 & $\mathrm{Se}_{5}^{-}$ & - \\
\hline $\mathrm{Se}_{6}^{+}$ & $\begin{array}{l}480 \\
478\end{array}$ & $\begin{array}{l}- \\
-\end{array}$ & $\begin{array}{l}5.7 \\
9.1\end{array}$ & $\begin{array}{c}16.2 \\
-\end{array}$ & $\begin{array}{c}14.4 \\
-\end{array}$ & ${ }^{478} \mathrm{Se}_{4}^{+} /{ }^{480} \mathrm{Se}_{4}^{+}=62.6$ & - & & \\
\hline $\mathrm{Se}^{++}$ & 40 & 0.71 & 0.21 & - & - & - & & & \\
\hline $\mathrm{Se}_{2}^{+} / \mathrm{Se}^{+}$ & - & 1.42 & 1.43 & 2.86 & 5.12 & - & 16.66 & $\mathrm{Se}_{2}^{-} / \mathrm{Se}^{-}$ & 1.63 \\
\hline
\end{tabular}

of the $\mathrm{Se}^{+}, \mathrm{Se}_{3}^{+}, \mathrm{Se}_{4}^{+}$, and $\mathrm{Se}_{5}^{+}$ions are of the same order, whereas that of $\mathrm{Se}_{2}^{+}$is maximum, as was in the case of electron impact. As concerning the mass spectrum of negative ions, the $\mathrm{Se}_{2}^{-}$ion has the maximum intensity, and the intensity of the $\mathrm{Se}^{-}$atomic ion is only 1.5 times lower. This is an additional confirmation of different mechanisms governing the formation of atomic and molecular selenium ions at the interaction with electrons and photons.

The analysis of the intensity ratios of the positive and negative diatomic molecular selenium ions to selenium atoms, which are given in Table 2, testifies to a significant difference with analogous data obtained for sulfur. First, the magnitude of this ratio decreases for positive ions created by the electron impact and considerably increases in the case of photon-induced ionization. Second, in the case of negative ions created by photons, this ratio is close to the electronimpact value of the $\mathrm{Se}_{2}^{+} / \mathrm{Se}^{+}$ratio (see Table 2 ).

\subsubsection{Tellurium}

Unlike the sulfur and selenium cases, the mass spectrum of tellurium is mainly characterized by a rela- tively high intensity of natural isotopes. The intensity of spectral peaks is the sum of the probabilities of all combinations for various isotopes with the same $m / z$ value $[41,42]$. Furthermore, the tellurium atom has a large mass in comparison with sulfur and selenium. At the same time, as was marked above, the technical parameters of a mass spectrometer MX7304A restricted the interval of examined masses to 500 a.m.u. Therefore, it was reasonable to confine the evaporation temperature of tellurium in our experiments to values, at which the $\mathrm{Te}_{n}$ molecules with $n>3$ were practically absent [42].

Figure 3,c demonstrates the tellurium mass spectrum. One of its specific features is the presence of the peak of a doubly charged $\mathrm{Te}^{2+}$ ion, which was detected by us for the first time. This mass spectrum consists of four groups of peaks corresponding to the atomic, $\mathrm{Te}^{+}$, molecular, $\mathrm{Te}_{2}^{+}$and $\mathrm{Te}_{3}^{+}$, and doubly charged, $\mathrm{Te}^{2+}$, tellurium ions. In each group, the satellite peaks corresponding to tellurium isotopes can be clearly distinguished, whereas the most intense ones belong to the ${ }^{65} \mathrm{Te}^{2+},{ }^{128} \mathrm{Te}^{+},{ }^{130} \mathrm{Te}^{+},{ }^{256} \mathrm{Te}_{2}^{+}$, ${ }^{260} \mathrm{Te}_{2}^{+}$, and ${ }^{380} \mathrm{Te}_{3}^{+}$ions. The numbers of satellite peaks in the groups are different: there are 8 peaks in 
Table 3. Relative intensities of molecular and atomic tellurium ions at $\mathbf{T}=600 \mathrm{~K}$

\begin{tabular}{|c|c|c|c|c|c|c|c|c|c|}
\hline \multicolumn{10}{|c|}{ Relative peak intensities, $\%$} \\
\hline \multirow{2}{*}{$\begin{array}{l}\text { Positive } \\
\text { ions }\end{array}$} & \multicolumn{3}{|c|}{$\begin{array}{l}\text { Electron-impact } \\
\text { formation }\end{array}$} & \multirow{2}{*}{$\begin{array}{c}\begin{array}{c}\text { Photon-induced } \\
\text { formation }\end{array} \\
{[40]}\end{array}$} & \multirow{2}{*}{$\begin{array}{c}\text { Photon-induced } \\
\text { negative ions }\end{array}$} & \multicolumn{4}{|c|}{$\begin{array}{l}\text { Photon-induced } \\
\text { formation }\end{array}$} \\
\hline & Our data & {$[18]$} & {$[42]$} & & & {$[45]$} & {$[44]$} & {$[40]$} & {$[46]$} \\
\hline${ }^{130} \mathrm{Te}^{+}$ & 77 & 78 & 88 & - & ${ }^{130} \mathrm{Te}^{-}$ & 73 & 3 & 14 & 77 \\
\hline${ }^{260} \mathrm{Te}_{2}^{+}$ & 100 & 100 & 100 & 100 & ${ }^{260} \mathrm{Te}_{2}^{-}$ & 100 & 100 & 100 & 100 \\
\hline${ }^{380} \mathrm{Te}_{3}^{+}$ & 23 & 21 & 26 & 24 & ${ }^{380} \mathrm{Te}_{3}^{-}$ & 38 & 60 & 43 & 23 \\
\hline${ }^{380} \mathrm{Te}_{4}^{+}$ & - & - & 16 & 10 & ${ }^{380} \mathrm{Te}_{4}^{-}$ & 8 & 67 & 10 & 23 \\
\hline${ }^{65} \mathrm{Te}^{++}$ & 4.4 & - & - & - & - & - & - & - & - \\
\hline $\mathrm{Te}_{2}^{+} / \mathrm{Te}^{+}$ & 1.28 & 1.28 & 1.13 & - & $\mathrm{Te}_{2}^{-} / \mathrm{Te}^{-}$ & 1.37 & 33 & 7.14 & 1.43 \\
\hline
\end{tabular}

the $\mathrm{Te}^{+}$group and 16 peaks in each of the $\mathrm{Te}_{2}^{+}$and $\mathrm{Te}_{3}^{+}$groups, which is in agreement with the results of theoretical calculations [42]. Note that the intensity ratio between the isotope and main peaks is preserved for both atomic and molecular ions.

The intensities of the tellurium ion peaks in those groups are different. They depend on both the effective cross-section of the process [43] and the evaporation temperature of the specimen (Fig. 3,c). The highest peak in the mass spectrum belongs to a $\mathrm{Te}_{2}^{+}$ molecular ion, because the state of a $\mathrm{Te}_{2}$ molecule is the most stable for tellurium in the gaseous phase within a wide interval of evaporation temperatures. It is in this state that the maximum number of diatomic tellurium molecules are observed in the vapor composition [44]. By the way, a similar situation is observed in the mass spectrum in the course of photodissociative ionization of tellurium clusters (see Table 3 ) [45]. Note also that the intensity of $\mathrm{Te}_{2}^{-}$molecular ions in the mass spectrum of negative ions is higher than the intensity of atomic negative tellurium ions $[40,44]$. As was emphasized above, such a behavior is also inherent to negative selenium ions: the maximum peak in the selenium mass spectra also belongs to the $\mathrm{Se}_{2}^{-}$molecular ions. In the case of sulfur, however, the intensities of the $\mathrm{S}^{-}$and $\mathrm{S}_{2}^{-}$ions are almost identical. In Table 3, the relative intensities of the molecular and atomic tellurium ions in the mass spectra obtained by the electron and photon ionization methods are compared. The analysis of the data in this table testifies that $\mathrm{Te}^{+}$ions appear in the mass spectrum mainly owing to the dissociative ionization process, which dominates over the direct ionization one.
The intensity ratio between the positive diatomic molecular and atomic tellurium ions, $\mathrm{Te}_{2}^{+} / \mathrm{Te}^{+}$, corresponding to the electron impact ionization decreased in comparison with the sulfur and selenium cases. For negative tellurium ions created by the photon ionization, the analogous ratio, $\mathrm{Te}_{2}^{-} / \mathrm{Te}^{-}$, has different values $[40,44-46]$.

\subsection{Temperature dependences for the formation of positive sulfur, selenium, and tellurium ions}

Let us analyze the temperature dependences of the molecular ion formation obtained by measuring the mass spectra in a definite temperature interval. A characteristic feature of sulfur, selenium, and tellurium consists in their sensitivity to the temperature changes in the gaseous phase. That is why so much attention was paid to study their thermodynamic properties $[42,45]$. It is known that not only atoms, but also molecules with various numbers of atoms are formed in the process of chalcogen evaporation.

The temperature dependences of the sulfur, selenium, and tellurium ion formations are shown in Fig. 4. As one can see, the intensity of some ion peaks drastically increases with the temperature, and their intensity ratio changes at different temperatures.

\subsubsection{Sulfur}

Sulfur has the most complicated structure among chalcogens. Therefore, its molecular composition substantially changes with the temperature. In Fig. 4, $a$, the temperature dependences of the formation of positive sulfur ions $\mathrm{S}_{n}^{+}$with $n=1 \div 6$ are shown. Inter- 


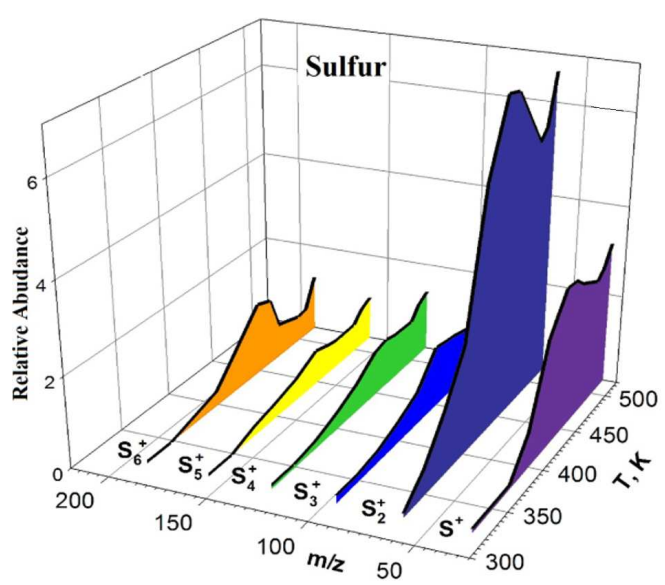

$a$
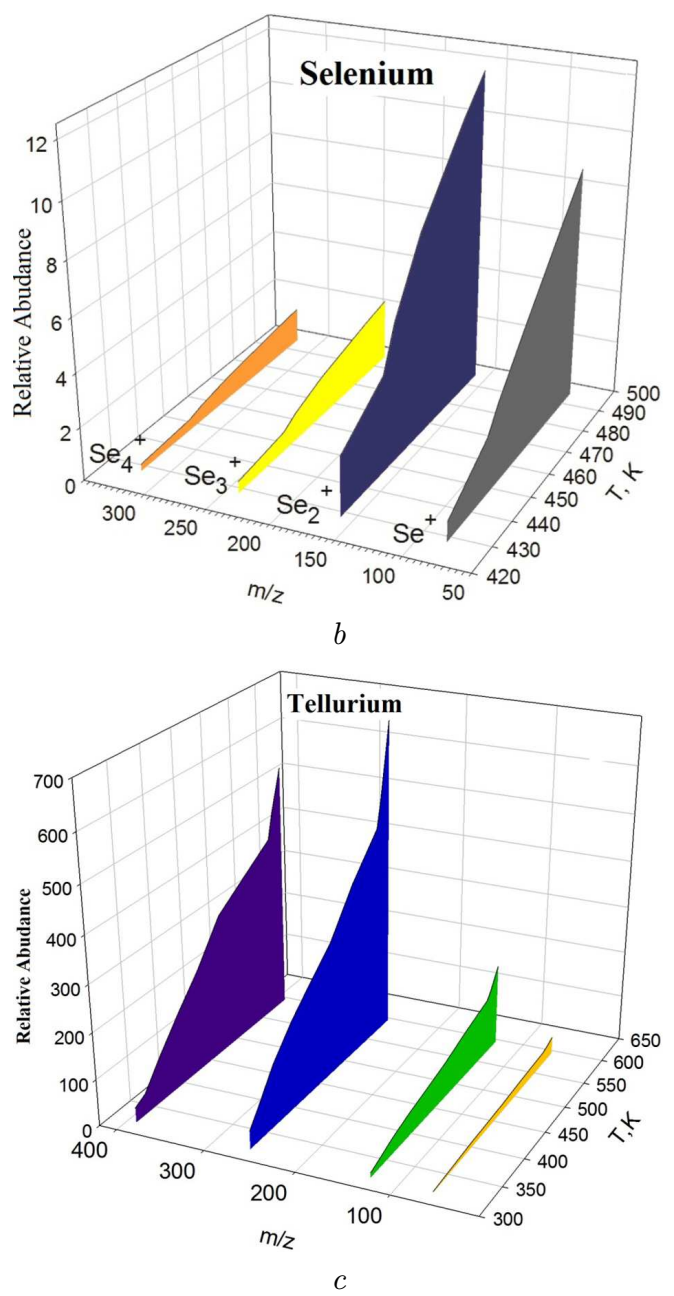

Fig. 4. Temperature dependences of the intensities of the sulfur $(a)$, selenium $(b)$, and tellurium $(c)$ ion formations at an electron energy of $70 \mathrm{eV}$ molecular bonds in sulfur crystals become broken at the temperature $T=372.5 \mathrm{~K}$, which leads to the formation of cyclic $S_{8}$ molecules. As the temperature grows further to $468 \mathrm{~K}$, the two-stage polymerization begins and gives rise to the formation of molecular homochains $\mathrm{S}_{5}-\mathrm{S}_{2}-\mathrm{S}_{4}$. If the temperature increases to $650 \mathrm{~K}$, a considerable contribution to the molecular composition is given by $\mathrm{S}_{3}$ molecules. Therefore, the contribution of the thermal destruction to the intensity of the $\mathrm{S}^{+}, \mathrm{S}_{2}^{+}, \mathrm{S}_{4}^{+}$, and $\mathrm{S}_{5}^{+}$ion peaks should be minimal. From whence, it follows that an additional contribution to the intensity of the $\mathrm{S}_{n}^{+}(n=1 \div 5)$ ion peaks at temperatures below $400 \mathrm{~K}$ is mainly provided by the fragmentation (dissociation) processes of the $\mathrm{S}_{8}$ molecule as a result of its interaction with electrons.

Note that all dependences have a maximum at a temperature of about $450 \mathrm{~K}$. Most probably, it is associated with the thermal destruction of the sulfur crystalline lattice and the break of the $\mathrm{S}_{8}$ molecular ring giving rise to the formation of an open atomic chain [6]. Assuming that $\mathrm{S}_{8}$ molecules are formed with an open-chain structure, we can explain a substantial increase in the intensities of molecular $\mathrm{S}_{2}^{+}$and atomic $\mathrm{S}^{+}$ions (see Fig. 4,a), because the interatomic bonds in those molecules are weaker.

As concerning the functional dependences describing the formation of molecular ions $\mathrm{S}_{3}^{+}, \mathrm{S}_{4}^{+}, \mathrm{S}_{5}^{+}$, and $\mathrm{S}_{6}^{+}$, they behave similarly to one another up to a temperature of $570 \mathrm{~K}$. At higher temperatures, the intensity of the $\mathrm{S}_{6}^{+}$molecular ion increases more slowly. This effect is explained by the fact that higher temperatures enable new fragmentation channels for the $S_{6}$ and $S_{8}$ molecules due to the changes in their structures and vapor compositions, which results in the formation of $\mathrm{S}_{3}^{+}, \mathrm{S}_{4}^{+}$, and $\mathrm{S}_{5}^{+}$ionic fragments.

\subsubsection{Selenium}

Unlike sulfur, selenium has a cubic modification and a monoclinic one. At the temperatures $T=373.15 \div$ $423.15 \mathrm{~K}$, the both transform into a hexagonal one. In Fig. $4, b$, the temperature dependences of the $\mathrm{Se}_{n}^{+}$ $(n=1 \div 4)$ ion formation in the interval from 420 to $500 \mathrm{~K}$ are shown. One can see that all dependences demonstrate a strong intensity growth at a temperature of $440 \mathrm{~K}$, which testifies to the enabling of the processes leading to the growth in the number of appearing ions. The $\mathrm{Se}_{8}$ molecule has the high- 
est concentration in a selenium vapor at $440 \mathrm{~K}$. Therefore, we may assume that this phenomenon is a result of the disintegration of just this molecule. Theoretical calculations showed that the ring shape of the $\mathrm{S}_{8}$ molecule is the stablest one. Therefore, the assumption can be made that the ring structure of the molecule transforms at a temperature of $440 \mathrm{~K}$ [35], which gives rise to its more efficient fragmentation at its interaction with electrons.

\subsubsection{Tellurium}

The thermodynamic properties of tellurium, which has a hexagonal structure, are substantially different from those of sulfur and selenium. The analysis of the structure and composition of $\mathrm{Se}_{n}$ and $\mathrm{Te}_{n}$ clusters, as well as their comparison, was made in works $[38,39,66]$. In particular, it was shown that their mass spectra differ considerably: a certain periodicity is observed for selenium, but not for tellurium. Therefore, the cyclic structure of selenium molecules does not allow the formation of large $\mathrm{Se}_{n}$ clusters $\left(n_{\max }=8\right)$, whereas large tellurium $\mathrm{Te}_{n}$ clusters are easily formed $\left(n_{\max }=56\right)$.

Our measurements of mass spectra in various temperature regimes made it possible to obtain the dependences of the tellurium ion formation in the temperature interval from 450 to $610 \mathrm{~K}$ (Fig. 4, c). It turned out that the relative intensities of tellurium ion peaks in the examined temperature interval have an almost linear character, in contrast to the analogous dependences for selenium and sulfur [25,63], for which the deviation of the temperature coefficients from the linearity was observed for all researched ions. As was in the case of sulfur and selenium, the state of the $\mathrm{Te}_{2}$ molecule is the stablest in the gaseous phase within a wide range of evaporation temperatures, and it is in this state that the maximum number of diatomic tellurium molecules in the vapor composition is observed [20].

It is worth to note that the study of the intensity distribution of cluster tellurium ions $\mathrm{Te}_{n}^{+}$and $\mathrm{Te}_{n}^{-}$with $n=2 \div 56$ using the secondary-ion mass spectrometry method showed that, at certain $n$ values, the intensities for positive and negative ions change differently. This phenomenon is explained by the existence of non-functional fragmentation channels. Theoretical calculations of the tellurium structure and mass spectra performed in the framework of

ISSN 2071-0194. Ukr. J. Phys. 2020. Vol. 65, No. 7 the density functional theory proved that the closed ring structure of tellurium is the stablest one. Its changes depend on the bond angle between the atoms, as well as on the atomic coordination number in the $\mathrm{Te}_{n}$ cluster [42].

\subsection{Energy dependences of the appearance intensity of positive ions}

The more detailed information concerning the mechanisms of ion formation, when electrons pass through a chalcogen vapor can be obtained by studying the energy dependences of the ion yield for ions with different masses. Particularly interesting in this case is the interval of collision energies near the threshold. We studied the energy dependences of the formation of separate components in the mass spectra, i.e., sulfur, selenium, and tellurium ions with definite masses in the energy interval of ionizing electrons from the ion formation threshold to $35-60 \mathrm{eV}$.

In Figs. 5-8, the yield curves are exhibited for the most intense fragments of the sulfur, selenium, and tellurium ions. The majority of the curves demonstrate a monotonous increase of the relative cross-sections with the energy of bombarding electrons. Some peculiarities can be observed in those dependences in the form of inflections, cusps, or small maxima. Let us analyze our results in more details.

\subsubsection{Sulfur}

Figure 5 illustrates the behavior of the relative crosssections of the $\mathrm{S}_{n}^{+}(n=1 \div 6)$ sulfur ion formation within a wide interval of incident electron energies. A general analysis of the measured curves testifies that the energy dependences of the relative formation cross-sections of the $\mathrm{S}^{+}, \mathrm{S}_{2}^{+}$, and $\mathrm{S}_{3}^{+}$ions slowly grow starting from the process threshold to about $15 \mathrm{eV}$; then they have an interval of a rather rapid growth; finally, the curves saturate. In the cases of $\mathrm{S}_{4}^{+}, \mathrm{S}_{5}^{+}$, and $\mathrm{S}_{6}^{+}$ions, the corresponding curves start to grow rapidly at lower electron energies.

In Table 4, the appearance energies calculated using the method of least squares for atomic and molecular sulfur ions created by directly ionizing the corresponding systems are quoted. In other words, these are ionization energies of the atoms and the corresponding molecules, being the minimum values characterizing the appearance of corresponding ions. It is of interest that the appearance energies of sulfur ions 

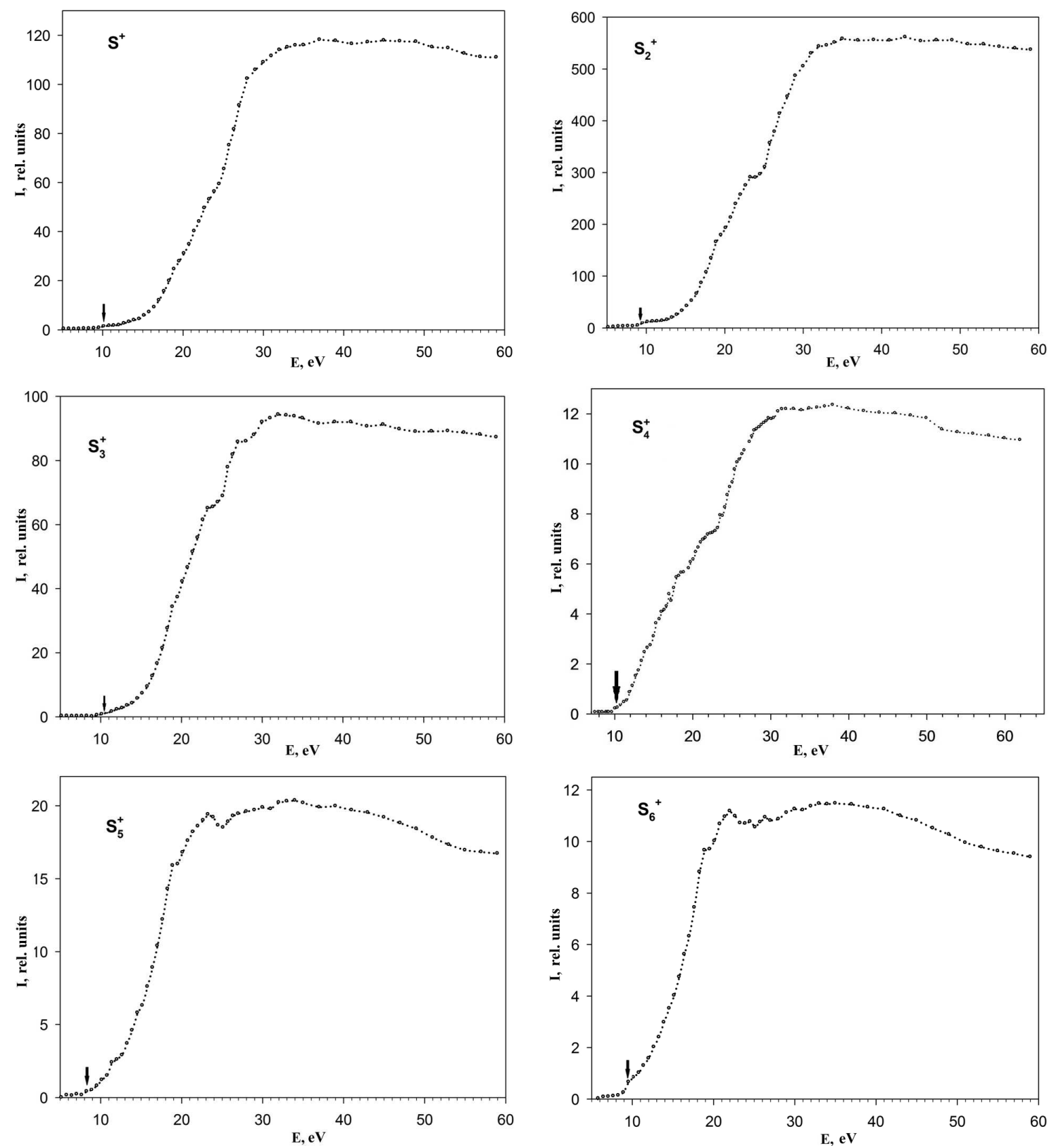

Fig. 5. Energy dependences of the relative formation cross-sections for positive sulfur ions. The ion appearance energies are marked by arrows

presented in Table 4 are substantially different and depend on the ion formation process. For instance, the $\mathrm{S}_{5}^{+}$ion has the lowest appearance energy among all sulfur ions, which testifies that this ion is a result of the direct ionization of a $\mathrm{S}_{5}$ molecule.

To determine the specific features of the ionization process, experiments were carried out on an in- stallation with a hypocycloidal electron spectrometer (see Fig. 2). In particular, the total yield of ions formed, when electrons passed through the vapors of examined elements, was measured. The electron energy homogeneity in those experiments was rather high, $\Delta E_{1 / 2}=0.11 \mathrm{eV}$, and the electron energy was scanned with an increment of $0.05 \mathrm{eV}$. As follows from 

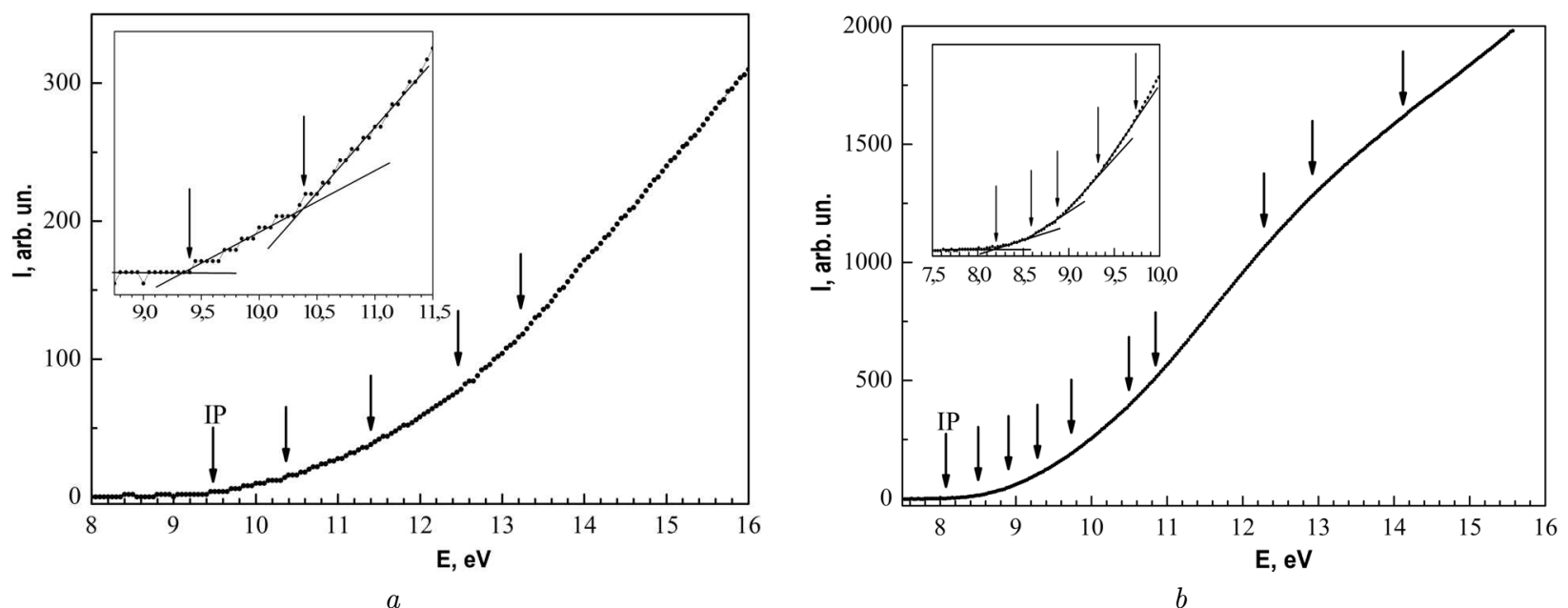

Fig. 6. Initial sections in the energy dependences of the total effective formation cross-sections for positive sulfur (a) and selenium $(b)$ ions. The procedure of linear approximation in the near-threshold interval of electron energies is illustrated in the insets

Fig. 6, a, a large body of experimental data allowed a number of peculiarities in the curve to be identified. In Fig. 6, $a$, they are marked with arrows.

The energy dependences of the total effective crosssection of the positive sulfur atomic ion formation (Fig. 6, a) have breakpoints at energies of $11.5 \pm 0.2$, $13.8 \pm 0.2$, and $16.7 \pm 0.2 \mathrm{eV}$. The increase or decrease of the curve slope at the breakpoint testifies to both the enabling of dissociative ionization processes and the excitation of ionic energy levels. The peculiarities at 11.5 and $13.8 \mathrm{eV}$ in the energy dependence for the $\mathrm{S}^{+}$ion testify to the opening of new channels of its formation. This conclusion was confirmed by theoretical calculations [49], which showed that, at energies of 11.07 and $13.8 \mathrm{eV}, \mathrm{S}^{+}$ions can appear in the dissociation of $\mathrm{S}_{8}$ and $\mathrm{S}_{2}$ molecules owing to the following reactions:

$\mathrm{S}_{8}+\mathrm{e}^{-} \rightarrow \mathrm{S}^{+}+\mathrm{S}_{4}+\mathrm{S}_{3}+2 \mathrm{e}^{-}$,

$\mathrm{S}_{2}+\mathrm{e}^{-} \rightarrow \mathrm{S}^{+}+\mathrm{S}+2 \mathrm{e}^{-}$.

Hence, we may assert that the peculiarities in the curves for $\mathrm{S}_{n}^{+}$at 11.5 and $138 \mathrm{eV}$ are a result of the dissociative ionization of the $\mathrm{S}_{n}$ sulfur molecules with $n=8$ and 2 , respectively. The activation of additional channels for the formation of parent $\mathrm{S}^{+}$ions gives rise to the appearance of a maximum in the energy dependence for the $\mathrm{S}^{+}$ion at an energy of $16.7 \mathrm{eV}$ (see Fig. 6, $a$ ).

As concerning the energy dependence of the effective cross-section of the $\mathrm{S}_{2}^{+}$molecular ion forma-

ISSN 2071-0194. Ukr. J. Phys. 2020. Vol. 65, No. 7
Table 4. Appearance energies (in eV)

of sulfur ions $S_{n}^{+}(n=1 \div 6), S_{2}^{2+}$, and $S_{2}^{3+}$

and the results of other works

\begin{tabular}{|c|c|c|c|c|c|c|}
\hline \multirow{2}{*}{ Ion } & \multicolumn{2}{|c|}{ Our data } & \multirow{2}{*}[47]{} & {$[6]$} & {$[38]$} & {$[65]$} \\
\cline { 2 - 6 } & IMMS & IHES & & & & \\
\hline $\mathrm{S}^{+}$ & $10.3 \pm 0.2$ & $10.36 \pm 0.1$ & $10.4 \pm 0.3$ & - & - & - \\
$\mathrm{S}_{2}^{+}$ & $9.6 \pm 0.2$ & - & 9.6 & 9.9 & 9.36 & - \\
$\mathrm{S}_{3}^{+}$ & $10.2 \pm 0.2$ & - & 10.2 & 10.5 & 9.68 & - \\
$\mathrm{S}_{4}^{+}$ & $10.1 \pm 0.2$ & - & 10.1 & 10.4 & - & - \\
$\mathrm{S}_{5}^{+}$ & $8.7 \pm 0.2$ & - & 8.8 & 9.6 & 8.6 & - \\
$\mathrm{S}_{6}^{+}$ & $9.5 \pm 0.2$ & - & 9.7 & 9.0 & 9.0 & - \\
$\mathrm{S}_{2}^{2+}$ & - & $17.37 \pm 0.1$ & - & - & - & 16.84 \\
$\mathrm{~S}_{2}^{3+}$ & - & $29.40 \pm 0.1$ & - & - & - & 29.28 \\
$\mathrm{~S}^{2+}$ & $21.9 \pm 0.2$ & - & & & & \\
\hline
\end{tabular}

tion, it has a breakpoint at an energy of $13.8 \pm 0.2 \mathrm{eV}$ and two maxima at energies of $12.8 \pm 0.2$ and $16.5 \pm$ $\pm 0.2 \mathrm{eV}$. The former maximum corresponds to the appearance energy of the $\mathrm{S}_{2}^{+}$ion through the dissociative ionization of the $\mathrm{S}_{6}$ molecule according to the reaction

$\mathrm{S}_{6}+\mathrm{e}^{-} \rightarrow \mathrm{S}_{2}^{+}+\mathrm{S}_{3}+\mathrm{S}+2 \mathrm{e}^{-}$.

The slope of the curve in Fig. 6, $a$ changes at an energy of $13.8 \mathrm{eV}$, i.e., a new channel of the $\mathrm{S}_{2}^{+}$molecular ion formation becomes activated. In their turn, the maxima at energies of 12.8 and $16.5 \mathrm{eV}$ arise due 

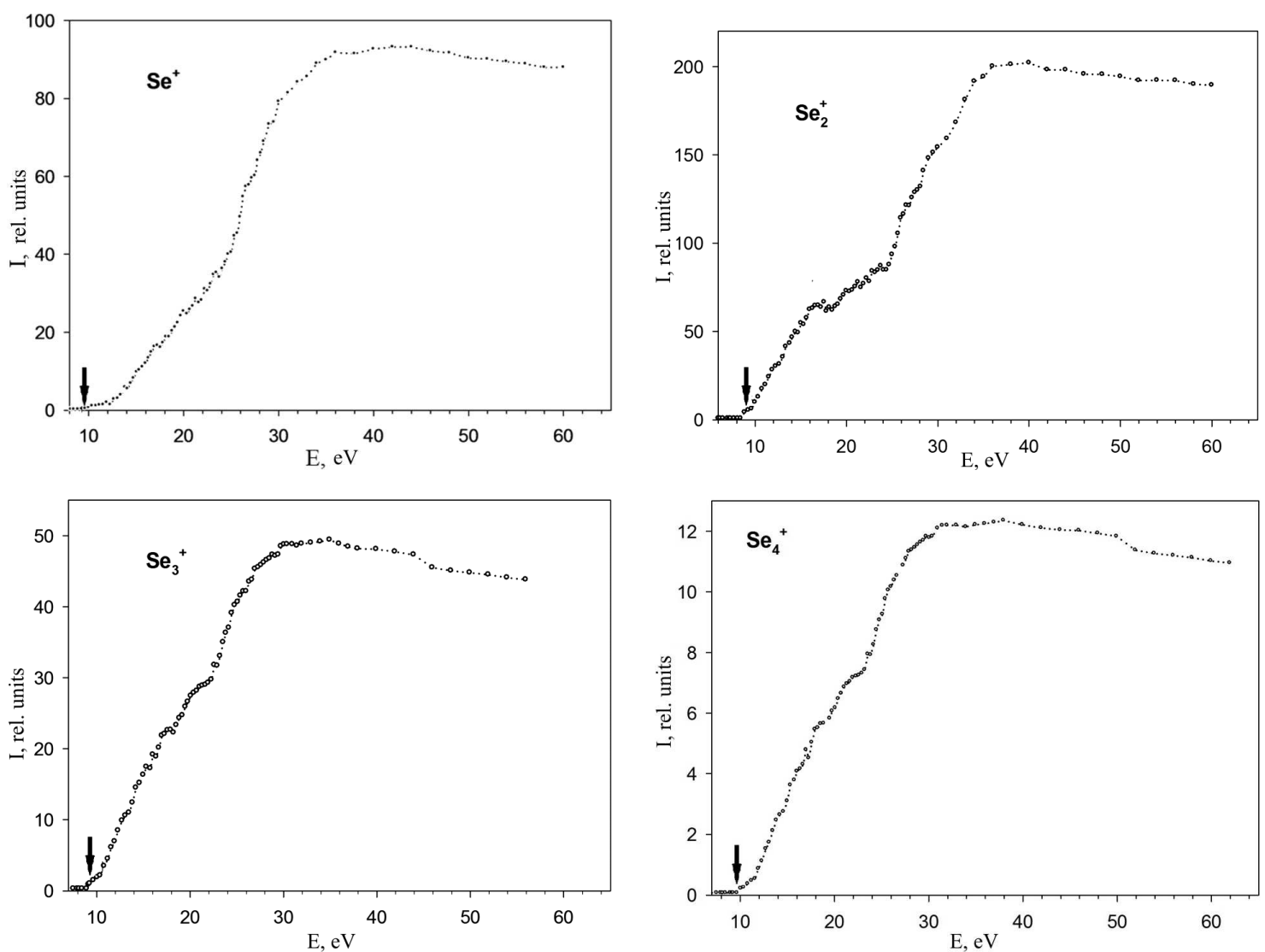

Fig. 7. Energy dependences of the relative formation cross-sections for positive selenium ions. The ion appearance energies are marked by arrows

to the excitation of the energy levels of the $\mathrm{S}_{2}^{+}$molecular ion. More specifically, the peculiarity at an energy of $12.8 \mathrm{eV}$ corresponds to the excitation energy of the ${ }^{2} \Pi_{u}$ state of the $\mathrm{S}_{2}^{+}$ion $[60,61]$, and the appearance of the maximum at an energy of $16.5 \mathrm{eV}$ is most probably associated with the excitation of the higher energy states of this molecular ion.

\subsubsection{Selenium}

Analogously to what was done for sulfur, we measured the energy dependences of the complete effective cross-section of the $\mathrm{Se}_{n}^{+}(n=1 \div 4)$ selenium ion formation within the energy interval from the process threshold to $60 \mathrm{eV}$ (see Fig. 7). A general analysis of the obtained curves shows that they are similar to the energy dependences of the relative cross-sections of sulfur ionization (Fig. 5): there is a slow growth starting from the process threshold; then a rather rapid growth takes place, after which the curve sat- urates. In the energy interval from the threshold to $30 \mathrm{eV}$, the energy dependences of the relative crosssections of the positive selenium ion formation have a number of peculiarities in the form of breakpoints and maxima. The initial sections of the curves, as was done in the case of sulfur, were used to determine the appearance energies for the $\mathrm{Se}_{n}^{+}$ions with $n=1 \div 4$ with the help of the method of least squares. The results of calculations are presented in Table 5 together with the results of other works for the sake of comparison. As one can see, the appearance energies determined for selenium ions are in good agreement with the results of other works obtained using various ionization methods [37-39]. However, for some ions, e.g., $\mathrm{Se}_{3}^{+}$, there is a substantial discrepancy among the appearance energy values. This circumstance can be explained by the fact that ions with higher appearance energies may probably be formed as a result of the dissociative ionization rather than the direct one. 
Table 5. Appearance energies (in $\mathrm{eV})$ of selenium ions $\mathrm{Se}_{n}^{+}(n=1 \div 8)$ and $\mathrm{Se}^{2+}$ and the results of other works

\begin{tabular}{|c|c|c|c|c|c|c|}
\hline \multirow{2}{*}{ Ion } & \multicolumn{2}{|c|}{ Our data } & \multicolumn{3}{|c|}{ Electron-impact } & \multirow{2}{*}{$\begin{array}{c}\text { Photon-induced } \\
{[37]}\end{array}$} \\
\hline & IMMS & IHES & {$[38]$} & {$[20]$} & {$[36]$} & \\
\hline $\mathrm{Se}^{+}$ & $9.8 \pm 0.2$ & $9.75 \pm 0.1$ & - & - & - & $9.75 \pm 0.05$ \\
\hline $\mathrm{Se}_{2}^{+}$ & $9.0 \pm 0.2$ & $8.87 \pm 0.1$ & $9.2 \pm 0.2$ & 9.4 & - & $8.84 \pm 0.05$ \\
\hline $\mathrm{Se}_{3}^{+}$ & $10.4 \pm 0.2$ & $9.3 \pm 0.1$ & $10.4 \pm 0.2$ & 10.2 & - & $9.58 \pm 0.05$ \\
\hline $\mathrm{Se}_{4}^{+}$ & $10.3 \pm 0.2$ & $9.3 \pm 0.1$ & $10.1 \pm 0.2$ & 10.8 & - & $9.14 \pm 0.05$ \\
\hline $\mathrm{Se}_{5}^{+}$ & - & $9.1 \pm 0.1$ & $8.6 \pm 0.2$ & 9.6 & $9.2 \pm 0.2$ & $7.93 \pm 0.05$ \\
\hline $\mathrm{Se}_{6}^{+}$ & - & $8.5 \pm 0.1$ & $8.9 \pm 0.2$ & 9.7 & $9.08 \pm 0.05$ & $8.24 \pm 0.05$ \\
\hline $\mathrm{Se}_{7}^{+}$ & & $8.8 \pm 0.1$ & $8.4 \pm 0.2$ & 8.9 & $8.87 \pm 0.05$ & $7.94 \pm 0.05$ \\
\hline $\mathrm{Se}_{8}^{+}$ & - & $8.05 \pm 0.1$ & $8.6 \pm 0.2$ & 9.0 & $8.97 \pm 0.05$ & $8.11 \pm 0.05$ \\
\hline $\mathrm{Se}^{2+}$ & $21.2 \pm 0.2$ & - & - & - & - & - \\
\hline
\end{tabular}

The installation with a hypocycloidal electron monochromator was used to measure the energy dependence of the total cross-section of selenium vapor ionization in the electron energy interval from 7.5 to $16 \mathrm{eV}$. This dependence is shown in Fig. $6, b$. In the measurements, the energy homogeneity of electrons in the beam was $0.1-0.15 \mathrm{eV}$, and the electron energy was changed with an increment of $0.03 \mathrm{eV}$. As one can see from the figure, unlike sulfur (Fig. 6, a), the crosssection of selenium ionization rapidly increases within the interval from the threshold value to $12 \mathrm{eV}$; then, a reduction in the growth rate of the measured signal intensity is observed. The process threshold value was determined using the linear approximation method and was found to equal $E_{I P}=8.05 \pm 0.1 \mathrm{eV}$, which is in good agreement with the appearance energy of the $\mathrm{Se}_{8}^{+}$molecular ion [50].

Due to the high energy homogeneity of electrons in the beam and the small scanning increment of the energy of ionizing electrons, we managed to detect four additional peculiarities in the near-threshold region. These are breakpoints at energies of $8.5 \pm 0.1$, $8.87 \pm 0.1,9.3 \pm 0.1$, and $9.75 \pm 0.1 \mathrm{eV}$, which were identified as the appearance energies of the $\mathrm{Se}_{6}^{+}$, $\mathrm{Se}_{2}^{+}, \mathrm{Se}_{4}^{+} / \mathrm{Se}_{3}^{+}$molecular ions and the $\mathrm{Se}^{+}$atomic ion, respectively. The appearance energies of the $\mathrm{Se}^{+}$ atomic and $\mathrm{Se}_{2}^{+}$molecular ions are in good agreement with the values obtained using the mass spectrometry method (Table 5). However, there is a $1-\mathrm{eV}$ difference in the case of molecular $\mathrm{Se}_{4}^{+}$and $\mathrm{Se}_{3}^{+}$ions. It can be explained by the fact that those ions most likely emerge in mass spectrometric researches as a result

ISSN 2071-0194. Ukr. J. Phys. 2020. Vol. 65, No. 7 of the dissociative rather than direct ionization of selenium molecules with large numbers of atoms.

Five breakpoints were found at electron energies above the threshold value: $10.5 \pm 0.1,10.94 \pm 0.1$, $12.24 \pm 0.1,12.95 \pm 0.1$, and $14.1 \pm 0.1 \mathrm{eV}$. At the $10.5-\mathrm{eV}$ and $10.95-\mathrm{eV}$ breakpoints, the slope of the curve increases, which evidences the activation of new ionization channels giving rise to a growth in the number of generated ions. Probably, this is a result of the dissociative ionization of $\mathrm{Se}_{n}$ selenium molecules with $n=3 \div 8$ and the formation of $\mathrm{Se}^{+}$and $\mathrm{Se}_{2}^{+}$ions. At other breakpoints, the slope of the curve decreases, i.e., the number of created ions diminishes. We assume that this is a result of the fragmentation of $\mathrm{Se}_{2}^{+}$, $\mathrm{Se}_{4}^{+}, \mathrm{Se}_{3}^{+}$, and $\mathrm{Se}_{6}^{+}$ions, which give the largest contribution to the total ionization cross-section.

The breakpoints at energies of $12.1 \pm 0.2$ and $14.1 \pm 0.2 \mathrm{eV}$ evidence that new channels become open for the formation of $\mathrm{Se}^{+}$ions. In work [37], on the basis of theoretical calculations, the photodissociation reactions of selenium molecules $\mathrm{Se}_{n}$ with $n=3 \div 7$ giving rise to the formation of $\mathrm{Se}^{+}$ions were proposed. The energy of the breakpoint detected at $12.1 \mathrm{eV}$ coincides with the photodissociation energy of a $\mathrm{Se}_{5}$ molecule, which is equal to $12.18 \mathrm{eV}$ according to reaction (4),

$\mathrm{Se}_{5}+h \nu \rightarrow \mathrm{Se}^{+}+\mathrm{Se}_{4}+\mathrm{e}^{-}$.

The energy position of the other breakpoint $(14.1 \mathrm{eV})$ is in good agreement with the photodissociation energies of $\mathrm{Se}_{5}$, and $\mathrm{Se}_{6}$ molecules, which amount to 14.28 and $13.85 \mathrm{eV}$, respectively [37], and corresponds to 

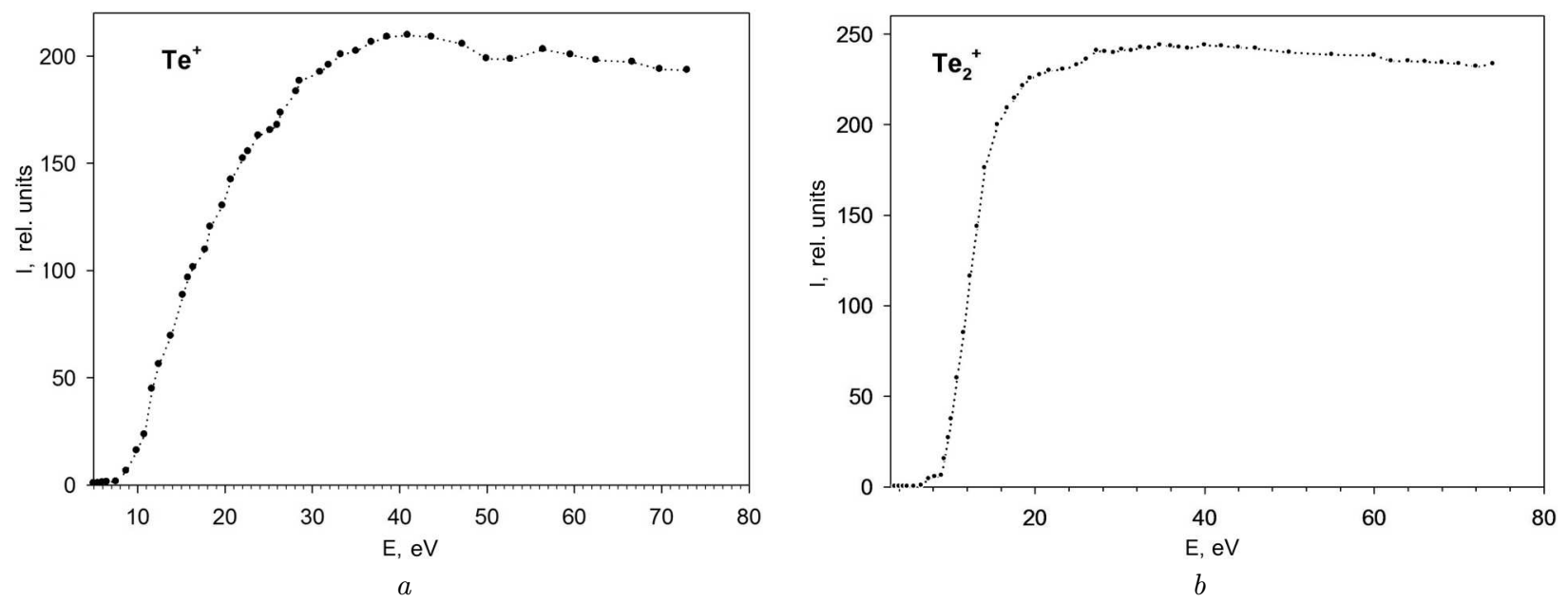

Fig. 8. Energy dependences of the relative formation cross-sections for tellurium ions

the reactions

$\mathrm{Se}_{5}+h \nu \rightarrow \mathrm{Se}^{+}+\mathrm{Se}+\mathrm{Se}_{3}+\mathrm{e}^{-}$,

$\mathrm{Se}_{6}+h \nu \rightarrow \mathrm{Se}^{+}+\mathrm{Se}_{2}+\mathrm{Se}_{3}+\mathrm{e}^{-}$.

A similar reaction is possible in the case of a $\mathrm{Se}_{8}$ molecule,

$\mathrm{Se}_{8}+h \nu \rightarrow \mathrm{Se}^{+}+\mathrm{Se}_{3}+\mathrm{Se}_{4}+\mathrm{e}^{-}$.

Taking into account that the $\mathrm{Se}_{5}$ and $\mathrm{Se}_{6}$ molecules dominate in a selenium vapor at low temperatures [38], we may assume that analogous processes of dissociative ionization with the participation of electrons also took place in our experiment. An interesting result is that the energy of the first breakpoint $(9.8 \mathrm{eV})$ is identical to the appearance energy of a $\mathrm{Se}^{+}$ion (see Fig. 6, b). On this basis, we may assume that the $\mathrm{Se}^{+}$ion was formed as a result of the fragmentation of a $\mathrm{Se}_{2}^{+}$one. This hypothesis is confirmed by a decrease of the curve slope, which testifies to the fragmentation of this ion at this energy. As concerning the breakpoints at energies of 11.8 and $15.4 \mathrm{eV}$, it is most probably that they appear as a result of the fragmentation of parent $\mathrm{Se}_{2}^{+}$ions, because a recession in the relative intensity of this ion formation is observed.

\subsubsection{Tellurium}

We also measured the energy dependences of the total effective formation cross-sections for the tellurium ions corresponding to the most intense lines in the mass spectrum. A characteristic behavior of all curves is that the effective ionization cross-sections drastically increase from the process threshold to 20$30 \mathrm{eV}$, but practically does not change at higher energies. Such a behavior is typical of the electron-impact ionization of atoms in the gaseous phase [50].

The energy dependence of the appearance intensity of atomic tellurium ions (Fig. 8) in the energy interval 9-18 eV demonstrates a strong growth of the cross-section with a few features near the threshold and, then, a weak recession up to $E=70 \mathrm{eV}$. By carrying out a linear extrapolation in the threshold section of the curve, we obtained two points of the curve intersection with the energy axis: at 8.8 and $10.9 \mathrm{eV}$. In essence, those values reflect the ionization energy $E_{\mathrm{IP}}$ of the tellurium atom and the appearance energy $E_{\mathrm{AP}}$ of the $\mathrm{Te}^{+}$ion. On the other hand, the difference between those energies equals $2.1 \mathrm{eV}$, which corresponds to the dissociation energy of a $\mathrm{Te}_{2}$ molecule. Therefore, we may assume that the ionization process mainly occurs according to the scenario

$\mathrm{Te}_{2}+\mathrm{e}^{-} \rightarrow \mathrm{Te}^{+}+\mathrm{Te}+2 \mathrm{e}^{-}$.

The molecular tellurium ions are formed according to the scheme

$\mathrm{Te}_{n}+\mathrm{e}^{-} \rightarrow \mathrm{Te}_{n-k}^{+}+\mathrm{Te}_{k}+2 \mathrm{e}^{-}$.

According to Eqs. (14) and (15), the energy scales of the initial sections in the corresponding energy dependence curves are quite different. The general be- 
Table 6. Appearance and ionization energies of some atomic and molecular tellurium ions

\begin{tabular}{|c|c|c|c|c|c|c|c|c|c|c|c|}
\hline \multirow{2}{*}{ Ioн } & \multicolumn{4}{|c|}{ Appearance energy $E_{\mathrm{AP}}, \mathrm{eV}$} & \multicolumn{5}{c|}{ Ionization energy $E_{\mathrm{IP}}, \mathrm{eV}$} \\
\cline { 2 - 12 } & Our data & {$[46]$} & {$[20]$} & {$[18]$} & {$[51]$} & Our data & {$[52]$} & {$[18]$} & {$[46]$} & {$[56]$} & {$[38]$} \\
\hline $\mathrm{Te}^{+}$ & $10.9 \pm 0.25$ & - & 12.20 & $10.8 \pm 0.5$ & $8.8 \pm 0.2$ & $8.8 \pm 0.25$ & $9.5 \pm 1.0$ & 8.9 & 8.96 & 9.009 & - \\
$\mathrm{Te}_{2}^{+}$ & $9.2 \pm 0.25$ & 8.26 & 9.00 & - & $9.0 \pm 0.2$ & $8.3 \pm 0.25$ & $8.4 \pm 0.6$ & $8.3 \pm 0.2$ & - & - & $11.71 \pm 0.01$ \\
$\mathrm{Te}_{3}^{+}$ & - & & & & & $8.1 \pm 0.25$ & $8.2 \pm 0.6$ & 9.3 & - & - & - \\
$\mathrm{Te}^{2+}$ & - & - & - & - & - & $20.6 \pm 0.25$ & - & - & 27.3 & 18.6 & - \\
\hline
\end{tabular}

haviors of the curves in the examined energy interval are also different. In particular, the $\mathrm{Te}_{2}^{+}$ionization function increases rapidly from the threshold to $14 \mathrm{eV}$; then, the cross-section practically does not change with the energy up to $70 \mathrm{eV}$. On the contrary, as concerning the ionization function for the formation of doubly charged $\mathrm{Te}^{2+}$ ions, it increases very slowly from the threshold to $50 \mathrm{eV}$. According to the results of work [50], the ratio between the magnitudes of the effective cross-sections of the $\mathrm{Te}_{2}^{+}$and $\mathrm{Te}^{2+}$ ion formation at the electron energy $E=70 \mathrm{eV}$ equals $\mathrm{Te}_{2}^{+} / \mathrm{Te}^{2+}=10$. Note that the intensity ratio between the corresponding peaks of the $\mathrm{Te}_{2}^{+}$and $\mathrm{Te}^{2+}$ ions in the mass spectrum has the same order of magnitude (Fig. 3, c).

In Table 6 , the appearance energies of the tellurium ions $\mathrm{Te}^{+}, \mathrm{Te}_{2}^{+}, \mathrm{Te}_{3}^{+}$, and $\mathrm{Te}^{2+}$ are quoted. They were calculated from the threshold sections of their relative ionization cross-sections (see Fig. 8) using the method of least squares [29]. In Table 6, we compare them with the results of other works. It should be emphasized that the data presented for the appearance energies and ionization potentials were obtained in the last century, except for work [20].

Note that there is good agreement of our results obtained for the appearance energies and ionization potentials of molecular and atomic tellurium ions with the NIST database [18]. At the same time, the results of other works differ substantially, especially for $\mathrm{Te}^{2+}$. It is possible that, in our work and work [46], the DI process of some tellurium molecule affected the formation energy of a doubly charged atomic tellurium ion, which led to overestimated ionization energies. Thus, by analyzing the data in Table 6 , we may conclude that the most comprehensive information about tellurium ions is contained in our work.

ISSN 2071-0194. Ukr. J. Phys. 2020. Vol. 65, No. 7

\subsection{Energy dependences of the intensity of the doubly charged ion formation}

We are the first who detected the appearance of doubly charged $\mathrm{S}_{2}^{2+}, \mathrm{S}^{2+}, \mathrm{Se}^{2+}$, and $\mathrm{Te}^{2+}$ ions in a chalcogen vapor and measured the energy dependences of the intensity of their formation by electron impact in the energy interval $10-70 \mathrm{eV}$. In Fig. 9, the near-threshold sections of those dependences are depicted. They were used to determine the appearance energies of the $\mathrm{S}^{2+}, \mathrm{Se}^{2+}$, and $\mathrm{Te}^{2+}$ ions with the help of the method of least squares [29]. The results of calculations are given in Tables 4 to 6 .

By the example of a doubly charged $\mathrm{Te}^{2+}$ ion, let us present the most probable schemes for the formation of doubly charged ions. Their appearance can occur accordingly to the following processes of two-electron direct and dissociative ionizations:

$\mathrm{Te}+\mathrm{e}^{-} \rightarrow \mathrm{Te}^{2+}+3 \mathrm{e}^{-}$,

$\mathrm{Te}_{2}+\mathrm{e}^{-} \rightarrow \mathrm{Te}^{2+}+\mathrm{Te}+3 \mathrm{e}^{-}$.

Reaction (17) may play the dominant role because, as was shown above, diatomic molecules in the gaseous phase have the maximum content under our experimental conditions (see Fig. 3).

A general characteristic feature of the curves exhibited in Fig. 9 is a rather rapid growth of the effective cross-sections for sulfur and selenium from the threshold energy to $28 \mathrm{eV}$, and a slower growth for tellurium. At the same time, the energy dependences have some peculiarities in the form of breakpoints, which are observed most clearly in the cases of selenium and tellurium. A possible explanation for the appearance of those peculiarities at energies about 22,25 , and $27 \mathrm{eV}$ is the activation of new processes of direct and dissociative ionizations, which increases 


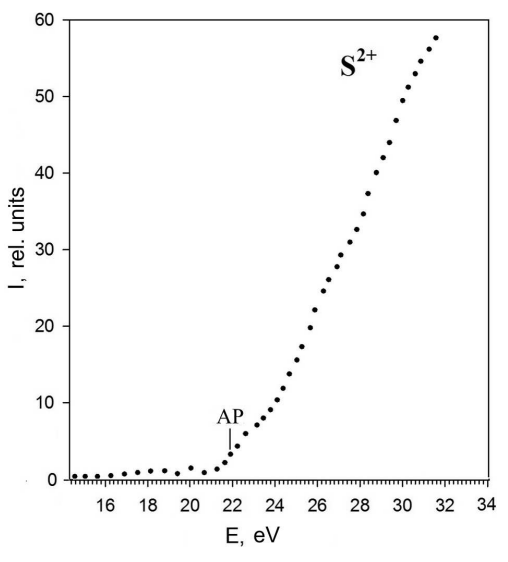

$a$
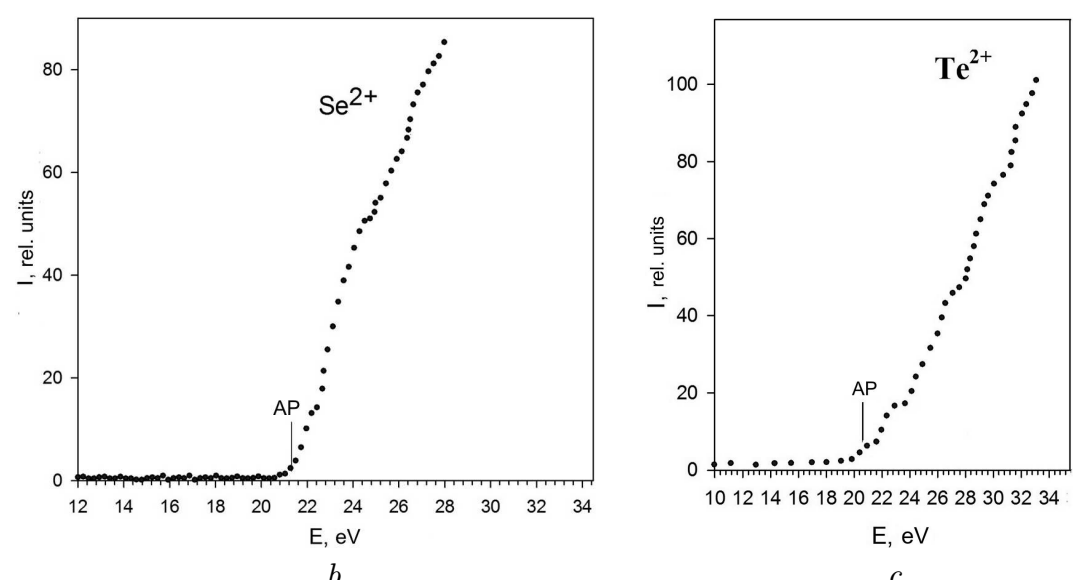

$c$

Fig. 9. Energy dependences of the formation intensity for doubly charged sulfur $(a)$, selenium (b), and tellurium $(c)$ ions. The ion appearance energies are marked by AP

the number of generated ions, as well as the excitation of certain energy levels of ions. For example, for a doubly charged selenium ion, the breakpoints can be exactly identified making allowance for the excitation of the atomic and ionic energy levels located in this energy interval [44].

Hence, by analyzing the results obtained for the ionization and appearance energies of positive chalcogen ions at their interaction with electrons (see Tables 4 to 6 ), one can see that the most comprehensive information about the processes of atomic and molecular ion formations is given in our studies. Particular attention should be paid to doubly charged $\mathrm{S}^{2+}, \mathrm{Se}^{2+}$, and $\mathrm{Te}^{2+}$ ions detected by us in chalcogen vapors. We are the first who measured the energy dependences of the intensity of their electron-impact formation and determined the ionization potentials.

\subsection{Energy dependences of the intensity of the negative ion formation}

It is known [54] that negative ions are formed through the electron trapping by an atom or a molecule. A characteristic feature of this process, in which lowenergy bombarding electrons $(0-10 \mathrm{eV})$ participate, consists in the capture of an electron into a potential well created by the atom or the molecule in a certain state. The corresponding main mechanisms of negative ion formation are

- the radiative capture of a free electron by a neutral atom,

$\mathrm{A}+\mathrm{e}^{-} \rightarrow \mathbf{A}^{-}+h \nu$
- the electron capture and the excitation of a molecular ion,

$\mathrm{AB}+\mathrm{e}^{-} \rightarrow \mathrm{AB}^{-*}$

- the dissociative capture of a free electron,

$\mathrm{AB}+\mathrm{e}^{-} \rightarrow \mathrm{A}+\mathrm{B}^{-}\left(\right.$or $\left.\mathbf{A}^{-}+\mathrm{B}\right)$

- bipolar ionization,

$\mathrm{AB}+\mathrm{e}^{-} \rightarrow \mathbf{A}^{-}+\mathbf{B}^{+}+\mathrm{e}^{-}$.

The negative ion formation is a resonance process. It occurs as a result of the emergence of a quasistationary state, whose lifetime is longer than the time interval, within which the incident electron passes a distance of an order of atomic or molecular sizes. There are resonances of two types:

(i) resonances located below the parent state of the atom or molecule (Feschbach resonances) [55],

(ii) resonances located above the parent state of the atom or molecule (shape resonances) [56].

As concerning Feschbach resonances, their decay into the parent state is energetically forbidden, and the decay into other states is associated with a change in the atomic or molecular configuration. Feschbach resonances have a relatively long lifetime, about $10^{-10} \mathrm{~s}$, owing to the rather strong interaction between the incident electron and the excited state of the atom or molecule.

Shape resonances lie above the parent state of the atom or molecule. Therefore, in order to capture an 

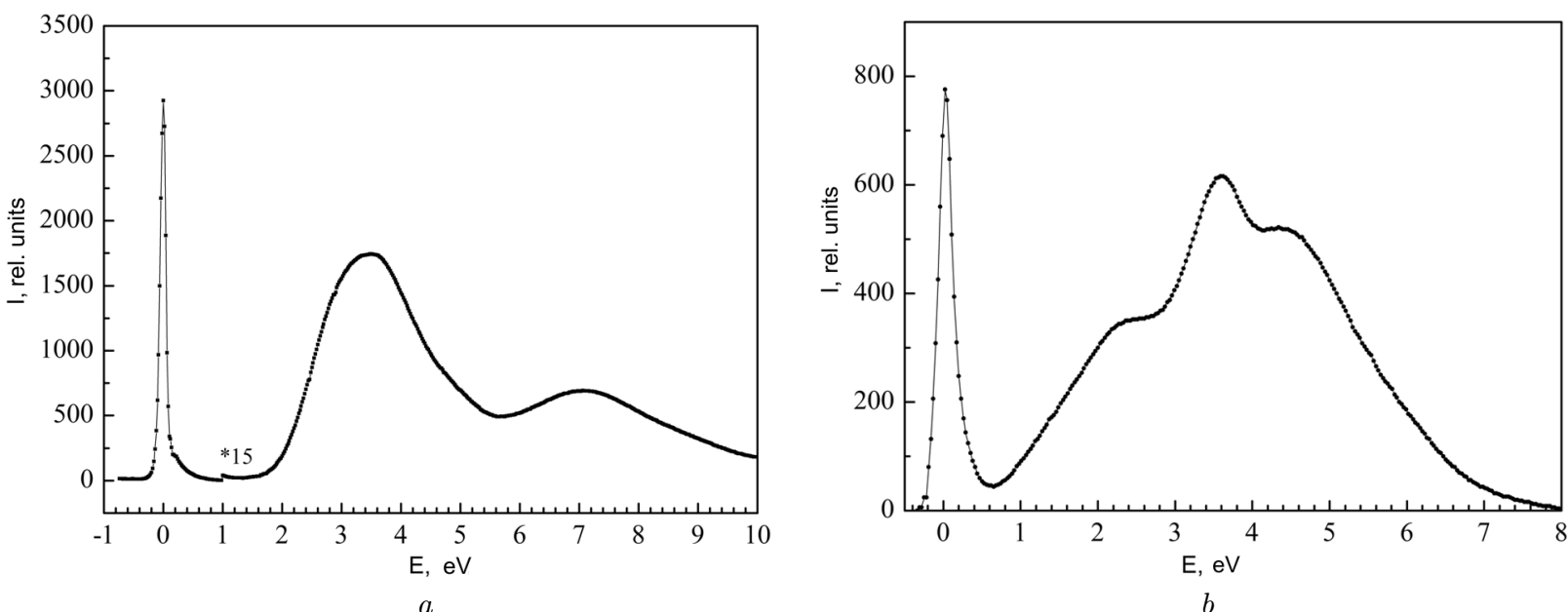

Fig. 10. Energy dependences of the formation intensity for negative sulfur $(a)$ and selenium $(b)$ ions

electron, the potential of the atom or molecule must have a specific profile. In this case, a bombarding electron is captured by the potential well confined by a barrier that is formed by the repulsive centrifugal potential. Shape resonances are characterized by a short lifetime, $10^{-15} \mathrm{~s}$, because of the weak interaction between the electron and the atom or molecule.

It should be noted that the number of works dealing with the formation of negative ions of sulfur and selenium atoms and molecules through the electron capture is small. In particular, in work [57], it was experimentally shown that, when electrons with an energy within the interval $0-11 \mathrm{eV}$ interact with a sulfur vapor at a temperature of $388 \mathrm{~K}$, the $\mathrm{S}_{2}^{-}, \mathrm{S}_{3}^{-}$, $\mathrm{S}_{4}^{-}$, and $\mathrm{S}_{5}^{-}$ions are most probably created. In the case of selenium, no work was found dealing with the formation of negative ions in its vapor by the electron impact. However, there are mass spectra obtained for negative ions of selenium molecules created by means of photons and the laser ablation [58, 59].

In this work, we studied the processes of negative ion formation on an installation with a hypocycloidal electron spectrometer (Fig. 2). The latter could generate an electron beam with a high energy homogeneity, which is an important requirement for precision studies of the processes of negative ion formation. A significant advantage of a spectrometer of this type consisted in that it enables the research of both positive and negative ions in the course of the same experiment, i.e., under the same experimental condi- tions. Namely, a negative potential was supplied to the ion detector, when positive ions were detected, and a positive one for negative ions (see Fig. 2). In order to prevent scattered electrons and the potential from penetrating into the region of the electron interaction with atoms (molecules), a grid with a low positive potential was mounted in front of the ion detector.

\subsubsection{Sulfur}

In Fig. 10, $a$, the energy dependence of the total crosssection of the negative ion formation in a sulfur vapor in the electron energy interval from 0 to $10 \mathrm{eV}$ and at a sulfur evaporation temperature of $400 \mathrm{~K}$ is depicted. The electron energy increment was $0.05 \mathrm{eV}$, the electron beam current $200 \mathrm{nA}$, and the energy homogeneity of electrons $0.15-0.2 \mathrm{eV}$. As one can see from Fig. 10, $a$, three maxima are observed at energies of about $0.1,3.5$, and $7.1 \mathrm{eV}$. The first sharp maximum (resonance) at almost zero energies has an intensity two orders of magnitude higher than the other maxima, and its energy width equals about $0.15 \mathrm{eV}$, thus practically coinciding with the energy homogeneity of electrons. The shape and the width of the first maximum evidence the resonant capture of slow electrons by sulfur atoms and molecules $\mathrm{S}_{n}(n=1 \div 8)$, among which the molecule $\mathrm{S}_{2}$ possessing the highest concentration in a sulfur vapor at the given temperature. This result is confirmed by the results of work [57], where the for- 
mation of the negative ion of a sulfur atom in the process of dissociative electron capture by the $\mathrm{S}_{2}$ molecule was studied, and it was shown that the negative ions of sulfur atoms are effectively formed through the dissociation of $\mathrm{S}_{2}$ molecules at energies of 2.4 and $4.55 \mathrm{eV}$ as a result of the electron capture.

In order to reveal the origin of resonances in the energy dependences of the negative sulfur ion formation, the angular distribution of negative $\mathrm{S}^{-}$ions was analyzed. It was found that the ions emerging at an energy of $2.4 \mathrm{eV}$ were formed as a result of the shape resonance of the ${ }^{4} \Sigma_{2}^{0}$ state of the $\mathrm{S}_{2}^{-}$molecule, and the ions emerging at an energy of $4.55 \mathrm{eV}$ appeared owing to the Feschbach resonance of the ${ }^{2} \Pi_{u}$ state.

It should be noted that the shapes and the energy positions of peculiarities in the energy dependences of the intensities of the $\mathrm{S}^{-}$and $\mathrm{S}_{3}^{-}$ion formations that were reported in work [57] coincide with our results (see Fig. 10,a). On the other hand, it turned out that molecular ions give the largest contribution to the total cross-section. In particular, their relative contributions are $13.2 \%$ for $\mathrm{S}_{2}^{-}, 49.8 \%$, for $\mathrm{S}_{3}^{-}, 24.3 \%$ for $\mathrm{S}_{4}^{-}$, and $7.8 \%$ for $\mathrm{S}_{5}^{-}$, whereas the total contribution of all other ions is about $5 \%$.

\subsubsection{Selenium}

In Fig. 10, b, the energy dependence of the intensity of the negative ion formation in a selenium vapor in the electron energy interval from 0 to $8 \mathrm{eV}$ and at a selenium evaporation temperature of $430 \mathrm{~K}$ is exhibited. The electron energy increment was $0.05 \mathrm{eV}$, the electron beam current $200 \mathrm{nA}$, and the energy homogeneity of electrons $0.15-0.2 \mathrm{eV}$. As one can see, unlike the case of sulfur, the obtained curve has four maxima at energies of $0,2.1,3.5$, and $4.3 \mathrm{eV}$. The first maximum, as was in the case of sulfur, can be associated with the ion formation through the resonant capture of low-energy electrons. Unlike the case of sulfur, the other maxima have the same order of magnitude as the first maximum has, which testifies to a high probability of the negative ion formation at relatively high energies.

In the case of selenium, there are no works dealing with the electron-impact formation of negative selenium ions in a selenium vapor. However, in works $[40,59]$, the mass spectra of negative ions of a sele- nium vapor were studied making use of the laser ablation method. The measured mass spectra contained peculiarities associated with the negative ions of selenium atoms and $\mathrm{Se}_{n}^{-}(n=2 \div 8)$ molecules.

Thus, we may assume that, as was in the case of sulfur, the ions $\mathrm{Se}_{n}^{-}(n=2 \div 8)$ of selenium molecules are mainly formed at energies of $0,3.5$, and $4.3 \mathrm{eV}$. At an energy of $2.1 \mathrm{eV}$, negative ions of the selenium atom are most likely formed as a result of the dissociative electron capture by $\mathrm{Se}_{2}$ molecules.

\subsection{Excitation processes and optical excitation functions}

The processes of atomic and molecular excitations are known to occur most effectively at low energies of bombarding electrons. In the course of the interaction, both the molecular states and the neutral atoms of the researched substance can be excited as a result of the direct or dissociative excitation giving rise to the formation of excited ions. We showed that the vapors of various chalcogens contain both the atoms of corresponding elements and their diatomic and polyatomic molecules in rather high concentrations in a wide temperature interval. Therefore, it was of interest to study the radiation spectra of chalcogen vapors and to trace the formation dynamics of their constituents.

\subsubsection{Radiation spectra}

The most effective way to study the radiation emission processes is to use the spectroscopic method. Owing to its high energy resolution, this method makes it possible to detect both the excited states of molecules and the excited states of atoms and ions emerging as a result of the dissociation of diatomic and polyatomic molecules [60].

We studied the radiation emission spectra of the sulfur, selenium, and tellurium vapors in the spectral interval $200-600 \mathrm{~nm}$, with electrons possessing fixed energies of $8,20,30$, and $50 \mathrm{eV}$ being used for the excitation. The experimental conditions were almost identical to those, under which the mass spectra were measured. The substance evaporation temperature was maintained constant (to an accuracy of $\pm 3 \mathrm{~K}$ ) in the vicinities of 330,450 , and $570 \mathrm{~K}$ for sulfur, selenium, and tellurium, respectively. The exciting electron current was $15-30 \mu \mathrm{A}$, the corresponding energy homogeneity of electrons was not worse than

ISSN 2071-0194. Ukr. J. Phys. 2020. Vol. 65, No. 7 
$\Delta E_{1 / 2}=0.3 \mathrm{eV}$, and the spectrometer resolution was $\Delta \lambda= \pm 2 \mathrm{~nm}$.

The experimental optical spectra of the electronimpact radiation emitted by sulfur, selenium, and tellurium vapors are shown in Fig. 11. As one can see, they are quite complicated. Broad bands are mainly observed at low electron energies. As the energy of exciting electrons increases, the spectra become more complicated, because there appear additional discrete lines in them. Let us consider those spectra in more details. For example, if the electron energy equals $8 \mathrm{eV}$, there is no lines in the sulfur spectrum that are inherent to the excitation of the energy levels of a sulfur atom. Therefore, we may assert that this spectrum describes the excitation of sulfur molecules.

As was shown in the previous section, the sulfur mass spectrum at the given temperature mainly consists of $\mathrm{S}_{2}$ molecules. Therefore, we may assume with a high probability that the radiation spectrum is a result of the excitation of diatomic sulfur molecules. Furthermore, the excitation probability of $\mathrm{S}_{2}$ molecules is much higher than the excitation probability of other vapor components $\left(\mathrm{S}_{3}\right.$ to $\left.\mathrm{S}_{8}\right)$. It should also be noted that the measured spectrum has the structure and the shape that are very similar to those of the $\mathrm{S}_{2}$ spectrum obtained in work [64]. The cited authors identified the detected molecular bands as the excitation of the electron-vibrational levels of $\mathrm{S}_{2}$ molecules in the $\mathrm{B}^{3} \Sigma_{n}^{-}$state followed by a transition to the vibrational levels of the $\mathrm{X}^{3} \Sigma_{\Sigma}$ state. The wavelengths of the lines detected by us coincide with the data of work [52]. There0fore, we may conclude that the sulfur vapor spectrum at $E=8 \mathrm{eV}$ is mainly associated with the excitation of the $\mathrm{B}^{3} \Sigma_{n}^{-}$state of the $\mathrm{S}_{2}$ molecule.

It is evident that the spectra of sulfur radiation at energies of 20 and $50 \mathrm{eV}$ (Fig. 11, a) become substantially complicated: there appear more pronounced lines, and the vibrational structure increases. An analysis of those lines showed that most of them can be unambiguously associated with the excitation of the $\mathrm{S}^{+*}$ sulfur ion lines. Therefore, we may assert that the following elementary processes take place at the interaction of electrons with a sulfur vapor:

- appearance of excited $\mathrm{S}_{2}^{*}$ molecules with the subsequent radiative transition into the ground state,

$\mathrm{S}_{2}+\mathrm{e}^{-} \rightarrow \mathrm{S}_{2}^{*}+\mathrm{e}^{-} \rightarrow \mathrm{S}_{2}+\mathrm{e}^{-}+h \nu$

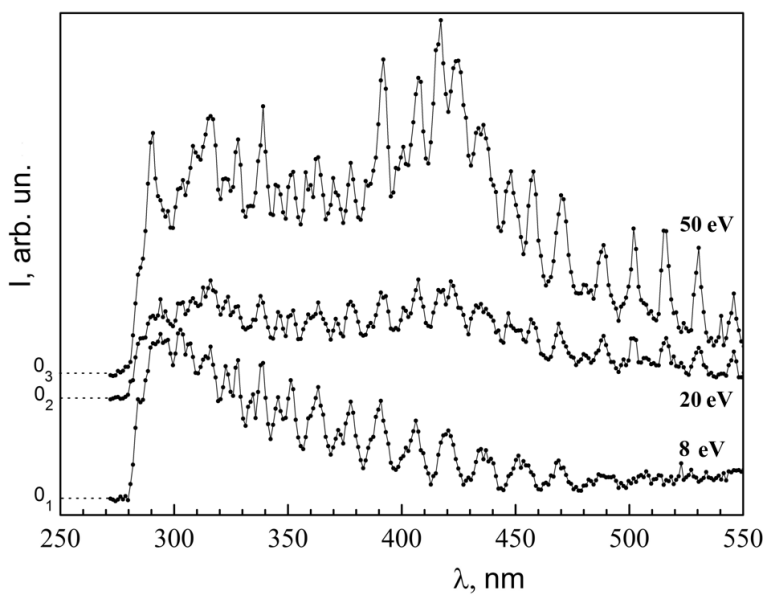

$a$

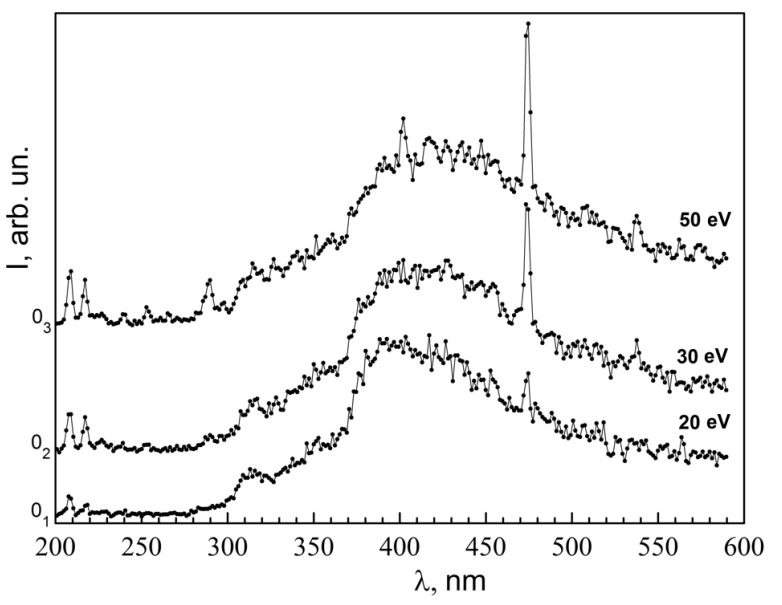

$b$

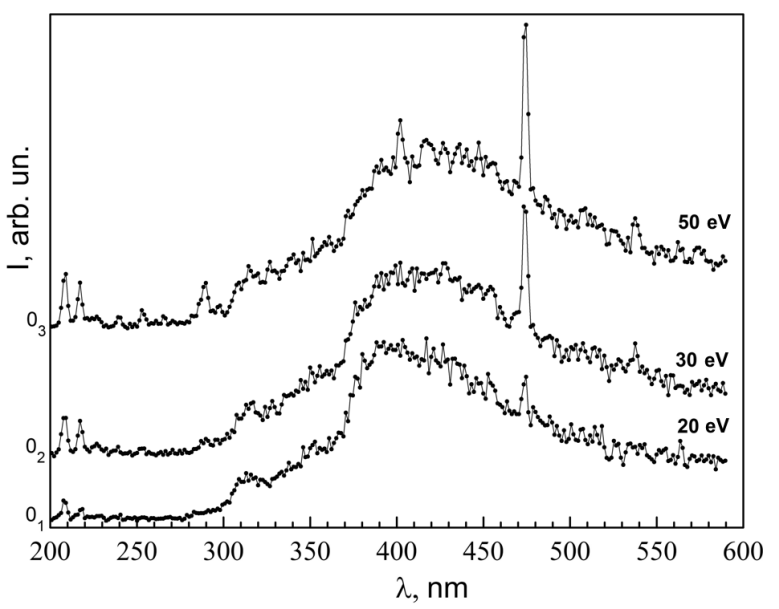

$c$

Fig. 11. Radiation spectra of sulfur $(a)$, selenium $(b)$, and tellurium $(c)$ at various electron energies 
- appearance of excited $\mathrm{S}_{2}^{*}$ molecular ions owing to the decay of polyatomic components,

$\mathrm{S}_{n}+\mathrm{e}^{-} \rightarrow \mathrm{S}_{n-2}+\mathrm{S}_{2}^{*}+\mathrm{e}^{-}$

- dissociative excitation of sulfur atoms,

$\mathrm{S}_{2}+\mathrm{e}^{-} \rightarrow \mathrm{S}^{*}+\mathrm{S}+\mathrm{e}^{-}$

or

$\mathrm{S}_{n}+\mathrm{e}^{-} \rightarrow \mathrm{S}^{*}+\mathrm{S}_{n-1}+\mathrm{e}^{-}$

- dissociative excitation of sulfur ions,

$\mathrm{S}_{2}+\mathrm{e}^{-} \rightarrow \mathrm{S}^{+*}+\mathrm{S}+2 \mathrm{e}^{-}$

Table 7. Spectroscopic identification

of sulfur ion lines observed in the emission spectrum of a sulfur vapor at an electron energy of $50 \mathrm{eV}$

\begin{tabular}{|c|c|c|c|}
\hline $\begin{array}{c}\text { Our } \\
\text { data } \\
\lambda, \mathrm{nm}\end{array}$ & $\begin{array}{c}\text { Ref. } \\
{[48]} \\
\lambda, \mathrm{nm}\end{array}$ & $\begin{array}{c}\text { Highest } \\
\text { level } \\
\text { energy, } \\
\text { eV [28] }\end{array}$ & Transitions \\
\hline 290.4 & 288.6 & 19.36 & $3 \mathrm{~s}^{2} 3 \mathrm{p}^{2}\left({ }^{1} \mathrm{D}\right) 4 \mathrm{~s}-3 \mathrm{~s}^{2} 3 \mathrm{p}^{2}\left({ }^{1} \mathrm{~S}\right) 4 \mathrm{p}$ \\
\hline 315.6 & 314.7 & 21.3 & $3 \mathrm{~s}^{2} 3 \mathrm{p}^{2}\left({ }^{1} \mathrm{D}\right) 3 \mathrm{~d}-3 \mathrm{~s}^{2} 3 \mathrm{p}^{2}\left({ }^{1} \mathrm{D}_{2}\right) 4 \mathrm{f}$ \\
\hline 322.4 & 321.4 & 20.05 & $3 \mathrm{~s}^{2} 3 \mathrm{p}^{2}\left({ }^{3} \mathrm{P}\right) 4 \mathrm{p}-3 \mathrm{~s}^{2} 3 \mathrm{p}^{2}\left({ }^{1} \mathrm{D}\right) 5 \mathrm{~s}$ \\
\hline 327.4 & 328.6 & 19.99 & $3 \mathrm{~s}^{2} 3 \mathrm{p}^{2}\left({ }^{3} \mathrm{P}\right) 3 \mathrm{~d}-3 \mathrm{~s}^{2} 3 \mathrm{p}^{2}\left({ }^{3} \mathrm{P}_{2}\right) 4 \mathrm{f}$ \\
\hline 339.2 & 339.7 & 19.87 & $3 \mathrm{~s}^{2} 3 \mathrm{p}^{2}\left({ }^{3} \mathrm{P}\right) 3 \mathrm{~d}-3 \mathrm{~s}^{2} 3 \mathrm{p}^{2}\left({ }^{3} \mathrm{P}_{1}\right) 4 \mathrm{f}$ \\
\hline 345.8 & 346.6 & 19.78 & $3 \mathrm{~s}^{2} 3 \mathrm{p}^{2}\left({ }^{3} \mathrm{P}\right) 4 \mathrm{p}-3 \mathrm{~s}^{2} 3 \mathrm{p}^{2}\left({ }^{3} \mathrm{P}\right) 4 \mathrm{~d}$ \\
\hline 351.7 & 352.7 & 21.37 & $3 \mathrm{~s}^{2} 3 \mathrm{p}^{2}\left({ }^{1} \mathrm{D}\right) 3 \mathrm{~d}-3 \mathrm{~s}^{2} 3 \mathrm{p}^{2}\left({ }^{1} \mathrm{D}_{2}\right) 4 \mathrm{f}$ \\
\hline 359.3 & 358.4 & 19.99 & $3 s^{2} 3 p^{2}\left({ }^{3} \mathrm{P}\right) 3 \mathrm{~d}-3 \mathrm{~s}^{2} 3 \mathrm{p}^{2}\left({ }^{3} \mathrm{P}_{2}\right) 4 \mathrm{f}$ \\
\hline 362.7 & 362.6 & 20 & $3 \mathrm{~s}^{2} 3 \mathrm{p}^{2}\left({ }^{3} \mathrm{P}\right) 3 \mathrm{~d}-3 \mathrm{~s}^{2} 3 \mathrm{p}^{2}\left({ }^{3} \mathrm{P}_{2}\right) 4 \mathrm{f}$ \\
\hline 370 & 370.8 & 19.54 & $3 \mathrm{~s}^{2} 3 \mathrm{p}^{2}\left({ }^{3} \mathrm{P}\right) 3 \mathrm{~d}-3 \mathrm{~s}^{2} 3 \mathrm{p}^{2}\left({ }^{3} \mathrm{P}\right) 5 \mathrm{p}$ \\
\hline 377.8 & 378.1 & 19.87 & $3 \mathrm{~s}^{2} 3 \mathrm{p}^{2}\left({ }^{3} \mathrm{P}\right) 3 \mathrm{~d}-3 \mathrm{~s}^{2} 3 \mathrm{p}^{2}\left({ }^{3} \mathrm{P}_{1}\right) 4 \mathrm{f}$ \\
\hline 392 & 393.4 & 19.42 & $3 \mathrm{~s}^{2} 3 \mathrm{p}^{2}\left({ }^{3} \mathrm{P}\right) 4 \mathrm{p}-3 \mathrm{~s}^{2} 3 \mathrm{p}^{2}\left({ }^{3} \mathrm{P}\right) 4 \mathrm{~d}$ \\
\hline 400.5 & 400.5 & 18.99 & $3 \mathrm{~s}^{2} 3 \mathrm{p}^{2}\left({ }^{3} \mathrm{P}\right) 4 \mathrm{p}-3 \mathrm{~s}^{2} 3 \mathrm{p}^{2}\left({ }^{3} \mathrm{P}\right) 4 \mathrm{~d}$ \\
\hline 407.2 & 406.6 & 16.2 & $3 \mathrm{~s}^{2} 3 \mathrm{p}^{2}\left({ }^{3} \mathrm{P}\right) 3 \mathrm{~d}-3 \mathrm{~s}^{2} 3 \mathrm{p}^{2}\left({ }^{3} \mathrm{P}\right) 4 \mathrm{p}$ \\
\hline 416.4 & 415.3 & 18.88 & $3 \mathrm{~s}^{2} 3 \mathrm{p}^{2}\left({ }^{3} \mathrm{P}\right) 4 \mathrm{p}-3 \mathrm{~s}^{2} 3 \mathrm{p}^{2}\left({ }^{3} \mathrm{P}\right) 4 \mathrm{~d}$ \\
\hline 424.8 & 425.1 & 20.36 & $3 \mathrm{~s}^{2} 3 \mathrm{p}^{2}\left({ }^{1} \mathrm{D}\right) 4 \mathrm{p}-3 \mathrm{~s}^{2} 3 \mathrm{p}^{2}\left({ }^{1} \mathrm{D}\right) 4 \mathrm{~d}$ \\
\hline 434.9 & 434.4 & 18.72 & $3 \mathrm{~s}^{2} 3 \mathrm{p}^{2}\left({ }^{3} \mathrm{P}\right) 4 \mathrm{p}-3 \mathrm{~s}^{2} 3 \mathrm{p}^{2}\left({ }^{3} \mathrm{P}\right) 5 \mathrm{~s}$ \\
\hline 448.3 & 446.5 & 18.72 & $3 \mathrm{~s}^{2} 3 \mathrm{p}^{2}\left({ }^{1} \mathrm{D}\right) 3 \mathrm{~d}-3 \mathrm{~s}^{2} 3 \mathrm{p}^{2}\left({ }^{3} \mathrm{P}_{2}\right) 4 \mathrm{f}$ \\
\hline 457.6 & 456.3 & 19.89 & $3 \mathrm{~s}^{2} 3 \mathrm{p}^{2}\left({ }^{1} \mathrm{D}\right) 3 \mathrm{~d}-3 \mathrm{~s}^{2} 3 \mathrm{p}^{2}\left({ }^{3} \mathrm{P}_{1}\right) 4 \mathrm{f}$ \\
\hline 470.2 & 470.2 & 18.83 & $3 \mathrm{~s}^{2} 3 \mathrm{p}^{2}\left({ }^{3} \mathrm{P}\right) 4 \mathrm{p}-3 \mathrm{~s}^{2} 3 \mathrm{p}^{2}\left({ }^{3} \mathrm{P}\right) 5 \mathrm{~s}$ \\
\hline 481 & 480.5 & 16.2 & $3 \mathrm{~s}^{2} 3 \mathrm{p}^{2}\left({ }^{3} \mathrm{P}\right) 4 \mathrm{~s}-3 \mathrm{~s}^{2} 3 \mathrm{p}^{2}\left({ }^{3} \mathrm{P}\right) 4 \mathrm{p}$ \\
\hline 488.6 & 488.5 & 16.54 & $3 \mathrm{~s}^{2} 3 \mathrm{p}^{2}\left({ }^{3} \mathrm{P}\right) 4 \mathrm{p}-3 \mathrm{~s}^{2} 3 \mathrm{p}^{2}\left({ }^{3} \mathrm{P}\right) 5 \mathrm{~s}$ \\
\hline 502.1 & 502.8 & 15.56 & $3 \mathrm{~s}^{2} 3 \mathrm{p}^{2}\left({ }^{3} \mathrm{P}\right) 3 \mathrm{~d}-3 \mathrm{~s}^{2} 3 \mathrm{p}^{2}\left({ }^{3} \mathrm{P}\right) 4 \mathrm{p}$ \\
\hline 515.5 & 514.4 & 15.56 & $3 \mathrm{~s}^{2} 3 \mathrm{p}^{2}\left({ }^{3} \mathrm{P}\right) 3 \mathrm{~d}-3 \mathrm{~s}^{2} 3 \mathrm{p}^{2}\left({ }^{3} \mathrm{P}\right) 4 \mathrm{p}$ \\
\hline 540.7 & 540.2 & 18.83 & $3 \mathrm{~s}^{2} 3 \mathrm{p}^{2}\left({ }^{3} \mathrm{P}\right) 4 \mathrm{p}-3 \mathrm{~s}^{2} 3 \mathrm{p}^{2}\left({ }^{3} \mathrm{P}\right) 5 \mathrm{~s}$ \\
\hline 545.7 & 545.5 & 15.94 & $3 \mathrm{~s}^{2} 3 \mathrm{p}^{2}\left({ }^{3} \mathrm{P}\right) 4 \mathrm{~s}-3 \mathrm{~s}^{2} 3 \mathrm{p}^{2}\left({ }^{3} \mathrm{P}\right) 4 \mathrm{p}$ \\
\hline
\end{tabular}

or

$\mathrm{S}_{n}+\mathrm{e}^{-} \rightarrow \mathrm{S}^{+*}+\mathrm{S}_{n-1}+\mathrm{e}^{-}$.

From the obtained optical spectra (Fig. 11) and on the basis of the proposed elementary processes (22)(25), we identified 26 sulfur ion lines (see Table 7 ). It is worth noting that the lines of a sulfur atom are practically absent from those spectra. Probably, this circumstance may be associated with the fact that the most intense lines of a sulfur atom are located in the VUV spectral interval, i.e., below $\lambda=200 \mathrm{~nm}$.

Unlike sulfur, the selenium spectra demonstrate a continuous band in the interval 300-550 nm (Fig. 11, b). This band can be separated into two subbands with their peaks at $310-320$ and 400 $420 \mathrm{~nm}$. As was shown above, under our research conditions $(T=440 \pm 5 \mathrm{~K}), \mathrm{Se}_{2}$ molecules are the main component of a selenium vapor. Therefore, we may assume that the continuous molecular bands are mainly appear as a result of the excitation of electronvibrational states of the $\mathrm{Se}_{2}$ molecule. Most probably, these are the electron-vibrational levels of the $\mathrm{B}^{3} \Sigma_{4}^{-}$ state, which, similarly to the sulfur case, are the most effectively excited ones among all levels of the lowenergy states.

The dissimilarity of the selenium and sulfur spectra (the vibrational states are clearly distinguished in the latter case) is a result of the superposition of the excitation bands belonging to various states of a $\mathrm{Se}_{2}$ molecule, as well as the excitation of $\mathrm{Se}_{n}$ molecules with the number of selenium atoms $n>2$ and a much shorter distance between the vibrational levels. The insufficient resolution of our spectral instrument can also be a cause for the spectral difference. The selenium spectrum also contains atomic and ionic lines, among which we identified 4 lines of a Se atom and several ionic lines (see Table 8).

As for the tellurium spectrum, Fig. 11, $c$ demonstrates that it is similar to the $\mathrm{S}$ and Se spectra. However, in the tellurium case, atomic tellurium lines can be clearly distinguished at $E=15 \mathrm{eV}$, and the lines of $\mathrm{Te}^{+*}$ ion appear at $E=50 \mathrm{eV}$ (also see Table 9).

Hence, we may conclude that, when electrons pass through the sulfur, selenium, and tellurium vapors, the process of molecular excitation takes place, as well as the dissociative excitation and ionization of molecules and atoms. It should be noted that the probability of the creation of excited atomic states 
Table 8. Spectroscopic identification of selenium ion lines observed

in the emission spectrum of a selenium vapor at an electron energy of $50 \mathrm{eV}$

\begin{tabular}{|c|c|c|c|}
\hline $\begin{array}{l}\text { Our data } \\
\lambda, \mathrm{nm}\end{array}$ & $\begin{array}{l}\text { Ref. [52] } \\
\lambda, \mathrm{nm}\end{array}$ & $\begin{array}{l}\text { Highest level } \\
\text { energy, eV [54] }\end{array}$ & Transitions \\
\hline 288.9 & 288.8 & 15 & $?$ \\
\hline 297.9 & 296.3 & 14.8 & ${ }^{4} \mathrm{P}_{11 / 2}-{ }^{4} \mathrm{~S}_{11 / 2}$ \\
\hline 314.4 & 314.1 & 14.6 & $4 \mathrm{~s} 4 \mathrm{p}^{4{ }^{4}} \mathrm{P}_{11 / 2}-4 \mathrm{~s}^{2} 4 \mathrm{p}^{2}\left({ }^{3} \mathrm{P}\right) 5 \mathrm{p}^{2} \mathrm{~S}_{1 / 2}$ \\
\hline 360.6 & 361.1 & 15.9 & $?$ \\
\hline 402 & 401.9 & 17.5 & $4 s^{2} 4 p^{2}\left({ }^{3} P\right) 5 p^{4} D_{21 / 2}-6 s^{2} P_{11 / 2}$ \\
\hline 416.5 & 416.6 & 14.2 & $?$ \\
\hline 455.7 & 455.3 & 17.8 & $?$ \\
\hline 562 & 562.3 & 14 & $4 s^{2} 4 p^{2}\left({ }^{3} \mathrm{P}\right) 5 \mathrm{~s}^{4} \mathrm{P}_{1 / 2}-4 \mathrm{~s}^{2} 4 \mathrm{p}^{2}\left({ }^{3} \mathrm{P}\right) 5 \mathrm{p}{ }^{4} \mathrm{P}_{1 / 2}$ \\
\hline 574 & 574.7 & 14.4 & $4 \mathrm{~s}^{2} 4 \mathrm{p}^{2}\left({ }^{3} \mathrm{P}\right) 5 \mathrm{~s}^{4} \mathrm{P}_{21 / 2}-{ }^{4} \mathrm{D}_{21 / 2}$ \\
\hline
\end{tabular}

is much lower than the probability of the creation of ionized atomic states. It is at electron energies of 30 $50 \mathrm{eV}$ that the largest number of sulfur, selenium, and tellurium ionic lines were revealed in the spectra (see Table 9).

\subsubsection{Optical excitation functions (OEFs)}

Now, let us consider the energy dependences describing the excitation of molecular bands and spectral lines. As one can see from Fig. 12, the OEFs for molecular emissions of sulfur, selenium, and tellurium have a clear excitation threshold at energies of 2.5$4 \mathrm{eV}$, a rapid increase of excitation cross-sections to energies of $5-6 \mathrm{eV}$, where peculiarities in the form of breakpoints or weakly pronounced maxima are observed, a further increase up to $7-10 \mathrm{eV}$, then a small recession followed by an insignificant growth, and finally a broad maximum at $15-20 \mathrm{eV}$. Note that, within the limits of the broad radiation band, the excitation thresholds of individual lines become shifted toward higher energies at the transition into the short-wave spectral interval (see Fig. 12,a). This fact testifies to the transitions from a higher vibrational level of the corresponding molecule. On the other hand, narrow peculiarities (breakpoints, peaks) in the OEF in the vicinity of the threshold (Figs. 12, a and $b$ ) mean that the excitation of the parent molecular levels occurs through the resonance formation and the decay of short-term states of negative molecular ions.

Let us consider the OEFs for the atomic lines of researched elements. Figure 13 shows the OEFs for the atomic spectral lines of sulfur, selenium, and tel-
Table 9. Spectroscopic identification of tellurium ion lines observed in the emission spectrum of a tellurium vapor at an electron energy of $50 \mathrm{eV}$

\begin{tabular}{|c|c|c|}
\hline$\lambda, \mathrm{nm}$ & $\begin{array}{c}\text { Highest level } \\
\text { energy, eV }\end{array}$ & Transitions \\
\hline 214.2 & 5.72 & $5 \mathrm{~s}^{2} 5 \mathrm{p}^{43} \mathrm{p}_{2}-5 \mathrm{~s}^{2} 5 \mathrm{p}^{3} 6 \mathrm{~s}^{3} \mathrm{~S}_{1}^{0}$ \\
225.9 & 5.49 & $5 \mathrm{~s}^{2} 5 \mathrm{p}^{43} \mathrm{p}_{2}-5 \mathrm{~s}^{2} 5 \mathrm{p}^{3} 6 \mathrm{~s}^{5} \mathrm{~S}_{1}$ \\
238.6 & 5.78 & $5 \mathrm{~s}^{2} 5 \mathrm{p}^{43} \mathrm{p}_{1}-5 \mathrm{~s}^{2} 5 \mathrm{p}^{3} \mathrm{~S}_{1}^{0}$ \\
253.0 & 5.49 & $5 \mathrm{~s}^{2} 5 \mathrm{p}^{43} \mathrm{p}_{1}-5 \mathrm{~s}^{2} 5 \mathrm{p}^{3} 6 \mathrm{~s}^{5} \mathrm{~S}_{2}$ \\
289.5 & 15.22 & - \\
305.3 & 12.08 & - \\
335.2 & 15.20 & - \\
\hline
\end{tabular}

lurium. The excitation energy thresholds for them are $8.2 \mathrm{eV}$ for Te, $9.2 \mathrm{eV}$ for Se, and $13.5 \mathrm{eV}$ for $\mathrm{S}$. As one can see, all exhibited OEFs have a similar character: a pronounced excitation threshold and a substantial growth of the excitation cross-section near the thresholds with maxima at about $13-15 \mathrm{eV}$ for selenium and tellurium.

Note that the excitation threshold values that were determined for the atomic lines are shifted with respect to the spectroscopic excitation energies of molecular lines: by $4.4 \mathrm{eV}$ for sulfur, $4.2 \mathrm{eV}$ for selenium, and $2.7 \mathrm{eV}$ for tellurium. This shift serves as a confirmation of the fact that electrons excite those atoms not through direct collisions with the examined elements, but with the corresponding molecules $-\mathrm{S}_{2}$, $\mathrm{Se}_{2}$, and $\mathrm{Te}_{2}$. The shift of the excitation thresholds of those lines is exactly equal to the energy of molecular 


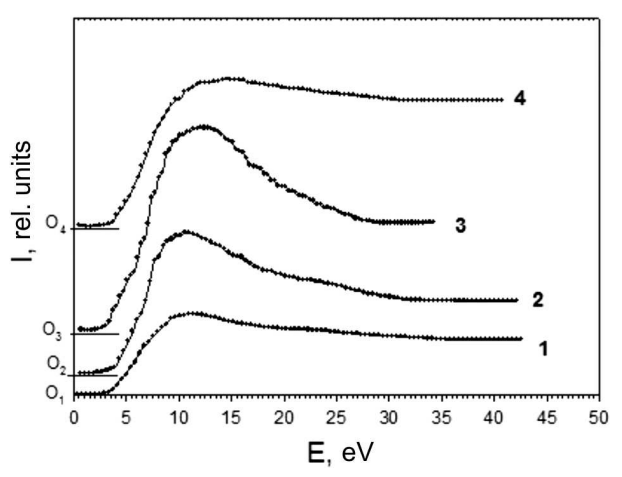

$a$

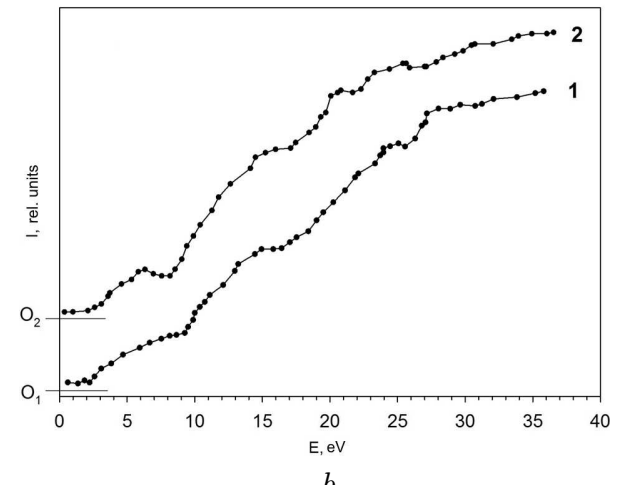

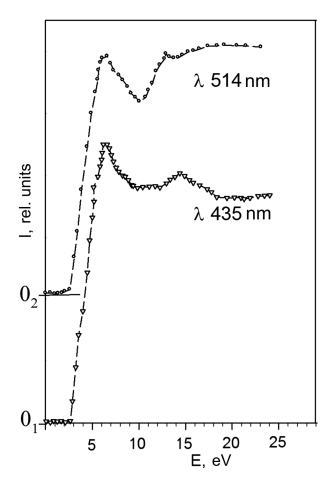

$c$

Fig. 12. Optical emission excitation functions of sulfur (a): $282.9 \mathrm{~nm}(1), 290 \mathrm{~nm}(2), 293 \mathrm{~nm}(3), 336.9 \mathrm{~nm}(4)$; selenium (b): $473.1 / 473.9 / 474.2 \mathrm{~nm}(1), 536.5 / 537.0 / 536.4 \mathrm{~nm}(2)$, and tellurium molecules (c): $435 \mathrm{~nm}, 514 \mathrm{~nm}$

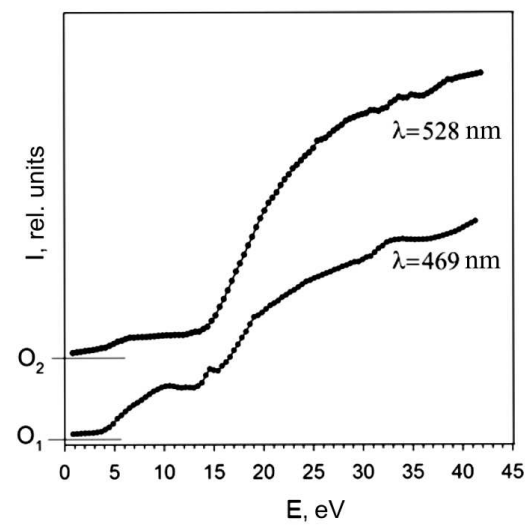

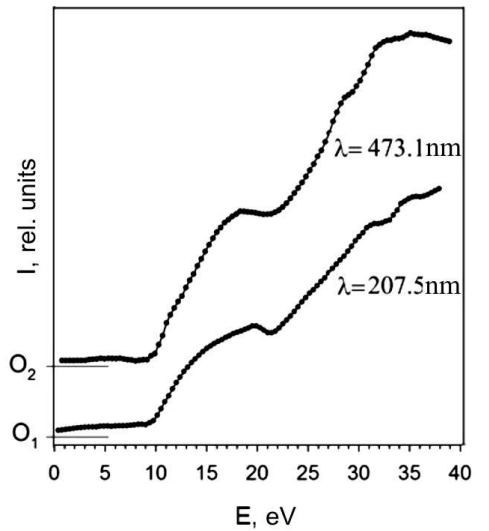

$b$

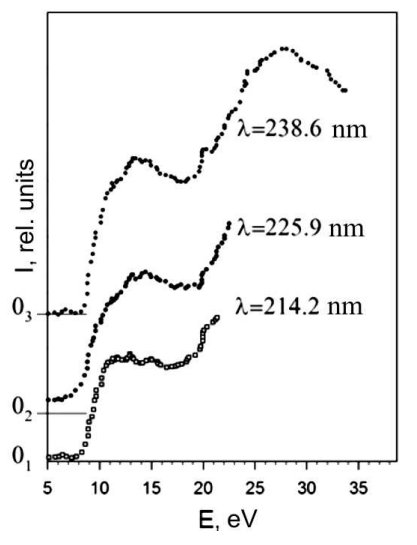

$c$

Fig. 13. Optical excitation functions of sulfur $(a)$, selenium $(b)$, and tellurium $(c)$ atomic spectral lines

dissociation, i.e., the excitation occurs according to the following scheme:

$\mathrm{A}_{2}+\mathrm{e}^{-} \rightarrow \mathrm{A}^{*}+A+\mathrm{e}^{-}$.

Note that the excitation thresholds measured for other atomic lines of chalcogens are also shifted by the magnitude of dissociation energy for the corresponding molecules.

The data presented above bring us to a contradiction. On the one hand, the mass spectra reveal the existence of atomic ions and their appearance thresholds coincide with available spectroscopic data [53]. On the other hand, the spectral lines of the excited $M^{+*}$ ions are not observed in the optical spectra. This situation obviously takes place owing to the fact that the mass spectroscopy method is much more sensitive than the optical method. Furthermore, the binding energy of atoms in the $\mathrm{S}_{n}, \mathrm{Se}_{n}$, and $\mathrm{Te}_{n}$ molecules with $n \geq 2$ is very low, and it is very difficult to register a change in the reaction threshold value, i.e., the ionization reaction may run according to the scheme

$A_{n}+\mathrm{e}^{-} \rightarrow A^{+}+A_{n-1}+2 \mathrm{e}^{-}$

or

$\mathrm{A}+\mathrm{e}^{-} \rightarrow \mathrm{A}^{+}+2 \mathrm{e}^{-}$

Thus, our statement given above about the presence of a considerable number of diatomic molecules in the gaseous phase of sulfur, selenium, and tellurium, finds its confirmation. The excitation of the atoms of those elements takes place following schemes (27), and the presence of peculiarities in the form of peaks and breakpoints in the OEFs for the spectral 
lines of sulfur, selenium, and tellurium atoms testify to the existence of additional excitation mechanisms. As such, there can be resonance phenomena, cascade transitions from higher levels, and the formation and decay of highly excited molecular ionic states. The low thresholds for molecular emission excitation of selenium $(3.2 \mathrm{eV}$ at $\lambda=383 \mathrm{~nm})$ and tellurium $(2.9 \mathrm{eV}$ at $\lambda=430 \mathrm{~nm})$ testify to the excitation of transitions between the zeroth and the first excited electron-vibrational level in the ground state of $\mathrm{Se}_{2}$ and $\mathrm{Te}_{2}$ molecules.

\section{Theoretical Studies}

\section{of the Structural Parameters of Chalcogen Molecules and the Appearance Energy of Ionic Fragments}

\subsection{Basic issues}

The appearance energy, $E_{\mathrm{AP}}$, of an atomic or a molecular ion at DI of a molecule is equal to the energy required for the ion to escape from the neutral molecule (see works [67-75]). The $E_{\mathrm{AP}}$ minimum is a value, at which the end products - atoms, molecular fragments, and their ions - are in the ground state and possess zero kinetic energies. The DI reaction occurs at the threshold of two complicated processes, the autoionization and dissociation. The simultaneous occurrence of those processes is possible provided a strong interaction between the electronic and atomic (mainly, vibrational) types of motion in an excited molecule. Such an interaction is especially important in the cases where the reaction gives rise to the emergence of a large number of atomic products of the reaction.

The behavior of chemical reactions is characterized by such an important energy parameter as the internal energy, i.e., the total interaction energy of particles with one another in those quantum systems that participate in reactions and processes. For atoms and molecules in various quantum states, the main contribution to the internal energy is given by the interaction between electrons and between the atoms composing such systems. Any molecule is also characterized by complicated types of motion of its atoms and the molecule as a whole: vibrational and rotational ones, which make a certain contribution to the total energy of the molecule.

The internal energy is closely related to such a quantity as the enthalpy. The enthalpy of a molec- ular system is defined as the sum of the internal energy (the total energy of the system at $0 \mathrm{~K}$ ) and the thermal energy, which includes the vibrational and rotational energies of the molecule at a given temperature. The enthalpy difference between the initial components and the final products of chemical reactions is called the standard reaction enthalpy [76]. This quantity can be negative or positive, and it characterizes the total thermal energy released or absorbed during a definite reaction. The term "enthalpy" is also used to describe the processes of dissociative ionization of molecules by the electron impact.

When measuring $E_{\mathrm{AP}}$, it is desirable to determine the states of all reaction products. The registration of only an ion of a molecular fragment makes it possible to determine the appearance energy. Generally speaking, the latter may be determined by the states of the final products that were formed in the most probable processes. Note that the final atomic and molecular products can be in excited states during the DI process and form bound states with particles, e.g., negative ionic states. The formation of negative ions is an inherently threshold process and can be effective, if the electron affinity energy of atoms or molecules is high. The electron excitation of reaction products leads to the growth of $E_{\mathrm{AP}}$, whereas the binding (association) of atoms and molecules, as well as the electron capture in the final states, results in its reduction.

An interesting process in the course of DI is the formation of doubly charged atomic and molecular ions. Atomic ions with any degree of ionization are always stable. But doubly and multiply charged molecular ions can be unstable. Molecular ions of this kind can undergo a Coulombic decay as a result of the socalled Coulombic explosion. The observation of doubly charged ionic fragments provides some challenge to experimental methods and theoretical calculations.

The account of the final states and the kinetic energies of the DI products is an important general problem dealing with the theoretical and experimental determinations of the appearance energies, in particular, at the inelastic collisions of fast ions with molecules, which lead to the formation of multiply charged molecular ions followed by their Coulombic decay. For example, it occurs in the processes of interaction of the $\mathrm{H}^{+}, \mathrm{He}^{+}$, and $\mathrm{N}^{+}$ions (with energies of 1 and $2 \mathrm{MeV})$ with water and ethane $\left(\mathrm{C}_{2} \mathrm{H}_{6}\right)$ molecules [77-79]. In the framework of this problem, 
the determination of the total released kinetic energy of fragments is an important component in the microscopic analysis of the dynamics of various reactions running in the course of the DI process.

Let us analyze the course of the electron-impact DI processes with such homoatomic molecular targets as sulfur $\left(\mathrm{S}_{n}, n=2 \div 8\right)$, selenium $\left(\mathrm{Se}_{n}, n=2 \div 8\right)$, and tellurium $\left(\mathrm{Te}_{n}, n=2 \div 8\right)$ clusters. The appearance energies of ionic fragments will be calculated using theoretical $a b$ initio methods that are applied to study the structure of molecules.

The energy $E_{\mathrm{AP}}$ required for an ionic fragment $M_{k}^{+}$ to appear from a homoatomic molecule $M_{n}$ containing $n$ atoms according to the reaction

$\mathrm{e}^{-}+\mathrm{M}_{n} \rightarrow \mathrm{M}_{k}^{+}+m \mathrm{M}+2 \mathrm{e}^{-}$,

where $m=n-k$, can be calculated using the formula $[72,73,75]$

$$
\begin{aligned}
& E_{\mathrm{AP}}\left[\left(\mathrm{M}_{k}^{+}-m \mathrm{M}\right) / \mathrm{M}_{n}\right]= \\
& =E_{t}\left(\mathrm{M}_{k}^{+}\right)+m E_{t}(\mathrm{M})-E_{t}\left(\mathrm{M}_{n}\right)
\end{aligned}
$$

or

$$
\begin{aligned}
& E_{\mathrm{AP}}\left[\left(\mathrm{M}_{k}^{+}-m \mathrm{M}\right) / \mathrm{M}_{n}\right]= \\
& =D\left[\left(\mathrm{M}_{k}-m \mathrm{M}\right) / \mathrm{M}_{n}\right]+I\left(\mathrm{M}_{k}\right) .
\end{aligned}
$$

Here, $E_{t}$ is the total energy of the corresponding molecule or atom in the ground state; $D$ and $I$ are the dissociation and ionization, respectively, energies of the molecule; and $n$ and $k$ are the numbers of atoms in the molecules. From whence, one can see that, in the case where the molecule $\mathrm{M}_{n}$ becomes ionized as a whole entity $(k=n)$, and atoms are not detached from it $(m=0)$, the energy received by the molecule is minimal. The appearance of, e.g., a singly ionized atomic ion $\mathrm{M}^{+}(k=1)$ can be accompanied by either a detachment of $(n-1)$ atoms from $\mathrm{M}$ or a formation of various molecular fragments from those atoms. The energy of the incident electron is higher in the former case and lower in the latter one. The formation of an $\mathrm{M}_{n-1}$ molecule in the latter case corresponds to the lowest appearance energy of the $\mathrm{M}^{+}$ion.

The presence of molecules in the gaseous phase at a given temperature means that they can be in various excited $(*)$ states - electron, $E_{\mathrm{el}}$, vibrational, $E_{\mathrm{vib}}$, and rotational, $E_{\text {rot }}$, ones, for which $E_{\mathrm{el}} \gg E_{\mathrm{vib}} \gg$ $E_{\text {rot }}-$ and even in ionized $(+)$ states. As was mentioned above, the end products - atoms, molecular fragments, and their ions - have to be in the ground states at that. The appearance energy $E_{\mathrm{AP}}$ of the $\mathrm{M}_{k}^{+}$ fragment in the reaction

$\mathrm{e}^{-}+\mathrm{M}_{n}^{*} \rightarrow \mathrm{M}_{k}^{+}+\mathrm{M}_{m}+2 \mathrm{e}^{-}$

equals

$E_{\mathrm{AP}}\left[\frac{\mathrm{M}_{k}^{+}-\mathrm{M}_{m}}{\mathrm{M}_{n}^{*}}\right]=D\left[\frac{\mathrm{M}_{k}-\mathrm{M}_{m}}{\mathrm{M}_{n}}\right]+I\left(\mathrm{M}_{k}\right)-$

$-E\left(\mathrm{M}_{n}^{*}\right)=D\left[\frac{\mathrm{M}_{k}^{+}-\mathrm{M}_{m}}{\mathrm{M}_{n}^{+}}\right]+I\left(\mathrm{M}_{n}^{*}\right)$.

Here, $E\left(\mathrm{M}_{n}^{*}\right)$ is the excitation energy of the initial molecule $\mathrm{M}_{n}$, and $I\left(\mathrm{M}_{n}^{*}\right)=I\left(\mathrm{M}_{n}\right)-E\left(\mathrm{M}_{n}^{*}\right)$ is the ionization energy of the excited molecule $\mathrm{M}_{n}^{*}$. Hence, reaction (31) is associated with a set of values for the appearance energy of the fragment $\mathrm{M}_{k}^{+}$, which are connected with definite excitations of the initial molecule. If the excitation energy $E\left(\mathrm{M}_{n}^{*}\right)$ is equal to the ionization energy $I\left(\mathrm{M}_{n}\right)$ of the $\mathrm{M}_{n}$ molecule, $E\left(\mathrm{M}_{n}^{*}\right)=I\left(\mathrm{M}_{n}\right)$, then the appearance energy of the $\mathrm{M}_{k}^{+}$fragment corresponds to the dissociation energy $D\left[\left(\mathrm{M}_{k}^{+}-\mathrm{M}_{m}\right) / \mathrm{M}_{n}^{+}\right]$of the $\mathrm{M}_{n}^{+}$molecular ion according to the reaction

$\mathrm{e}^{-}+\mathrm{M}_{n}^{+} \rightarrow \mathrm{M}_{k}^{+}+\mathrm{M}_{m}+\mathrm{e}^{-}$.

The direct ionization process is described by the reaction scheme $\mathrm{e}^{-}+\mathrm{M}_{n}^{*} \rightarrow \mathrm{M}_{n}^{+}+2 \mathrm{e}^{-}$characterized by the appearance energy

$E_{\mathrm{AP}}\left(\mathrm{M}_{n}^{+} / \mathrm{M}_{n}^{*}\right)=I\left(\mathrm{M}_{n}^{*}\right)=I\left(\mathrm{M}_{n}\right)-E\left(\mathrm{M}_{n}^{*}\right)$.

In other words, the set of appearance energies $E_{\mathrm{AP}}\left[\left(\mathrm{M}_{k}^{+}-\mathrm{M}_{m}\right) / \mathrm{M}_{n}^{*}\right]$ ranges from the minimum value $D\left[\left(\mathrm{M}_{k}^{+}-\mathrm{M}_{m}\right) / \mathrm{M}_{n}^{+}\right]\left(\right.$at $\left.E\left(\mathrm{M}_{n}^{*}\right)=I\left(\mathrm{M}_{n}\right)\right)$ to the maximum one (at $E\left(\mathrm{M}_{n}^{*}\right)=0$ )

$D\left[\left(\mathrm{M}_{k}^{+}-\mathrm{M}_{m}\right) / \mathrm{M}_{k}^{+}\right]+I\left(\mathrm{M}_{n}\right)=$

$=D\left[\left(\mathrm{M}_{k}-\mathrm{M}_{m}\right) / \mathrm{M}_{n}\right]+I\left(\mathrm{M}_{k}\right)$.

Note that, as was indicated above, every value of the appearance energy $E_{\mathrm{AP}}\left[\left(\mathrm{M}_{k}^{+}-\mathrm{M}_{m}\right) / \mathrm{M}_{n}^{*}\right]$ for the ionic fragment $\mathrm{M}_{k}^{+}$is also associated with its own set of energies corresponding to the formation of various neutral atomic or molecular fragments emerging from the atoms of the $\mathrm{M}_{m}$ molecule. The formation of those fragments is characterized by definite dissociation energies. This energy is the lowest in the presence

ISSN 2071-0194. Ukr. J. Phys. 2020. Vol. 65, No. 7 
of the $\mathrm{M}_{m}$ molecule and the highest, if this molecule completely dissociates into $m$ atoms.

A doubly charged ionic fragment $\mathrm{M}_{k}^{2+}$ can be formed as a result of the following reactions:

- double dissociative ionization of the excited molecule $\mathrm{M}_{n}^{*}$,

$\mathrm{e}^{-}+\mathrm{M}_{n}^{*} \rightarrow \mathrm{M}_{k}^{2+}+\mathrm{M}_{m}+3 \mathrm{e}^{-}$,

- dissociative ionization of the molecular ion $M_{n}^{+}$,

$\mathrm{e}^{-}+\mathrm{M}_{n}^{+} \rightarrow \mathrm{M}_{k}^{2+}+\mathrm{M}_{m}+2 \mathrm{e}^{-}$,

- direct ionization of the excited molecule $M_{k}^{*}$,

$\mathrm{e}^{-}+\mathrm{M}_{k}^{*} \rightarrow \mathrm{M}_{k}^{2+}+3 \mathrm{e}^{-}$.

The corresponding energies of the ion appearance are:

- for reaction (33),

$E_{\mathrm{AP}}\left[\frac{\mathrm{M}_{k}^{2+}-\mathrm{M}_{m}}{\mathrm{M}_{n}^{*}}\right]=D\left[\frac{\mathrm{M}_{k}-\mathrm{M}_{m}}{\mathrm{M}_{n}}\right]+$

$+I\left(\mathrm{M}_{k}\right)+I\left(\mathrm{M}_{k}^{+}\right)-E\left(\mathrm{M}_{n}^{*}\right)=$

$=D\left[\frac{\mathrm{M}_{k}^{2+}-\mathrm{M}_{m}}{\mathrm{M}_{n}^{2+}}\right]+I\left(\mathrm{M}_{n}\right)+I\left(\mathrm{M}_{n}^{+}\right)-E\left(\mathrm{M}_{n}^{*}\right)=$

$=D\left[\frac{\mathrm{M}_{k}^{2+}-\mathrm{M}_{m}}{\mathrm{M}_{n}^{+}}\right]+I\left(\mathrm{M}_{n}\right)-E\left(\mathrm{M}_{n}^{*}\right)$,

- for reaction (34),

$E_{\mathrm{AP}}\left[\frac{\mathrm{M}_{k}^{2+}-\mathrm{M}_{m}}{\mathrm{M}_{n}^{+}}\right]=D\left[\frac{\mathrm{M}_{k}^{+}-\mathrm{M}_{m}}{\mathrm{M}_{n}^{+}}\right]+I\left(\mathrm{M}_{k}^{+}\right)=$

$=D\left[\frac{\mathrm{M}_{k}^{2+}-\mathrm{M}_{m}}{\mathrm{M}_{n}^{2+}}\right]+I\left(\mathrm{M}_{n}^{+}\right)=D\left[\frac{\mathrm{M}_{k}^{2+}-\mathrm{M}_{m}}{\mathrm{M}_{n}^{+}}\right]$

- and for reaction (35),

$E_{\mathrm{AP}}\left(\mathrm{M}_{k}^{2+} / \mathrm{M}_{k}^{*}\right)=I\left(\mathrm{M}_{k}\right)+I\left(\mathrm{M}_{k}^{+}\right)-E\left(\mathrm{M}_{k}^{*}\right)$.

Reaction (34) is related to a set of appearance energies for the fragment $\mathrm{M}_{k}^{2+}$, which are associated with definite excitations of the parent molecule. If $E\left(\mathrm{M}_{n}^{*}\right)=I\left(\mathrm{M}_{n}\right)$, the appearance energy of the $\mathrm{M}_{k}^{2+}$ fragment can be determined from Eq. (37). In other words, as was in the case of formation of the singly charged ion $\mathrm{M}_{k}^{+}$, the set of the appearance energies $E_{\mathrm{AP}}\left[\left(\mathrm{M}_{k}^{2+}{ }^{2}-\mathrm{M}_{m}\right) / \mathrm{M}_{n}^{*}\right]$ for the doubly charged ISSN 2071-0194. Ukr. J. Phys. 2020. Vol. 65, No. 7 ion $\mathrm{M}_{k}^{2+}$ ranges from the minimum value $D\left[\left(\mathrm{M}_{k}^{2+}-\right.\right.$ $\left.\left.-\mathrm{M}_{m}\right) / \mathrm{M}_{n}^{+}\right]$at $E\left(\mathrm{M}_{n}^{*}\right)=I\left(\mathrm{M}_{n}\right)$ to the maximum one

$D\left[\left(\mathrm{M}_{k}^{2+}-\mathrm{M}_{m}\right) / \mathrm{M}_{n}^{+}\right]+I\left(\mathrm{M}_{n}\right)=$

$=D\left[\left(\mathrm{M}_{k}-\mathrm{M}_{m}\right) / \mathrm{M}_{n}\right]+I\left(\mathrm{M}_{k}\right)$

at $E\left(\mathrm{M}_{n}^{*}\right)=0$. It is worth to note that, as was indicated above, every value of the appearance energy $E_{\mathrm{AP}}\left[\left(\mathrm{M}_{k}^{2+}-\mathrm{M}_{m}\right) / \mathrm{M}_{n}^{*}\right]$ for the ion fragment $\mathrm{M}_{k}^{2+}$ is associated with its own set of energies related to the formation of various neutral atomic or molecular fragments of the $\mathrm{M}_{m}$ type.

As was mentioned above, the Coulombic decay of multiply charged molecular ions, even doubly charged ones, is an important factor. This decay can occur following various scenarios (channels). Some of those processes require some piece of energy for a relevant bond to be broken and the fragments to appear. In the others, some energy is released, being spent on the kinetic energy of dissociation fragments. For instance, let a doubly charged molecular ion $\mathrm{M}^{2+}$ be able to decay through the following channels giving rise to the formation of a pair of molecular fragments $M_{1}$ and $\mathrm{M}_{2}$ in various charged states:

$\mathrm{M}^{2+} \rightarrow\left\{\begin{array}{l}\mathrm{M}_{1}^{+}+\mathrm{M}_{2}^{+} \\ \mathrm{M}_{1}^{2+}+\mathrm{M}_{2} \\ \mathrm{M}_{1}+\mathrm{M}_{2}^{2+}\end{array}\right.$

Note that only the first reaction in Eq. (38) corresponds to the genuine Coulombic decay. In the other two reactions, one of the fragments is neutral and can be excited into an electron, vibrational or rotational state.

The following energy balances correspond to reactions (38):

$E\left[\left(\mathrm{M}_{1}^{+}-\mathrm{M}_{2}^{+}\right) / \mathrm{M}^{2+}\right]=E_{t}\left[\mathrm{M}^{2+}\right]-\left(E_{t}\left[\mathrm{M}_{1}^{+}\right]+E_{t}\left[\mathrm{M}_{2}^{+}\right]\right)$,

$E\left[\left(\mathrm{M}_{1}^{2+}-\mathrm{M}_{2}\right) / \mathrm{M}^{2+}\right]=E_{t}\left[\mathrm{M}^{2+}\right]-\left(E_{t}\left[\mathrm{M}_{1}^{2+}\right]+E_{t}\left[\mathrm{M}_{2}\right]\right)$

$E\left[\left(\mathrm{M}_{1}-\mathrm{M}_{2}^{2+}\right) / \mathrm{M}^{2+}\right]=E_{t}\left[\mathrm{M}^{2+}\right]-\left(E_{t}\left[\mathrm{M}_{1}\right]+E_{t}\left[\mathrm{M}_{2}^{2+}\right]\right)$.

From whence, using the dissociation energies and the corresponding ionization potentials, we obtain the ex- 
pressions

$$
\begin{aligned}
& E\left[\left(\mathrm{M}_{1}^{+}-\mathrm{M}_{2}^{+}\right) / \mathrm{M}^{2+}\right]=D\left[\left(\mathrm{M}_{1}-\mathrm{M}_{2}\right) / \mathrm{M}\right]+ \\
& +I\left(\mathrm{M}_{1}\right)+I\left(\mathrm{M}_{2}\right)-I(\mathrm{M})-I\left(\mathrm{M}^{+}\right), \\
& E\left[\left(\mathrm{M}_{1}^{2+}-\mathrm{M}_{2}\right) / \mathrm{M}^{2+}\right]=D\left[\left(\mathrm{M}_{1}-\mathrm{M}_{2}\right) / \mathrm{M}\right]+ \\
& +I\left(\mathrm{M}_{1}\right)+I\left(\mathrm{M}_{1}^{+}\right)-I(\mathrm{M})-I\left(\mathrm{M}^{+}\right), \\
& E\left[\left(\mathrm{M}_{1}-\mathrm{M}_{2}^{2+}\right) / \mathrm{M}^{2+}\right]=D\left[\left(\mathrm{M}_{1}-\mathrm{M}_{2}\right) / \mathrm{M}\right]+ \\
& +I\left(\mathrm{M}_{2}\right)+I\left(\mathrm{M}_{2}^{+}\right)-I(\mathrm{M})-I\left(\mathrm{M}^{+}\right) .
\end{aligned}
$$

If the energy $E<0$ in the corresponding channel, i.e., the absolute value of the total energy of the $\mathrm{M}^{2+}$ ion exceeds the sum of the absolute values of the total energies of the fragments, then the $\mathrm{M}^{2+}$ ion is stable with respect to its decay through the given channel, and this energy is the binding energy $E_{b}$ of the $\mathrm{M}^{2+}$ ion. But if $E>0$, then the $\mathrm{M}^{2+}$ ion is unstable and can decay through the corresponding channel, and the fragments fly apart with the total kinetic energy equal to $|E|$.

In order to determine the total energies of the molecules, atoms, and ions in the ground state, the GAMESS-US software package [80] based on the density functional theory (DFT) [81] was used. In all calculations, we applied supercomputers with a high parallelization degree at the IEF NASU (Uzhgorod, Ukraine) and the HPC Debrecen (Debrecen, Hungary). The calculations were performed with the help of hybrid functionals of two types in the generalized gradient approximation, B3LYP and B3PW91. The both functionals make allowance for the exchange interaction of the Hartree-Fock (HF, $20 \%$ ) and Slater $(80 \%)$ types. The correlation interaction is described by the Lee-Yang-Parr (LYP) functional in B3LYP and the Perdew-Wang functional in B3PW91 [82]. The standard set aug-cc-PVTZ [80] was used as basic functions in all calculations.

The total energies of all researched molecules and ionic fragments were calculated, firstly, for their two states characterized by the lowest multiplicity, and afterward the state with the lower energy was selected from them. The structure of the $\mathrm{M}_{n}$ molecules was optimized using the quadratic approximation method [83] and without taking the effect of molecular symmetry into account. After attaining an equilibrium optimized geometry of the $\mathrm{M}_{n}$ molecule, further calculations were performed to determine the energy parameters of the $\mathrm{M}_{k}^{+}$ionic fragments in the adiabatic approximation. For this purpose, the equilibrium geometries of the molecular and ionic fragments were also determined in the optimization process described above. The vibrational energy of the molecules was not taken into consideration. It is important to note that the calculation of the total energies of negative molecular ions, as it was in the case of atomic ions, requires that the electron-electron correlation interaction should be taken into account. The electron binding energy in such systems is very sensitive to the approximations used for this interaction.

Sulfur, selenium, and tellurium atoms can form various structures from linear to ring ones [84-87]. In the case of molecules with the number of atoms $n \geq 4$, only those possessing the ring structure were analyzed, because they are more stable (see works $[84,86,87])$.

In works [88-90], the appearance energies of ionic fragments from sulfur clusters were calculated, and the DI process from those clusters was simulated for the first time using the Monte Carlo method. In particular, the energies required for the appearance of $\mathrm{S}_{k}^{+}$ $(k=1 \div 6)$ fragments from the $\mathrm{S}_{n}$ clusters $(k \leq n \leq 8)$ were calculated and analyzed in works [88, 89]. In work [90], the probabilities of the formation of various ionic fragments from the $\mathrm{S}_{6}$ cluster was calculated and compared with available experimental data.

Note that, from the application viewpoint, the process of potential electron scattering by molecules is important. For instance, it is the process of elastic electron scattering by atoms, molecules, and their positive ions that is the main mechanism of electron cooling in various plasma media. This process is characterized by large cross-sections, which results in the effective formation of the electron energy distribution function. For example, in works [91-95] (see also references therein), the differential cross-sections and various kinds of integral ones of this process were studied in the framework of the model of independent atoms. In work [91], the elastic electron scattering by the sulfur atom and the homoatomic $\mathrm{S}_{n}(n=2 \div 4)$ sulfur clusters was considered. The electron scattering by selenium and tellurium clusters can be calculated and analyzed following the same way.

\subsection{Structural parameters of chalcogen molecules}

4.2.1. Sulfur molecules $S_{n}(n=2 \div 8)$

The importance of researches of $\mathrm{S}_{n}(n=2 \div 8)$ sulfur molecules and a success achieved in the study of their

ISSN 2071-0194. Ukr. J. Phys. 2020. Vol. 65, No. 7 
structure, as well as various processes of their interaction with electrons, are discussed in works [86, 96100]. In particular, mass spectrometry methods were used to experimentally study ionic products of the dissociative ionization processes $[86,96]$ and the processes of dissociative excitation of sulfur molecules that are formed as a result of their collisions with electrons at low energies [98, 99]. Sulfur clusters containing two to eight atoms and those in the gaseous phase were studied. In the cited works, it was shown that the efficiency of the electron-impact DI of various sulfur molecules $\mathrm{S}_{n}$ becomes considerable at energies higher than about $9.5 \mathrm{eV}$, which results in the appearance of ionic fragments $\mathrm{S}_{k}^{+}$with $k=1 \div n$. In work [97], the mechanisms of ionic fragment formation and the spectra of electrons ejected at the interaction of photons with sulfur molecules were studied in detail. The authors of work [97] made a thorough theoretical analysis of the bond structure and the stability for a number of sulfur clusters $\mathrm{S}_{n}(n=2 \div 18)$ in the framework of the density functional theory.

The energy parameters characterizing the appearance of ionic fragments were calculated by us as the difference between the total energies of the relaxed states of the initial molecule and the final molecular and atomic fragments $[88,90]$. The total energies of the initial sulfur molecules and their neutral and ionic fragments were determined making use of the software package GAMESS-US [80] on the basis of the DFT and the HF approximation; in the DFT case, the functional B3PW91 was applied. The effects of the electron correlation were take into account by applying the MP2 perturbation theory $[101,102]$ to determine more exactly the total energies calculated using the HF method. In all calculations, the standard set aug-cc-PVDZ [80] was used as the basis functions.

The data of works $[84,100]$ were used to set the initial geometric structure of sulfur molecules. The total electron energies of all molecular systems were calculated after their geometry optimization (in the adiabatic approximation). Examples of equilibrium structures of the $\mathrm{S}_{4}$ and $\mathrm{S}_{8}$ molecules are exhibited in Fig. 14, $a$ and $b$, respectively. Sulfur molecules with five or more atoms have a ring structure in the ground state (see Fig. 14, b).

The interatomic distances were calculated in the DFT/B3PW91 and HF/MP2 approximations for all sulfur molecules, and they are presented in Table 10 . The corresponding theoretical values $r_{n m}-$

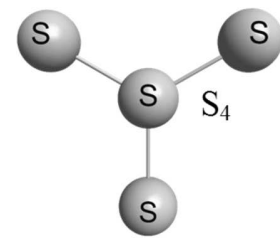

$a$

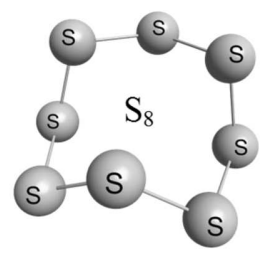

$b$
Fig. 14. Equilibrium geometric structures of the $\mathrm{S}_{4}(a)$ and $\mathrm{S}_{8}(b)$ molecules in the ground state

both in this table and in the other tables below were taken from the NIST database given for the most accurate available method [103]. From Table 10, one can see that our calculated interatomic distances are somewhat shorter than other theoretical data, being closer to the experimental values. The magnitudes of interatomic distances in the sulfur clusters increase non-monotonically as the number of atoms in them grows.

Positive molecular ions (cations) of sulfur (as well as selenium and tellurium) are characterized, as a rule, by an asymmetric structure. This means that the interatomic distances in the ions do not change proportionately as compared to those in the neutral systems. For example, the interatomic distances between the neighbor atoms in an $\mathrm{S}_{8}$ molecule are identical and, according to the DFT/B3PW91 calculation, equal to about $2.0497 \AA$. The equilibrium interatomic distances between the neighbor atoms in a molecular $\mathrm{S}_{8}^{+}$ion calculated using a similar method turn out not identical and vary from 2.0578 to $2.0774 \AA$. Our calculations showed that the equilibrium interatomic distances in all cations of the sulfur, selenium, and tellurium molecules do not strongly exceed the corresponding interatomic distances in the neutral molecules. Such an increase is usually not substantial and varies from 0.01 to $0.04 \AA$.

The adiabatic values of the ionization potential $I$, the electron affinity energy $E_{a}$, and the dissociation energy (the binding energy) for some sulfur molecules - both experimental and calculated by us in the B3PW91 and HF/MP2 approximations - are quoted in Table 11. All calculated energy parameters were determined by us adiabatically as the difference between the total energies of the corresponding neutral and ionized systems in the relaxed states. Our experimental results are shown in bold.

For the diatomic molecule $\mathrm{S}_{2}$, the calculated dissociation energy $D$ is in good agreement with the data 
Table 10. Calculated interatomic distances in $\mathbf{S}_{\boldsymbol{n}}$ molecules with $n=2 \div 8$ and the corresponding experimental and theoretical data

\begin{tabular}{|c|c|c|c|c|}
\hline \multirow{2}{*}{ Molecule } & \multirow{2}{*}{ Interatomic distances } & \multirow{2}{*}{$\begin{array}{c}\text { Calculated values } \\
r_{n m}(\AA) *\end{array}$} & \multicolumn{2}{|c|}{ Literature data $r_{n m}(\AA)$} \\
\hline & & & Experiment & Theory \\
\hline $\mathrm{S}_{8}$ & $\begin{array}{c}r_{\mathrm{S} m-\mathrm{S} n} \\
m=1-7, \\
n=(m+1)-8\end{array}$ & $2.0497 ; 2.0662$ & $\begin{array}{l}2.059[104] \\
2.055[100]\end{array}$ & $\begin{array}{l}2.108[100] \\
2.0835[103]\end{array}$ \\
\hline $\mathrm{S}_{7}$ & $\begin{array}{c}r_{\mathrm{S} 1-\mathrm{S} 2}, r_{\mathrm{S} 1-\mathrm{S} 7}, \\
r_{\mathrm{S} 2-\mathrm{S} 3}, r_{\mathrm{S} 6-\mathrm{S} 7}, \\
r_{\mathrm{S} 3-\mathrm{S} 4}, r_{\mathrm{S} 5-\mathrm{S} 6}, \\
r_{\mathrm{S} 4-\mathrm{S} 5}\end{array}$ & $\begin{array}{l}2.0565 ; 2.0641 \\
2.1161 ; 2.1164 \\
1.9934 ; 1.9980 \\
2.2084 ; 2.2256\end{array}$ & $\begin{array}{c}2.048, \\
2.090 \\
1.998 \\
2.175[100]\end{array}$ & $\begin{array}{c}2.099 \\
2.165 \\
2.031 \\
2.262[100]\end{array}$ \\
\hline $\mathrm{S}_{6}$ & $\begin{array}{c}r_{\mathrm{S} m-\mathrm{S} n} \\
m=1-5, \\
n=(m+1)-6\end{array}$ & $2.0751 ; 2.0818$ & $2.068[100]$ & $2.120[100]$ \\
\hline $\mathrm{S}_{5}$ & $\begin{array}{c}r_{\mathrm{S} 1-\mathrm{S} 2}, r_{\mathrm{S} 1-\mathrm{S} 5} \\
r_{\mathrm{S} 2-\mathrm{S} 3}, r_{\mathrm{S} 4-\mathrm{S} 5}, \\
r_{\mathrm{S} 3-\mathrm{S} 4}\end{array}$ & $\begin{array}{l}1.9212 ; 2.0532 \\
1.9210 ; 1.9577 \\
1.9019 ; 2.2549\end{array}$ & - & $\begin{array}{c}2.133 \\
2.072 \\
2.248[100]\end{array}$ \\
\hline $\mathrm{S}_{4}$ & $\begin{array}{c}r_{\mathrm{S} 1-\mathrm{S} 2}, r_{\mathrm{S} 3-\mathrm{S} 4}, \\
r_{\mathrm{S} 2-\mathrm{S} 3}, r_{\mathrm{S} 1-\mathrm{S} 4}\end{array}$ & $\begin{array}{l}1.9106 ; 1.9205 \\
1.9106 ; 1.9205\end{array}$ & - & $\begin{array}{c}2.168 ; 1.926 \\
2.168 ; 2.604[100]\end{array}$ \\
\hline $\mathrm{S}_{3}$ & $r_{\mathrm{S} 1-\mathrm{S} n}(n=2-3)$ & $1.9209 ; 1.9432$ & $1.90 \pm 0.05[100]$ & $1.960[100], 1.9769$ [103] \\
\hline $\mathrm{S}_{2}$ & $r_{\mathrm{S}-\mathrm{S}}$ & $1.9018 ; 1.9209$ & $1.8892[105]$ & 1.934 [100], 1.903 [103] \\
\hline
\end{tabular}

(*) The first and second values were calculated using the DFT/B3PW91 and HF/MP2 methods, respectively.

of work [106] and the reference book [107]. In general, the indicated values demonstrate a good consistency with one another.

The calculated value of the electron affinity energy $E_{a}$ of a sulfur molecule almost coincides with the experimental one in the $\mathrm{S}_{2}$ and $\mathrm{S}_{3}$ cases, but slightly (by $0.2-0.6 \mathrm{eV}$ ) exceeds it in the $\mathrm{S}_{4}$ case. The molecule $\mathrm{S}_{5}$ is of interest, because the $E_{a}$ energies calculated for it are close to zero or negative. This circumstance testifies to the complicated structures of both the corresponding neutral molecule and its negative ion (here, a transition to the ring structure in sulfur clusters takes place). Beginning from $\mathrm{S}_{6}$, the theoretical value of $E_{a}$ is always lower than the corresponding experimental one. Furthermore, as the number of atoms in the molecule grows, the difference between the calculated and measured values of the energy $E_{a}$ increases.

The theoretical and experimental values for the ionization energy are in good agreement: the largest difference between them amounts to $0.5-1.5 \mathrm{eV}$. A probable origin of those deviations may be the neglect of the vibrational energy of molecules in the ground state. Thus, the results of calculations can be applied to the analysis of the appearance energies of the sulfur ionic fragments.

\subsubsection{Selenium molecules $S e_{n}(n=2 \div 8)$}

There are a number of papers dealing with experimental [37, 115-120] and theoretical [85, 121-124] researches of various parameters of selenium clusters. It is worth noting that, in the majority of experimental studies [37, 116-118], photons were used as particles colliding with a vapor of selenium clusters in the gaseous phase. For example, the PhotoElectronPhotoIon Coincidence (PEPICO) method was successfully used in works $[37,116]$ to determine the appearance energies of selenium ion fragments and the distribution of photoelectrons. It is also worth noting that a very careful theoretical analysis of possible fragmentation channels of selenium clusters and the appearance energies of various fragments was given in work [37]. In works $[117,118]$, the photodissociation of selenium molecules was experimentally studied, and, with the help of a time-of-flight spectrometer, the appearance potentials (energies) of cations in various photoreactions were measured. Researches 
Table 11. Calculated adiabatic and experimental

energy characteristics $E_{a}, I$, and $D$ of some sulfur molecules

\begin{tabular}{|c|c|c|c|}
\hline \multirow{2}{*}{ Energies } & \multicolumn{2}{|c|}{ Calculated data, eV } & \multirow{2}{*}{ Experimental data, eV } \\
\hline & B3PW91 & $\mathrm{HF} / \mathrm{MP} 2$ & \\
\hline \multicolumn{4}{|c|}{$\mathrm{S}$} \\
\hline$E_{a}$ & 2.157 & 1.80 & $2.077[108,109]$ \\
\hline$I(\mathrm{~S})$ & 10.48 & 9.78 & $\begin{array}{c}10.36012[108,109] ; 10.4 \pm 0.3[35] ; 10.3[110] ; \\
10.3 \pm 0.2 \text { (IMMS); } 10.36 \pm 0.1 \text { (IHES) }\end{array}$ \\
\hline$I\left(\mathrm{~S}^{+}\right)$ & 23.426 & 23.209 & $23.338[108,109]$ \\
\hline$I\left(\mathrm{~S}^{2+}\right)$ & 34.95 & - & $34.83[109]$ \\
\hline \multicolumn{4}{|c|}{$\mathrm{S}_{2}$} \\
\hline$E_{a}$ & 1.66 & 1.45 & $1.565 \pm 0.050[111] ; 1.670 \pm 0.015[112] ; 1.66[107]$ \\
\hline$I\left(\mathrm{~S}_{2}\right)$ & 9.65 & 9.17 & $\begin{array}{c}9.356 \pm 0.002[113] ; 9.6 \pm 0.2[98,113] ; 9.4[107] \\
9.6[47] ; 9.9[6] ; 9.36[48] ; 9.6 \pm 0.2(\text { IMMS })\end{array}$ \\
\hline$I\left(\mathrm{~S}_{2}^{+}\right)$ & 17.31 & - & - \\
\hline$I\left(\mathrm{~S}_{2}^{2+}\right)$ & 29.22 & - & - \\
\hline$D\left(2 \mathrm{~S} / \mathrm{S}_{2}\right)$ & 4.50 & 4.03 & $4.45[106] ; 4.4[107]$ \\
\hline \multicolumn{4}{|c|}{$\mathrm{S}_{3}$} \\
\hline$E_{a}$ & 2.57 & 2.22 & $2.31 \pm 0.10[111] ; 2.00 \pm 0.15,2.09 \pm 0.03[112]$ \\
\hline$I\left(\mathrm{~S}_{3}\right)$ & 9.89 & 9.83 & $\begin{array}{c}9.68 \pm 0.03,9.9 \pm 0.4[114] ; 10.2 \pm 0.2[98] ; \\
10.2[47] ; 10.5[6] ; 9.68[48] ; 10.2 \pm 0.2 \text { (IMMS) }\end{array}$ \\
\hline$I\left(\mathrm{~S}_{3}^{+}\right)$ & 25.26 & - & - \\
\hline$D\left(3 \mathrm{~S} / \mathrm{S}_{3}\right)$ & 6.97 & 6.44 & - \\
\hline$D\left(\mathrm{~S}+\mathrm{S}_{2} / \mathrm{S}_{3}\right)$ & 2.47 & 2.41 & - \\
\hline \multicolumn{4}{|c|}{$\mathrm{S}_{4}$} \\
\hline$E_{a}$ & 2.84 & 2.40 & $2.220 \pm 0.030[111]$ \\
\hline$I\left(\mathrm{~S}_{4}\right)$ & 9.49 & 10.71 & $\begin{array}{c}10.1 \pm 0.2[98] ; 10.4 \pm 0.5[114] ; 10.1[47] ; 10.4[6] \\
10.1 \pm 0.2 \text { (IMMS) }\end{array}$ \\
\hline$I\left(\mathrm{~S}_{4}^{+}\right)$ & 22.78 & - & 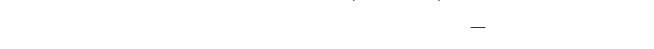 \\
\hline$D\left(4 \mathrm{~S} / \mathrm{S}_{4}\right)$ & 8.69 & 7.94 & - \\
\hline$D\left(2 \mathrm{~S}_{2} / \mathrm{S}_{4}\right)$ & -0.32 & -0.11 & - \\
\hline$D\left(2 \mathrm{~S}+\mathrm{S}_{2} / \mathrm{S}_{4}\right)$ & 4.19 & 3.92 & - \\
\hline$D\left(\mathrm{~S}+\mathrm{S}_{3} / \mathrm{S}_{4}\right)$ & 1.72 & 1.51 & - \\
\hline \multicolumn{4}{|c|}{$\mathrm{S}_{5}$} \\
\hline$E_{a}$ & -0.28 & 0.60 & $2.80 \pm 0.05[111]$ \\
\hline$I\left(\mathrm{~S}_{5}\right)$ & 7.81 & 8.62 & $\begin{array}{c}8.60 \pm 0.05[114] ; 8.8 \pm 0.2[98] ; 8.8[47] ; 9.6[6] ; \\
8.6[48] ; 8.7 \pm 0.2 \text { (IMMS) }\end{array}$ \\
\hline$I\left(\mathrm{~S}_{5}^{+}\right)$ & 21.85 & - & - \\
\hline$D\left(5 \mathrm{~S} / \mathrm{S}_{5}\right)$ & 11.42 & 10.43 & - \\
\hline$D\left(\mathrm{~S}_{2}+\mathrm{S}_{3} / \mathrm{S}_{5}\right)$ & -0.06 & -0.03 & - \\
\hline$D\left(\mathrm{~S}+\mathrm{S}_{4} / \mathrm{S}_{5}\right)$ & 2.73 & 2.49 & - \\
\hline$D\left(3 \mathrm{~S}+\mathrm{S}_{2} / \mathrm{S}_{5}\right)$ & 6.91 & 6.41 & - \\
\hline$D\left(2 \mathrm{~S}+\mathrm{S}_{3} / \mathrm{S}_{5}\right)$ & 4.45 & 4.00 & - \\
\hline$D\left(\mathrm{~S}+2 \mathrm{~S}_{2} / \mathrm{S}_{5}\right)$ & 2.41 & 2.38 & - \\
\hline
\end{tabular}


Continuation of Table 11

\begin{tabular}{|c|c|c|c|}
\hline \multirow{2}{*}{ Energies } & \multicolumn{2}{|c|}{ Calculated data, $\mathrm{eV}$} & \multirow{2}{*}{ Experimental data, eV } \\
\hline & B3PW91 & $\mathrm{HF} / \mathrm{MP} 2$ & \\
\hline \multicolumn{4}{|c|}{$\mathrm{S}_{6}$} \\
\hline$E_{a}$ & 1.73 & 1.48 & $3.210 \pm 0.070[111]$ \\
\hline$I\left(\mathrm{~S}_{6}\right)$ & 8.72 & 8.39 & $\begin{array}{c}9.356 \pm 0.002 ; 9.6 \pm 0.2[113] ; 8.5 \pm 0.3 ; 9.7 \pm 0.3[114] \\
9.2 \pm 0.2[98] ; 9.7[47] ; 9.0[6] ; 9.0[48] \\
9.5 \pm 0.2(\mathrm{IMMS})\end{array}$ \\
\hline$I\left(\mathrm{~S}_{6}^{+}\right)$ & 22.98 & - & - \\
\hline$D\left(6 \mathrm{~S} / \mathrm{S}_{6}\right)$ & 15.90 & 14.41 & - \\
\hline$D\left(4 \mathrm{~S}+\mathrm{S}_{2} / \mathrm{S}_{6}\right)$ & 11.39 & 10.39 & - \\
\hline$D\left(3 \mathrm{~S}+\mathrm{S}_{3} / \mathrm{S}_{6}\right)$ & 8.92 & 7.98 & - \\
\hline$D\left(2 \mathrm{~S}+\mathrm{S}_{4} / \mathrm{S}_{6}\right)$ & 7.20 & 6.47 & - \\
\hline$D\left(\mathrm{~S}+\mathrm{S}_{5} / \mathrm{S}_{6}\right)$ & 4.48 & 3.98 & - \\
\hline$D\left(\mathrm{~S}_{2}+\mathrm{S}_{4} / \mathrm{S}_{6}\right)$ & 2.70 & 2.44 & - \\
\hline$D\left(3 \mathrm{~S}_{2} / \mathrm{S}_{6}\right)$ & 2.38 & 2.34 & - \\
\hline$D\left(2 \mathrm{~S}_{3} / \mathrm{S}_{6}\right)$ & 1.95 & 1.54 & - \\
\hline \multicolumn{4}{|c|}{$\mathrm{S}_{7}$} \\
\hline$E_{a}$ & 1.90 & 1.67 & $3.160 \pm 0.050[111]$ \\
\hline$I\left(\mathrm{~S}_{7}\right)$ & 8.53 & 8.47 & $8.67 \pm 0.03 ; 9.3 \pm 0.3[114] ; 9.0 \pm 0.2[98]$ \\
\hline$I\left(\mathrm{~S}_{7}^{+}\right)$ & 22.84 & - & - \\
\hline$D\left(7 \mathrm{~S} / \mathrm{S}_{7}\right)$ & 18.64 & 16.93 & - \\
\hline$D\left(5 \mathrm{~S}+\mathrm{S}_{2} / \mathrm{S}_{7}\right)$ & 14.14 & 12.91 & - \\
\hline$D\left(4 \mathrm{~S}+\mathrm{S}_{3} / \mathrm{S}_{7}\right)$ & 11.67 & 10.50 & - \\
\hline$D\left(3 \mathrm{~S}+\mathrm{S}_{4} / \mathrm{S}_{7}\right)$ & 9.95 & 8.99 & - \\
\hline$D\left(2 \mathrm{~S}+\mathrm{S}_{5} / \mathrm{S}_{7}\right)$ & 7.22 & 6.50 & - \\
\hline$D\left(\mathrm{~S}+\mathrm{S}_{6} / \mathrm{S}_{7}\right)$ & 2.74 & 2.52 & - \\
\hline$D\left(\mathrm{~S}+2 \mathrm{~S}_{3} / \mathrm{S}_{7}\right)$ & 4.69 & 4.06 & - \\
\hline$D\left(\mathrm{~S}_{2}+\mathrm{S}_{5} / \mathrm{S}_{7}\right)$ & 2.72 & 2.47 & - \\
\hline$D\left(2 \mathrm{~S}_{2}+\mathrm{S}_{3} / \mathrm{S}_{7}\right)$ & 2.66 & 2.44 & - \\
\hline$D\left(3 \mathrm{~S}_{2}+\mathrm{S} / \mathrm{S}_{7}\right)$ & 5.13 & 4.85 & - \\
\hline$D\left(\mathrm{~S}_{3}+\mathrm{S}_{4} / \mathrm{S}_{7}\right)$ & 2.97 & 2.55 & - \\
\hline$D\left(2 \mathrm{~S}_{3}+\mathrm{S} / \mathrm{S}_{7}\right)$ & 4.69 & 4.06 & - \\
\hline \multicolumn{4}{|c|}{$\mathrm{S}_{8}$} \\
\hline$E_{a}$ & 2.09 & 1.50 & $3.590 \pm 0.050[111]$ \\
\hline$I\left(\mathrm{~S}_{8}\right)$ & 8.06 & 7.52 & $9.3 \pm 0.2[98,113] ; 7.3 \pm 0.3,9.04 \pm 0.03,9.6 \pm 0.2[114]$ \\
\hline$I\left(\mathrm{~S}_{8}^{+}\right)$ & 21.65 & - & - \\
\hline$D\left(8 \mathrm{~S} / \mathrm{S}_{8}\right)$ & 21.18 & 19.30 & - \\
\hline$D\left(6 \mathrm{~S}+\mathrm{S}_{2} / \mathrm{S}_{8}\right)$ & 16.67 & 15.27 & - \\
\hline$D\left(5 \mathrm{~S}+\mathrm{S}_{3} / \mathrm{S}_{8}\right)$ & 14.20 & 12.86 & - \\
\hline$D\left(4 \mathrm{~S}+\mathrm{S}_{4} / \mathrm{S}_{8}\right)$ & 12.49 & 11.35 & - \\
\hline$D\left(3 \mathrm{~S}+\mathrm{S}_{5} / \mathrm{S}_{8}\right)$ & 9.76 & 8.86 & - \\
\hline$D\left(2 \mathrm{~S}+\mathrm{S}_{6} / \mathrm{S}_{8}\right)$ & 5.28 & 4.88 & - \\
\hline$D\left(\mathrm{~S}+\mathrm{S}_{7} / \mathrm{S}_{8}\right)$ & 2.54 & 2.36 & - \\
\hline$D\left(\mathrm{~S}_{2}+\mathrm{S}_{6} / \mathrm{S}_{8}\right)$ & 0.78 & 0.86 & - \\
\hline$D\left(2 \mathrm{~S}_{2}+\mathrm{S}_{4} / \mathrm{S}_{8}\right)$ & 3.48 & 3.30 & - \\
\hline$D\left(4 \mathrm{~S}_{2} / \mathrm{S}_{8}\right)$ & 3.16 & 3.19 & - \\
\hline$D\left(\mathrm{~S}_{3}+\mathrm{S}_{5} / \mathrm{S}_{8}\right)$ & 2.79 & 2.43 & - \\
\hline$D\left(2 \mathrm{~S}_{3}+\mathrm{S}_{2} / \mathrm{S}_{8}\right)$ & 2.73 & 2.40 & - \\
\hline$D\left(2 \mathrm{~S}_{4} / \mathrm{S}_{8}\right)$ & 3.79 & 3.41 & - \\
\hline
\end{tabular}


Table 12. Calculated interatomic distances in $\mathbf{S e}_{\boldsymbol{n}}$ molecules with $n=2 \div 8$ and the corresponding experimental and theoretical data

\begin{tabular}{|c|c|c|c|c|}
\hline \multirow{2}{*}{ Molecule } & \multirow{2}{*}{ Interatomic distances } & \multirow{2}{*}{$\begin{array}{l}\text { Calculated values } \\
\qquad r_{n m}(\AA)^{*}\end{array}$} & \multicolumn{2}{|c|}{ Literature data } \\
\hline & & & Experiment & Theory \\
\hline $\mathrm{Se}_{8}$ & $\begin{array}{c}r_{\text {Se } m-\operatorname{Se} n} \\
m=1-7 \\
n=(m+1)-8\end{array}$ & 2.3705 & $2.336 \pm 0.006[85]$ & $2.31[85]$ \\
\hline $\mathrm{Se}_{7}$ & $\begin{array}{c}r_{\mathrm{Se} 1-\mathrm{Se} 2}, r_{\mathrm{Se} 1-\mathrm{Se} 7} \\
r_{\mathrm{Se} 2-\mathrm{Se} 3}, r_{\mathrm{Se} 6-\mathrm{Se} 7} \\
r_{\mathrm{Se} 3-\mathrm{Se} 4}, r_{\mathrm{Se} 5-\mathrm{Se} 6} \\
r_{\mathrm{Se} 4-\mathrm{Se} 5}\end{array}$ & $\begin{array}{c}2.3546,2.4522 \\
2.3343,2.2768 \\
2.4814,2.5689 \\
2.2684\end{array}$ & & $2.28-2.39[85]$ \\
\hline $\mathrm{Se}_{6}$ & $\begin{array}{c}r_{\mathrm{Se} m-\operatorname{Se} n} \\
m=1-5 \\
n=(m+1)-6\end{array}$ & 2.3794 & $2.31[85]$ & $2.322[85]$ \\
\hline $\mathrm{Se}_{5}$ & $\begin{array}{c}r_{\mathrm{Se} 1-\mathrm{Se} 2}, r_{\mathrm{Se} 1-\mathrm{Se} 5} \\
r_{\mathrm{Se} 2-\mathrm{Se} 3}, r_{\mathrm{Se} 4-\mathrm{Se} 5} \\
r_{\mathrm{Se} 3-\mathrm{Se} 4}\end{array}$ & $\begin{array}{l}2.391 \\
2.338 \\
2.496\end{array}$ & & $\begin{array}{c}2.336,2.393,2.505[121] \\
2.319,2.322,2.392[85]\end{array}$ \\
\hline $\mathrm{Se}_{4}$ & $\begin{array}{c}r_{\mathrm{Se} 1-\mathrm{Se} 2}, r_{\mathrm{Se} 3-\mathrm{Se} 4} \\
r_{\mathrm{Se} 2-\mathrm{Se} 3}, r_{\mathrm{Se} 1-\mathrm{Se} 4}\end{array}$ & $\begin{array}{l}2.8349 \\
2.1923\end{array}$ & & $\begin{array}{c}2.435,2.228[121] \\
2.505,2.192[85]\end{array}$ \\
\hline $\mathrm{Se}_{3}$ & $r_{\mathrm{Se} 1-\operatorname{Sen}}(n=2-3)$ & 2.3952 & & $\begin{array}{l}2.43 ; 2.377[121] \\
2.402[85]\end{array}$ \\
\hline $\mathrm{Se}_{2}$ & $r_{\mathrm{Se}-\mathrm{Se}}$ & 2.1991 & $2.166[121]$ & $2.200 ; 2.191[121] ; 2.14[85]$ \\
\hline
\end{tabular}

$\left(^{*}\right)$ The values were calculated using the DFT/B3PW91 method.

of the interaction between selenium molecules and low-energy electrons allowed the ionization potential and the appearance energy to be determined for some selenium ionic fragments $[115,119,120]$. The authors of theoretical works $[85,121-124]$ calculated the equilibrium structure and some energy characteristics (the binding energies, the electron affinity energies, and the ionization potentials) for neutral selenium molecules. In work [85], the vibrational energies of the $\mathrm{Se}_{n}(n=2 \div 8)$ clusters were determined using various theoretical methods (HF, MP2, DFT/B3LYP).

We calculated the total energies of all neutral and ionized selenium clusters using the software package GAMESS-US on the basis of DFT/B3LYP with the basis function set aug-cc-PVDZ [80]. To describe the initial geometric structure of the $\operatorname{Se}_{n}(n=2 \div 8)$ molecules, the data of works $[85,121,122,124]$ were applied.

In Fig. 15, the equilibrium geometric structures of the selenium molecules (a) $\mathrm{Se}_{6}$ and (b) $\mathrm{Se}_{7}$ in the ground state are shown. One can see that the

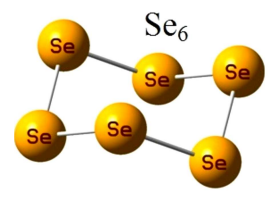

$a$

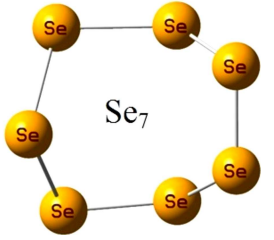

$b$
Fig. 15. Equilibrium geometric structures of the $\mathrm{Se}_{6}(a)$ and $\mathrm{Se}_{7}(b)$ molecules in the ground state

equilibrium structures of selenium clusters are very similar, in most cases even identical, to the structures of sulfur molecules: only the interatomic distances become larger. This growth is explained by the larger size of the atomic components of the molecules. Namely, selenium atoms, if compared with sulfur ones, contain additional $3 d, 4 s$, and $4 p$ electron subshells, which substantially increases their covalent radius. Selenium molecules with more than 4 atoms mainly possess a ring structure in the ground state, similarly to the case of sulfur clusters. 


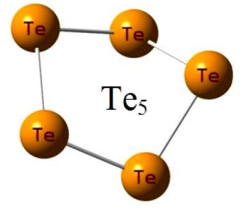

$a$

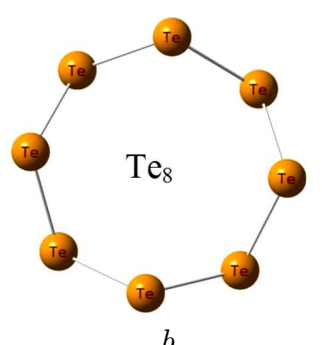

$b$
Fig. 16. Equilibrium geometric structures of the $\mathrm{Te}_{5}(a)$ and $\mathrm{Te}_{8}(b)$ molecules in the ground state

The interatomic distances calculated for some selenium molecules in the DFT/B3LYP approximation are quoted in Table 12. The corresponding theoretical values, $r_{n m}$, shown in Table 12 were taken from the NIST database [103] for the most accurate available method. This table demonstrates that the interatomic distances calculated for the molecules from $\mathrm{Se}_{8}$ to $\mathrm{Se}_{4}$ are somewhat larger and, for the molecules from $\mathrm{Se}_{3}, \mathrm{Se}_{2}$, somewhat smaller than other theoretical data. They are closer to experimental values than it was in the case of sulfur clusters. As it was in the case of sulfur clusters, the interatomic distances in selenium clusters increase non-monotonically with the number of atoms in them. The equilibrium interatomic distances in the ionized selenium clusters are also somewhat larger than in the neutral molecules.

In Table 13, experimental and theoretical (calculated by us in the DFT/B3LYP approximation) adiabatic values of the ionization potential $I$, the electron affinity energy $E_{a}$, and the dissociation energy (the binding energy) are shown for some selenium molecules. As was in the case of sulfur, all energy characteristics calculated by us were determined adiabatically as the difference between the total energies of the corresponding neutral and ionized systems in the relaxed states. For the diatomic molecule $\mathrm{Se}_{2}$, the calculated dissociation energy is a little higher (by about $0.4 \mathrm{eV}$ ) than the value from the reference book [107]. We believe that this is quite a satisfactory agreement between the given values.

The values of the electron affinity energy $E_{a}$ calculated for the selenium molecules almost coincide with the experimental ones in the cases of $\mathrm{Se}_{2}$ and $\mathrm{Se}_{4}$, but somewhat exceed them (by $0.7-1.2 \mathrm{eV}$ ) in the $\mathrm{Se}_{3}$ case. For the $\mathrm{Se}_{5}, \mathrm{Se}_{6}$, and $\mathrm{Se}_{7}$ molecules, the calculated $E_{a}$ values exceed the experimental en- ergies by $0.9,0.55$, and $0.9 \mathrm{eV}$, respectively. We did not manage to calculate the affinity energy $E_{a}$ for the $\mathrm{Se}_{8}$ molecule, whereas its experimental value is about $1.7 \mathrm{eV}$ [122]. The neglect of the vibrational energy of the molecules in the ground state can be one of the origins of such mismatches. The results of calculations were used to analyze the appearance energies of the selenium ionic fragments.

\subsubsection{Tellurium molecules $\mathrm{Te}_{n}(n=2 \div 8)$}

The involved dissociation and ionization processes of tellurium clusters with various sizes were studied both experimentally $[46,116,120,126,127]$ and theoretically $[87,123,128,129]$. Works $[116,120,123]$ have already been discussed above. In most of the researches [46,116, 126,127], photon beams were applied. In particular, the photoelectron spectra were measured and used to determine the threshold appearance energies (the appearance energies and the ionization potentials) for various ionic fragments. The experimental work [120] is the only one where the excitation and ionization of $\mathrm{Te}_{n}(n=2 \div 8)$ clusters at their collisions with low-energy electrons were studied. In theoretical works $[87,123,128,129]$, the stability conditions for and the equilibrium structures of neutral tellurium clusters were mainly considered. The authors of works $[128,129]$ also calculated the vibrational frequencies and the average binding energies for various tellurium configurations. In work [129], which is rather complicated, various DFT approximations were used to determine the electron affinity energies, the ionization energies, and the dissociation channels with the lowest energies. In work [123], the vertical ionization potentials for a number of $\mathrm{Te}_{n}$ clusters $(n=1 \div 6)$ were also determined.

The total energies of the tellurium clusters $\mathrm{Te}_{n}$ $(n=1 \div 8)$ in various states (neutral, negative, and positive) were calculated following the procedure described above for selenium clusters. The only difference consisted in that a basis set with the effective kernel potential CEP-112G-ECP (see work [80]) was used in the DFT/B3LYP calculations. Information about the initial structural parameters of tellurium molecules was taken from works [123, 128, 129].

The equilibrium geometric structures of the tellurium molecules $\mathrm{Te}_{5}$ and $\mathrm{Te}_{8}$ in the ground state are shown in Figs. 16, $a$ and $b$, respectively. One can see that eight tellurium atoms form a regular octagon.

ISSN 2071-0194. Ukr. J. Phys. 2020. Vol. 65, No. 7 
Table 13. Calculated adiabatic and experimental energy characteristics $E_{a}, I$, and $D$ of some selenium molecules

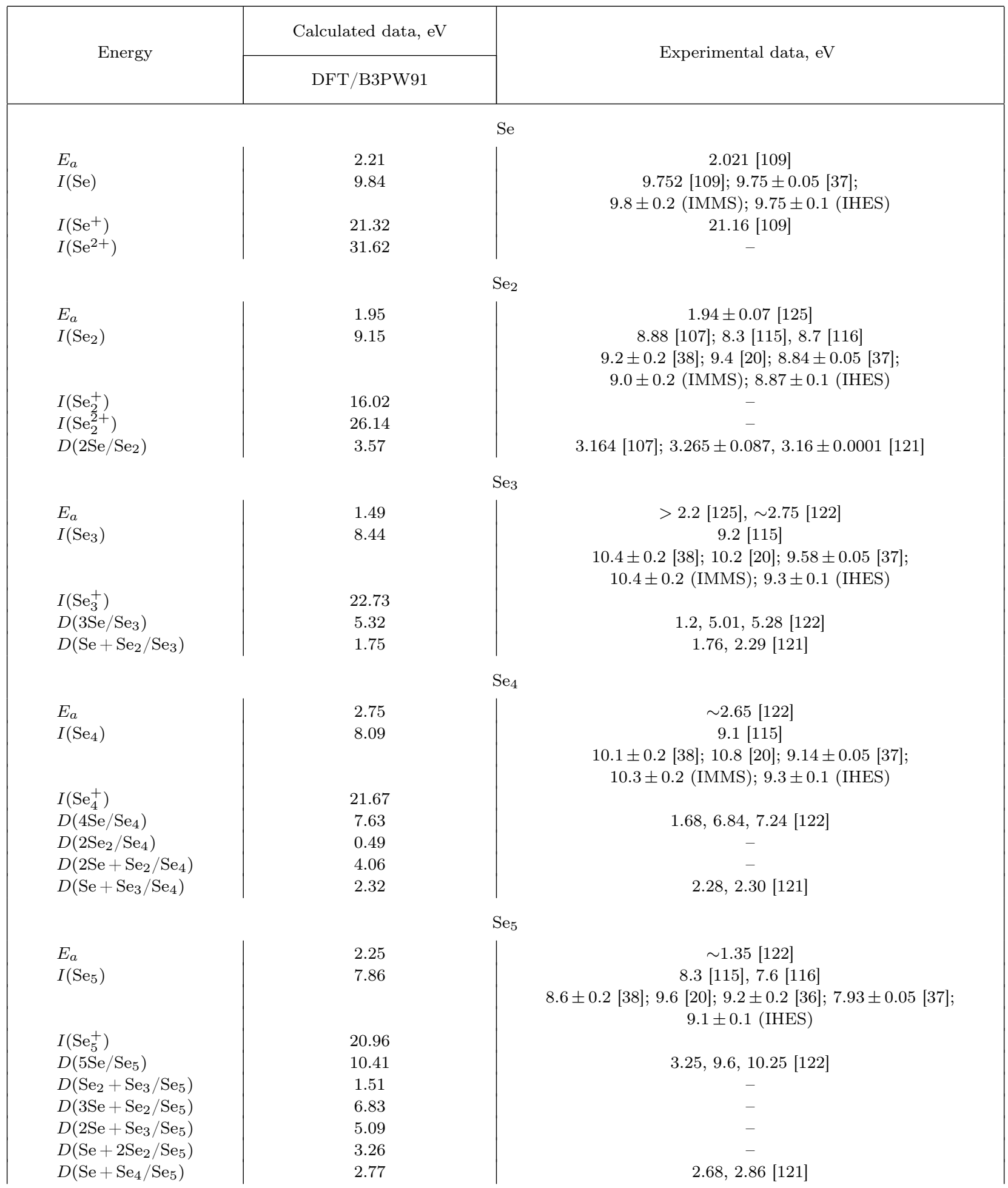


Continuation of Table 13

\begin{tabular}{|c|c|c|}
\hline \multirow{2}{*}{ Energy } & Calculated data, eV & \multirow{2}{*}{ Experimental data, eV } \\
\hline & DFT/B3PW91 & \\
\hline \multicolumn{3}{|c|}{$\mathrm{Se}_{6}$} \\
\hline$E_{a}$ & 1.96 & $\sim 1.41[122]$ \\
\hline$I\left(\mathrm{Se}_{6}\right)$ & 8.12 & $\begin{array}{c}8.4[115], 7.9[116] ; 8.9 \pm 0.2[38] ; 9.7[20] ; \\
9.08 \pm 0.05[36] ; 8.24 \pm 0.05[37] ; 8.5 \pm 0.1 \text { (IHES) }\end{array}$ \\
\hline$I\left(\mathrm{Se}_{6}^{+}\right)$ & 20.64 & $\begin{array}{r}0.00 \pm 0.00[00], 0.24 \perp 0.00[01], 0.0 \perp 0.1(\mathrm{HILN}) \\
-\end{array}$ \\
\hline$D\left(6 \mathrm{Se} / \mathrm{Se}_{6}\right)$ & 12.96 & $4.98,13.02,13.68[122]$ \\
\hline$D\left(2 \mathrm{Se}_{3} / \mathrm{Se}_{6}\right)$ & 2.32 & - \\
\hline$D\left(3 \mathrm{Se}_{2} / \mathrm{Se}_{6}\right)$ & 2.24 & - \\
\hline$D\left(4 \mathrm{Se}+\mathrm{Se}_{2} / \mathrm{Se}_{6}\right)$ & 9.39 & - \\
\hline$D\left(3 \mathrm{Se}+\mathrm{Se}_{3} / \mathrm{Se}_{6}\right)$ & 7.64 & - \\
\hline$D\left(2 \mathrm{Se}+\mathrm{Se}_{4} / \mathrm{Se}_{6}\right)$ & 5.33 & - \\
\hline$D\left(\mathrm{Se}_{2}+\mathrm{Se}_{4} / \mathrm{Se}_{6}\right)$ & 1.75 & - \\
\hline$D\left(\mathrm{Se}+\mathrm{Se}_{5} / \mathrm{Se}_{6}\right)$ & 2.56 & - \\
\hline \multicolumn{3}{|c|}{$\mathrm{Se}_{8}$} \\
\hline$E_{a}$ & 2.23 & $\sim 1.35[122]$ \\
\hline$I\left(\mathrm{Se}_{7}\right)$ & 7.93 & $\begin{array}{c}8.2[115], 7.6[116] ; 8.4 \pm 0.2[38] ; 8.9[20] ; \\
8.87 \pm 0.05[36] ; 7.94 \pm 0.05[37] ; 8.8 \pm 0.1 \text { (IHES) }\end{array}$ \\
\hline$I\left(\mathrm{Se}_{7}^{+}\right)$ & 20.10 & 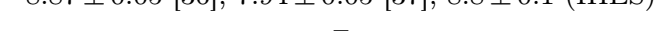 \\
\hline$D\left(7 \mathrm{Se} / \mathrm{Se}_{7}\right)$ & 15.00 & $5.81,15.19,15.96[122]$ \\
\hline$D\left(5 \mathrm{Se}+\mathrm{Se}_{2} / \mathrm{Se}_{7}\right)$ & 11.43 & - \\
\hline$D\left(4 \mathrm{Se}+\mathrm{Se}_{3} / \mathrm{Se}_{7}\right)$ & 9.69 & - \\
\hline$D\left(3 \mathrm{Se}+\mathrm{Se}_{4} / \mathrm{Se}_{7}\right)$ & 7.37 & - \\
\hline$D\left(2 \mathrm{Se}+\mathrm{Se}_{5} / \mathrm{Se}_{7}\right)$ & 4.60 & - \\
\hline$D\left(\mathrm{Se}_{3}+\mathrm{Se}_{4} / \mathrm{Se}_{7}\right)$ & 2.05 & - \\
\hline$D\left(\mathrm{Se}_{2}+\mathrm{Se}_{5} / \mathrm{Se}_{7}\right)$ & 1.03 & - \\
\hline$D\left(\mathrm{Se}+\mathrm{Se}_{6} / \mathrm{Se}_{7}\right)$ & 2.04 & - \\
\hline$D\left(\mathrm{Se}+2 \mathrm{Se}_{3} / \mathrm{Se}_{7}\right)$ & 4.37 & - \\
\hline$D\left(\mathrm{Se}_{2}+\mathrm{Se}_{5} / \mathrm{Se}_{7}\right)$ & 1.03 & - \\
\hline$D\left(2 \mathrm{Se}_{2}+\mathrm{Se}_{3} / \mathrm{Se}_{7}\right)$ & 2.54 & - \\
\hline$D\left(3 \mathrm{Se}_{2}+\mathrm{Se} / \mathrm{Se}_{7}\right)$ & 4.29 & - \\
\hline$D\left(\mathrm{Se}_{3}+\mathrm{Se}_{4} / \mathrm{Se}_{7}\right)$ & 2.05 & - \\
\hline \multicolumn{3}{|c|}{$\mathrm{Se}_{8}$} \\
\hline$E_{a}$ & - & $\sim 1.7[122]$ \\
\hline$I\left(\mathrm{Se}_{8}\right)$ & 7.93 & $\begin{array}{c}8.4[115], 7.8[116] ; 8.6 \pm 0.2[38] ; 9.0[20] ; \\
8.97 \pm 0.05[36] ; 8.11 \pm 0.05[37] ; 8.05 \pm 0.1 \text { (IHES) }\end{array}$ \\
\hline$I\left(\mathrm{Se}_{8}^{+}\right)$ & 19.59 & 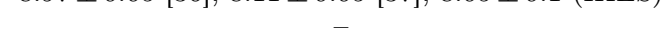 \\
\hline$D\left(8 \mathrm{Se} / \mathrm{Se}_{8}\right)$ & 17.68 & $6.64,17.36,18.24[122]$ \\
\hline$D\left(6 \mathrm{Se}+\mathrm{Se}_{2} / \mathrm{Se}_{8}\right)$ & 14.10 & - \\
\hline$D\left(5 \mathrm{Se}+\mathrm{Se}_{3} / \mathrm{Se}_{8}\right)$ & 12.36 & - \\
\hline$D\left(4 \mathrm{Se}+\mathrm{Se}_{4} / \mathrm{Se}_{8}\right)$ & 10.04 & - \\
\hline$D\left(3 \mathrm{Se}+\mathrm{Se}_{5} / \mathrm{Se}_{8}\right)$ & 7.27 & - \\
\hline$D\left(2 \mathrm{Se}+\mathrm{Se}_{6} / \mathrm{Se}_{8}\right)$ & 4.71 & - \\
\hline$D\left(\mathrm{Se}+\mathrm{Se}_{7} / \mathrm{Se}_{8}\right)$ & 2.67 & - \\
\hline$D\left(\mathrm{Se}_{2}+\mathrm{Se}_{6} / \mathrm{Se}_{8}\right)$ & 1.14 & - \\
\hline$D\left(2 \mathrm{Se}_{2}+\mathrm{Se}_{4} / \mathrm{Se}_{8}\right)$ & 2.89 & - \\
\hline$D\left(4 \mathrm{Se}_{2} / \mathrm{Se}_{8}\right)$ & 3.38 & - \\
\hline$D\left(\mathrm{Se}_{3}+\mathrm{Se}_{5} / \mathrm{Se}_{8}\right)$ & 1.95 & - \\
\hline$D\left(2 \mathrm{Se}_{3}+\mathrm{Se}_{2} / \mathrm{Se}_{8}\right)$ & 3.46 & - \\
\hline$D\left(2 \mathrm{Se}_{4} / \mathrm{Se}_{8}\right)$ & 2.41 & - \\
\hline
\end{tabular}


Table 14. Calculated interatomic distances in $\mathbf{T e}_{\boldsymbol{n}}$ molecules with $n=2 \div 8$ and the corresponding experimental and theoretical data

\begin{tabular}{|c|c|c|c|c|}
\hline \multirow{2}{*}{ Molecule } & \multirow{2}{*}{ Interatomic distances } & \multirow{2}{*}{$\begin{array}{l}\text { Calculated values } \\
r_{n m}, \AA^{*}\end{array}$} & \multicolumn{2}{|c|}{ Literature data $r_{n m}, \AA$} \\
\hline & & & Experiment & Theory \\
\hline $\mathrm{Te}_{8}$ & $\begin{array}{c}r_{\mathrm{Te} m-\mathrm{Te} n} \\
m=1-7 \\
n=(m+1)-8\end{array}$ & 2.8718 & & $2.834 ; 2.74[128]$ \\
\hline $\mathrm{Te}_{7}$ & $\begin{array}{c}r_{\mathrm{Te} 1-\mathrm{Te} 2}, r_{\mathrm{Te} 1-\mathrm{Te} 7}, \\
r_{\mathrm{Te} 2-\mathrm{S} 3}, r_{\mathrm{Te} 6-\mathrm{S} 7}, \\
r_{\mathrm{Te} 3-\mathrm{Te} 4}, r_{\mathrm{Te} 5-\mathrm{Te} 6}, \\
r_{\mathrm{S} 4-\mathrm{S} 5}\end{array}$ & $\begin{array}{c}2.8617,2.9343, \\
2.8386,2.7936, \\
2.9666,3.0351, \\
2.7851\end{array}$ & & \\
\hline $\mathrm{Te}_{6}$ & $\begin{array}{c}r_{\mathrm{Te} m-\mathrm{Te} n} \\
m=1-5 \\
n=(m+1)-6\end{array}$ & 2.8881 & & $2.74643[123]$ \\
\hline $\mathrm{Te}_{5}$ & $\begin{array}{c}r_{\mathrm{Te} 1-\mathrm{Te} 2}, r_{\mathrm{Te} 1-\mathrm{Te} 5}, \\
r_{\mathrm{Te} 2-\mathrm{Te} 3}, r_{\mathrm{Te} 4-\mathrm{Te} 5}, \\
r_{\mathrm{Te} 3-\mathrm{Te} 4}\end{array}$ & $\begin{array}{l}2.9900 \\
2.8535 \\
2.8966\end{array}$ & & $\begin{array}{c}2.7729, \\
2.6988 \\
2,7147[123]\end{array}$ \\
\hline $\mathrm{Te}_{4}$ & $\begin{array}{c}r_{\mathrm{Te} 1-\mathrm{Te} 2}, r_{\mathrm{Te} 3-\mathrm{Te} 4}, \\
r_{\mathrm{Te} 2-\mathrm{Te} 3}, r_{\mathrm{Te} 1-\mathrm{Te} 4}\end{array}$ & $\begin{array}{l}2.9553 \\
2.9551\end{array}$ & & $3.0322[123]$ \\
\hline $\mathrm{Te}_{3}$ & $r_{\mathrm{Te} 1-\mathrm{Ten}}(n=2-3)$ & 2.9195 & & $2.72[123]$ \\
\hline $\mathrm{Te}_{2}$ & $r_{\mathrm{Te}-\mathrm{Te}}$ & 2.6959 & $2.556[105]$ & $2.55 ; 2.5083 ; 2.577[123]$ \\
\hline
\end{tabular}

$\left({ }^{*}\right)$ The values were calculated using the DFT/B3PW91 method.

The interatomic distances for all tellurium molecules calculated in the DFT/B3LYP approximation are given in Table 14. The corresponding theoretical values, $r_{n m}$, were taken from the NIST database for the most accurate available method [103]. The table demonstrates that the interatomic distances calculated by us are somewhat larger than other theoretical results. The interatomic distances in tellurium clusters increase less nonmonotonically, as the number of atoms in the clusters grows. As was already shown for the sulfur and selenium chalcogen molecules, the equilibrium interatomic distances in the ionized tellurium clusters also increase asymmetrically (by about $0.01-0.15 \AA$ ) in comparison with the interatomic distances in the corresponding neutral clusters.

The analysis of the values calculated for the interatomic distances in the $\mathrm{S}_{n}, \mathrm{Se}_{n}$, and $\mathrm{Te}_{n}$ clusters with $n=2 \div 8$ and quoted in Tables 10,12 , and 14 , respectively, brings us to the following conclusions. The distances in clusters with the same number of atoms increase monotonically by tenths of angström. At the transition from selenium to tellurium, this distance growth is larger than at the transition from sulfur to selenium. Furthermore, the maximum interatomic distance in any sulfur cluster is almost always shorter than the minimum distance in the selenium clusters. Analogously, the maximum distance in the selenium clusters is always shorter than the minimum distance in the clusters of the heavy element tellurium.

Experimental and theoretical - calculated by us in the DFT/B3LYP (CEP-112G-ECP) approximation - adiabatic values of the ionization potential $I$, the electron affinity energy $E_{a}$, and the dissociation energy (the binding energy) obtained for some tellurium molecules are given in Table 15. As was in the previous cases of sulfur and selenium, all energy parameters calculated by us were determined adiabatically as the difference between the total energies of the corresponding neutral and ionized systems in the relaxed states. For the diatomic molecule $\mathrm{Te}_{2}$, the calculated value of the dissociation energy is a little lower (by $0.3 \mathrm{eV}$ ) than the value from the reference book [107]. In general, there is a satis- 
Table 15. Calculated adiabatic and experimental energy characteristics $E_{a}, I$, and $D$ of some selenium molecules

\begin{tabular}{|c|c|c|}
\hline \multirow{2}{*}{ Energy } & Calculated data, eV & \multirow{2}{*}{ Experimental data, eV } \\
\hline & $\begin{array}{c}\text { DFT } / \text { B3PW91 } \\
(\mathrm{CEP}-112 \mathrm{G}-\mathrm{ECP})\end{array}$ & \\
\hline \multicolumn{3}{|r|}{$\mathrm{Te}$} \\
\hline$E_{a}$ & 1.84 & $1.971[109]$ \\
\hline$I(\mathrm{Te})$ & 8.71 & $\begin{array}{c}9.5 \pm 1.0[52] ; 8.9[18] ; 8.96[46] ; 9.009[53] ; 7.28[109] \\
8.8 \pm 0.25\end{array}$ \\
\hline$I\left(\mathrm{Te}^{+}\right)$ & 18.87 & $18.6[109]$ \\
\hline$I\left(\mathrm{Te}^{2+}\right)$ & 27.79 & - \\
\hline \multicolumn{3}{|r|}{$\mathrm{Te}_{2}$} \\
\hline$E_{a}$ & 2.09 & $\sim 2.35 ; \sim 2.56[129]$ \\
\hline$I\left(\mathrm{Te}_{2}\right)$ & 8.57 & $\begin{array}{c}8.29[107] ; \sim 7.9[126], 7.87[123], \sim 7.95[129] \\
8.4 \pm 0.6[52] ; 8.3[18] ; 11.71 \pm 0.01[53] \\
8.3 \pm 0.25\end{array}$ \\
\hline$I\left(\mathrm{Te}_{2}^{+}\right)$ & 14.61 & - \\
\hline$I\left(\mathrm{Te}_{2}^{2+}\right)$ & 21.99 & - \\
\hline$D\left(2 \mathrm{Te} / \mathrm{Te}_{2}\right)$ & 2.20 & 2.5 [107]; 2.24 [123], 2.69 [105] \\
\hline \multicolumn{3}{|r|}{$\mathrm{Te}_{3}$} \\
\hline$E_{a}$ & 2.05 & $\sim 2.73 ; \sim 2.92[129]$ \\
\hline$I\left(\mathrm{Te}_{3}\right)$ & 7.90 & $\begin{array}{c}\sim 7.32[126] ; 7.43 ; 8.01[123], \sim 7.7[129] ; 8.2 \pm 0.6[52] ; 9.3[18] \\
8.1 \pm 0.25\end{array}$ \\
\hline$I\left(\mathrm{Te}_{3}^{+}\right)$ & 20.86 & - \\
\hline$D\left(3 \mathrm{Te} / \mathrm{Te}_{3}\right)$ & 3.13 & $3.57[123]$ \\
\hline$D\left(\mathrm{Te}+\mathrm{Te}_{2} / \mathrm{Te}_{3}\right)$ & 0.93 & $\sim 2.4 ; \sim 2.9[129]$ \\
\hline \multicolumn{3}{|r|}{$\mathrm{Te}_{4}$} \\
\hline$E_{a}$ & 2.87 & $\sim 2.4 ; \sim 2.9[129]$ \\
\hline$I\left(\mathrm{Te}_{4}\right)$ & 7.12 & $\sim 7.33[126] ; 6.52$ [123]. 7.45 [129] \\
\hline$I\left(\mathrm{Te}_{4}^{+}\right)$ & 19.33 & - \\
\hline$D\left(4 \mathrm{Te} / \mathrm{Te}_{4}\right)$ & 4.30 & $4.76[123]$ \\
\hline$D\left(\mathrm{Te}_{2}+\mathrm{Te}_{2} / \mathrm{Te}_{4}\right)$ & -0.11 & - \\
\hline$D\left(2 \mathrm{Te}+\mathrm{Te}_{2} / \mathrm{Te}_{4}\right)$ & 2.10 & - \\
\hline$D\left(\mathrm{Te}+\mathrm{Te}_{3} / \mathrm{Te}_{4}\right)$ & 1.17 & $\sim 1.5 ; \sim 1.9[129]$ \\
\hline \multicolumn{3}{|r|}{$\mathrm{Te}_{5}$} \\
\hline$E_{a}$ & 2.52 & $\sim 2.27 ; \sim 2.27[129]$ \\
\hline$I\left(\mathrm{Te}_{5}\right)$ & 7.48 & $\sim 7.25[126] ; 6.60[123], \sim 7.45[129]$ \\
\hline$I\left(\mathrm{Te}_{5}^{+}\right)$ & 19.43 & - \\
\hline$D\left(5 \mathrm{Te} / \mathrm{Te}_{5}\right)$ & 6.56 & $6.01[123]$ \\
\hline$D\left(\mathrm{Te}_{2}+\mathrm{Te}_{3} / \mathrm{Te}_{5}\right)$ & 1.23 & - \\
\hline$D\left(3 \mathrm{Te}+\mathrm{Te}_{2} / \mathrm{Te}_{5}\right)$ & 4.36 & - \\
\hline$D\left(2 \mathrm{Te}+\mathrm{Te}_{3} / \mathrm{Te}_{5}\right)$ & 3.43 & - \\
\hline$D\left(\mathrm{Te}+\mathrm{Te}_{4} / \mathrm{Te}_{5}\right)$ & 2.26 & - \\
\hline$D\left(\mathrm{Te}+2 \mathrm{Te}_{2} / \mathrm{Te}_{5}\right)$ & 2.16 & - \\
\hline
\end{tabular}


Inelastic Processes of Electron Interaction

Continuation of Table 15

\begin{tabular}{|c|c|c|}
\hline \multirow{2}{*}{ Energy } & Calculated data, eV & \multirow{2}{*}{ Experimental data, eV } \\
\hline & $\begin{array}{c}\text { DFT/B3PW91 } \\
(\mathrm{CEP}-112 \mathrm{G}-\mathrm{ECP})\end{array}$ & \\
\hline \multicolumn{3}{|c|}{$\mathrm{Te}_{6}$} \\
\hline $\begin{array}{l}E_{a} \\
I\left(\mathrm{Te}_{6}\right) \\
I\left(\mathrm{Te}_{6}^{+}\right) \\
D\left(6 \mathrm{Te}^{+} / \mathrm{Te}_{6}\right) \\
D\left(2 \mathrm{Te}_{3} / \mathrm{Te}_{6}\right) \\
D\left(3 \mathrm{Te}_{2} / \mathrm{Te}_{6}\right) \\
D\left(\mathrm{Te}_{2}+\mathrm{Te}_{4} / \mathrm{Te}_{6}\right) \\
D\left(4 \mathrm{Te}+\mathrm{Te}_{2} / \mathrm{Te}_{6}\right) \\
D\left(3 \mathrm{Te}+\mathrm{Te}_{3} / \mathrm{Te}_{6}\right) \\
D\left(2 \mathrm{Te}+\mathrm{Te}_{4} / \mathrm{Te}_{6}\right) \\
D\left(\mathrm{Te}+\mathrm{Te}_{5} / \mathrm{Te}_{6}\right)\end{array}$ & $\begin{array}{c}2.62 \\
7.62 \\
19.19 \\
8.26 \\
1.99 \\
1.64 \\
1.75 \\
6.05 \\
5.12 \\
3.95 \\
1.69\end{array}$ & 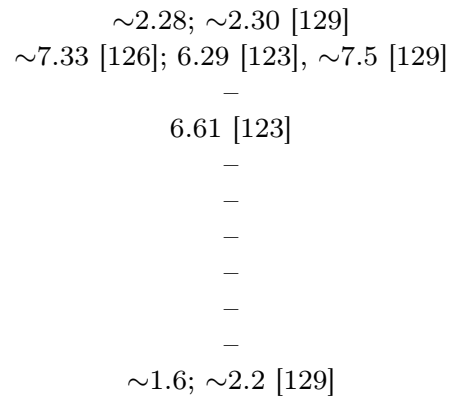 \\
\hline \multicolumn{3}{|c|}{$\mathrm{Te}_{7}$} \\
\hline $\begin{array}{l}E_{a} \\
I\left(\mathrm{Te}_{7}\right) \\
I\left(\mathrm{Te}_{7}^{+}\right) \\
D\left(7 \mathrm{Te} / \mathrm{Te}_{7}\right) \\
D\left(5 \mathrm{Te}+\mathrm{Te}_{2} / \mathrm{Te}_{7}\right) \\
D\left(4 \mathrm{Te}+\mathrm{Te}_{3} / \mathrm{Te}_{7}\right) \\
D\left(3 \mathrm{Te}+\mathrm{Te}_{4} / \mathrm{Te}_{7}\right) \\
D\left(2 \mathrm{Te}+\mathrm{Te}_{5} / \mathrm{Te}_{7}\right) \\
D\left(\mathrm{Te}+\mathrm{Te}_{6} / \mathrm{Te}_{7}\right) \\
D\left(\mathrm{Te}^{+} 2 \mathrm{Te}_{3} / \mathrm{Te}_{7}\right) \\
D\left(\mathrm{Te}_{2}+\mathrm{Te}_{5} / \mathrm{Te}_{7}\right) \\
D\left(2 \mathrm{Te}_{2}+\mathrm{Te}_{3} / \mathrm{Te}_{7}\right) \\
D\left(3 \mathrm{Te}_{2}+\mathrm{Te} / \mathrm{Te}_{7}\right) \\
D\left(\mathrm{Te}_{3}+\mathrm{Te}_{4} / \mathrm{Te}_{7}\right) \\
D\left(2 \mathrm{Te}_{3}+\mathrm{Te}_{7} / \mathrm{Te}_{7}\right)\end{array}$ & $\begin{array}{c}2.67 \\
7.58 \\
18.81 \\
9.58 \\
7.38 \\
6.45 \\
5.28 \\
3.02 \\
1.33 \\
3.31 \\
0.81 \\
2.04 \\
2.97 \\
2.15 \\
3.31\end{array}$ & $\begin{aligned} \sim 2.35 ; & \sim 2.40[129] \\
\sim 7.27[126] & \sim 7.35[129] \\
& - \\
& - \\
& - \\
& - \\
& - \\
& - \\
\sim 1.4 ; & \sim 1.9[129] \\
& - \\
& - \\
& - \\
& - \\
& - \\
& -\end{aligned}$ \\
\hline \multicolumn{3}{|c|}{$\mathrm{Te}_{8}$} \\
\hline $\begin{array}{l}E_{a} \\
I\left(\mathrm{Te}_{8}\right) \\
I\left(\mathrm{Te}_{8}^{+}\right) \\
D\left(8 \mathrm{Te} / \mathrm{Te}_{8}\right) \\
D\left(6 \mathrm{Te}+\mathrm{Te}_{2} / \mathrm{Te}_{8}\right) \\
D\left(5 \mathrm{Te}+\mathrm{Te}_{3} / \mathrm{Te}_{8}\right) \\
D\left(4 \mathrm{Te}+\mathrm{Te}_{4} / \mathrm{Te}_{8}\right) \\
D\left(3 \mathrm{Te}+\mathrm{Te}_{5} / \mathrm{Te}_{8}\right) \\
D\left(2 \mathrm{Te}+\mathrm{Te}_{6} / \mathrm{Te}_{8}\right) \\
D\left(\mathrm{Te}+\mathrm{Te}_{7} / \mathrm{Te}_{8}\right) \\
D\left(4 \mathrm{Te}_{2} / \mathrm{Te}_{8}\right) \\
D\left(3 \mathrm{Te}_{2}+\mathrm{Te}_{2} / \mathrm{Te}_{8}\right) \\
D\left(2 \mathrm{Te}_{2}+\mathrm{Te}_{4} / \mathrm{Te}_{8}\right) \\
D\left(\mathrm{Te}_{2}+\mathrm{Te}_{6} / \mathrm{Te}_{8}\right) \\
D\left(\mathrm{Te}_{3}+\mathrm{Te}_{5} / \mathrm{Te}_{8}\right) \\
D\left(2 \mathrm{Te}_{4} / \mathrm{Te}_{8}\right)\end{array}$ & $\begin{array}{c}2.78 \\
7.67 \\
18.63 \\
11.36 \\
9.16 \\
8.23 \\
7.06 \\
4.80 \\
3.11 \\
1.78 \\
2.55 \\
2.54 \\
2.65 \\
0.90 \\
1.67 \\
2.76\end{array}$ & $\begin{aligned} \sim 2.38 ; & \sim 2.52[129] \\
\sim 7.3 \pm 0.2[126], & \sim 7.55[129] \\
- & - \\
& - \\
& - \\
& - \\
& - \\
& - \\
\sim 1.4 ; & \sim 1.8[129] \\
& - \\
& - \\
& - \\
& - \\
& - \\
- & \end{aligned}$ \\
\hline
\end{tabular}


factory agreement between the presented values (see Table 15).

The values of the electron affinity energy $E_{a}$ calculated for the tellurium atom and the $\mathrm{Te}_{2}$ and $\mathrm{Te}_{3}$ molecules are lower than the corresponding experimental values by $0.13,0.3-0.5$, and $0.7-0.9 \mathrm{eV}$, respectively. But, for the molecules from $\mathrm{Te}_{4}$ to $\mathrm{Te}_{8}$, those energies already exceed the corresponding experimental values by up to $0.4 \mathrm{eV}$. All the results obtained were used to analyze the appearance energy of the tellurium ionic fragments.

\subsection{Formation of the ionic fragments of chalcogen molecules}

Our experimental results together with the experimental and theoretical data on the appearance energies of ionic fragments and the ionization energies of atoms and molecules taken from the literature are summarized in Tables 4 to 6 . We used them to make a comparison with the results of our calculations presented in Tables 16 to 18 . Such a comparison may favor a good qualitative and quantitative analysis of all results aimed at the determination of the gas mixture component that leads, through the process of its DI, to the appearance of that or another ionic fragment.

\subsubsection{Ionic fragments of sulfur molecules}

Singly charged ions of sulfur molecules. As was already mentioned above, the appearance energies of ionic fragments can be experimentally determined by measuring their partial yield cross-sections. For sulfur molecules, such processes were studied in works $[86,96-99]$ in detail.

The adiabatic energy values calculated in two approximations [88] for the appearance of the $\mathrm{S}_{k}^{+}$ sulfur ions from the $\mathrm{S}_{m}$ molecules $(m=8,6,2)$ are presented in Table 16 together with the available experimental data. Our results are shown in bold. In this table, the ionization energy of the parent molecule, $I\left(\mathrm{~S}_{m}\right)$, is put equal to the appearance energy $E_{\mathrm{AP}}\left(\mathrm{S}_{m}^{+} / \mathrm{S}_{m}\right)$. One can see that, in general, there is a satisfactory consistency between the theoretical and experimental values obtained for the appearance energies of sulfur ionic fragments. However, the experimental data on the appearance energy quoted for some ionic fragments can differ rather strongly, by several electronvolts, among themselves. This difference testifies to an uncertainty of the DI channels activated, when measuring the appearance energies using different methods.

The best correspondence of the calculated values with the experimental data is observed for DI of the $\mathrm{S}_{8}$ molecule. This behavior can be observed for all formation reactions of the $\mathrm{S}_{k}^{+}$ionic fragments. The theoretical appearance energies for $\mathrm{S}^{+}$and $\mathrm{S}_{2}^{+}$ions exceed the experimental values by $0.5-1.0 \mathrm{eV}$. For all other channels, the difference between the calculated and measured appearance energies is small, and they are in good agreement. However, it should be noted that the presented experimental data on the appearance energies of some ionic fragments can be quite different. For instance, this difference reaches almost $2.5 \mathrm{eV}$ in the case of the $\mathrm{S}_{3}^{+}$and $\mathrm{S}_{4}^{+}$ions, and up to $1.5 \mathrm{eV}$ for the $\mathrm{S}_{5}^{+}$one.

For DI of the $\mathrm{S}_{6}$ molecule, there is a certain difference between the theoretical and experimental values. A mismatch between the results of two methods applied to calculate the total energies is also rather large in this case. Note that the experimental data on the appearance energy differ by $3.2 \mathrm{eV}$ for the $\mathrm{S}_{2}^{+}$ ions and by $1.7 \mathrm{eV}$ for the $\mathrm{S}_{4}^{+}$ones. The calculated values of $E_{\mathrm{AP}}$ for the $\mathrm{S}_{4}^{+}$and $\mathrm{S}_{3}^{+}$ions are by about 0.5-1.0 eV larger than the experimental results, with this difference being minimum for the $\mathrm{S}_{2}^{+}$ion. Such an insignificant discrepancy between the calculated and measured $E_{\mathrm{AP}}$ values can be explained by the influence of the energy of molecular vibrations. This energy was not taken into consideration, because its account for all fragments is a difficult task. For the $\mathrm{S}^{+} / \mathrm{S}_{2}$ and $\mathrm{S}_{2}^{+} / \mathrm{S}_{2}$ DI channels, the experimental and theoretical $E_{\mathrm{AP}}$ values agree well.

For the $\mathrm{S}_{2}$ molecule, there is a rather good agreement between the experimental and theoretical DI data. But again, the corresponding experimental data on the appearance energies for some ionic fragments differ from one another by almost $1.5 \mathrm{eV}$.

In the case of the $\mathrm{S}_{2}^{+}$ion formation in the processes $\mathrm{S}_{6} \rightarrow \mathrm{S}_{2}^{+}+\mathrm{S}_{3}+\mathrm{S}+\mathrm{e}^{-}$and $\mathrm{S}_{6} \rightarrow \mathrm{S}_{2}^{+}+\mathrm{S}_{2}+2 \mathrm{~S}+\mathrm{e}^{-}$, it is possible to determine the binding energy of a sulfur atom in the $\mathrm{S}_{3}$ molecule, $E_{b}\left(\mathrm{~S}-\mathrm{S}_{2} / \mathrm{S}_{3}\right)$. It is equal to $2.47 \mathrm{eV}$ for the B3PW91 method, and to $2.41 \mathrm{eV}$ for the HF/MP2 one. One can see that the appearance energy of the $\mathrm{S}_{2}^{+}$ion in the former process is lower than that in the latter one. That is, in order to form a four-atom $\mathrm{S}_{4}$ molecule from two $\mathrm{S}_{2}$ molecules, we have to spend an energy of 0.31 or $0.11 \mathrm{eV}$ according to the B3PW91 and HF/MP2 
Table 16. Appearance energies of $\mathbf{S}_{\boldsymbol{k}}^{+}$ionic fragments from $\mathbf{S}_{\mathbf{8}}, \mathbf{S}_{\mathbf{6}}$, and $\mathbf{S}_{\mathbf{2}}$ molecules

\begin{tabular}{|c|c|c|c|c|}
\hline \multirow{2}{*}{ Ions } & \multirow{2}{*}{$\begin{array}{l}\text { Dissociative ionization } \\
\text { channel } \\
\mathrm{e}^{-}+\mathrm{S}_{n}(n=8,6,2) \rightarrow\end{array}$} & \multicolumn{2}{|c|}{$\begin{array}{c}\text { Calculated appearance } \\
\text { energy, eV }\end{array}$} & \multirow{2}{*}{ Experimental appearance energy, eV } \\
\hline & & B3PW91 & $\mathrm{HF} / \mathrm{MP} 2$ & \\
\hline \multicolumn{5}{|c|}{$E_{\mathrm{AP}}\left(\mathrm{S}_{k}^{+} / \mathrm{S}_{8}\right), k=1-8$} \\
\hline $\mathrm{S}_{8}^{+}$ & $\mathrm{S}_{8}^{+}+2 \mathrm{e}^{-}$ & 8.06 & 7.52 & $\begin{array}{c}9.3 \pm 0.2[98,113] ; 7.3 \pm 0.3 \\
9.04 \pm 0.03,9.6 \pm 0.2[114]\end{array}$ \\
\hline $\mathrm{S}_{6}^{+}$ & $\mathrm{S}_{6}^{+}+\mathrm{S}_{2}+2 \mathrm{e}^{-}$ & 9.50 & 9.25 & $9.7[47] ; 9.0[6] ; 9.0[48]$ \\
\hline & $\mathrm{S}_{6}^{+}+2 \mathrm{~S}+2 \mathrm{e}^{-}$ & 14.01 & 13.28 & $\begin{array}{c}10.1 \pm 0.3[114] ; 9.7 \pm 0.3[98] \\
\mathbf{9 . 5} \pm \mathbf{0 . 2}(\text { IMMS); } \mathbf{9 . 5} \pm \mathbf{0 . 3}[96]\end{array}$ \\
\hline $\mathrm{S}_{5}^{+}$ & $\mathrm{S}_{5}^{+}+\mathrm{S}_{3}+2 \mathrm{e}^{-}$ & 10.60 & 11.04 & $\begin{array}{c}8.8[47] ; 9.6[6] ; 8.6[48] ; \\
10.2[114] ; 8.8 \pm 0.2[98] ; \\
\mathbf{8 . 7} \pm \mathbf{0 . 2}(\text { IMMS); } 8.7 \pm \mathbf{0 . 2}[96]\end{array}$ \\
\hline $\mathrm{S}_{4}^{+}$ & $\mathrm{S}_{4}^{+}+2 \mathrm{~S}_{2}+2 \mathrm{e}^{-}$ & 12.97 & 14.01 & $10.1[47] ; 10.4[6]$ \\
\hline & $\mathrm{S}_{4}^{+}+\mathrm{S}_{4}+2 \mathrm{e}^{-}$ & 13.28 & 14.12 & $\begin{array}{c}12.5 \pm 0.3[114] ; 10.2 \pm 0.2[98] ; \mathbf{1 0 . 3} \pm \mathbf{0 . 2}[96] \\
\mathbf{1 0 . 1} \pm \mathbf{0 . 2}(\text { IMMS })\end{array}$ \\
\hline $\mathrm{S}_{3}^{+}$ & $\mathrm{S}_{3}^{+}+\mathrm{S}_{3}+\mathrm{S}_{2}+2 \mathrm{e}^{-}$ & 12.62 & 12.23 & $10.2[47] ; 10.5[6] ; 9.68[48]$ \\
\hline & $\mathrm{S}_{3}^{+}+\mathrm{S}_{5}+2 \mathrm{e}^{-}$ & 12.68 & 12.25 & $\begin{array}{c}12.6 \pm 0.5[114] ; \mathbf{1 0 . 2} \pm \mathbf{0 . 2}(\text { IMMS }) \\
\mathbf{1 0 . 2} \pm \mathbf{0 . 2}[96,98]\end{array}$ \\
\hline $\mathrm{S}_{2}^{+}$ & $\mathrm{S}_{2}^{+}+\mathrm{S}_{6}+2 \mathrm{e}^{-}$ & 10.43 & 10.02 & $\begin{array}{c}9.6[47] ; 9.9[6] ; 9.36[48] \\
9.6 \pm 0.2[98] \\
\mathbf{9 . 6} \pm \mathbf{0 . 2}(\mathbf{I M M S}) ; \mathbf{9 . 5 5} \pm \mathbf{0 . 2}[96]\end{array}$ \\
\hline $\mathrm{S}^{+}$ & $\mathrm{S}^{+}+\mathrm{S}_{4}+\mathrm{S}_{3}+2 \mathrm{e}^{-}$ & 11.07 & 10.84 & $\begin{array}{c}10.4 \pm 0.3[47] ; 10.40 \pm 0.1[98] \\
\mathbf{3 0} \pm \mathbf{0 . 2}(\mathbf{I M M S}) \\
\mathbf{1 0 . 3 6} \pm \mathbf{0 . 1}(\mathbf{I H E S}) \\
\mathbf{1 0 . 3 0} \pm \mathbf{0 . 2}[96]\end{array}$ \\
\hline \multicolumn{5}{|c|}{$E_{\mathrm{AP}}\left(\mathrm{S}_{k}^{+} / \mathrm{S}_{6}\right), k=1-6$} \\
\hline $\mathrm{S}_{6}^{+}$ & $\mathrm{S}_{6}^{+}+2 \mathrm{e}^{-}$ & 8.72 & 8.39 & $\begin{array}{c}9.7[47] ; 9.0[6] ; 9.0[48] \\
9.356 \pm 0.002 ; 9.6 \pm 0.2[113] \\
8.5 \pm 0.3 ; 9.7 \pm 0.3[114] \\
9.2 \pm 0.2[98] ; \\
\mathbf{9 . 5} \pm \mathbf{0 . 2} \text { (IMMS) }\end{array}$ \\
\hline $\mathrm{S}_{4}^{+}$ & $\mathrm{S}_{4}^{+}+\mathrm{S}_{2}+2 \mathrm{e}^{-}$ & 12.19 & 13.15 & $10.1[47] ; 10.4[6]$ \\
\hline & $\mathrm{S}_{4}^{+}+2 \mathrm{~S}+2 \mathrm{e}^{-}$ & 16.69 & 17.18 & $\begin{array}{c}11.94 \pm 0.05[114] \\
\mathbf{1 0 . 3} \pm \mathbf{0 . 2}[96] ; 10.2 \pm 0.2[98]\end{array}$ \\
\hline $\mathrm{S}_{3}^{+}$ & $\mathrm{S}_{3}^{+}+\mathrm{S}_{2}+\mathrm{S}+2 \mathrm{e}^{-}$ & 14.31 & 13.78 & $10.2[47] ; 10.5[6] ; 9.68[48] ;$ \\
\hline & $\mathrm{S}_{3}^{+}+3 \mathrm{~S}+2 \mathrm{e}^{-}$ & 18.81 & 17.81 & $13.3 \pm 0.5[114]$ \\
\hline $\mathrm{S}_{2}^{+}$ & $\mathrm{S}_{2}^{+}+2 \mathrm{~S}_{2}+2 \mathrm{e}^{-}$ & 12.04 & 11.50 & $9.6[47] ; 9.9[6] ; 9.36[48]$ \\
\hline & $\mathrm{S}_{2}^{+}+\mathrm{S}_{4}+2 \mathrm{e}^{-}$ & 12.35 & 11.61 & $12.8 \pm 1.0[114] ; \mathbf{9 . 5 5} \pm \mathbf{0 . 2}[96]$ \\
\hline & $\mathrm{S}_{2}^{+}+\mathrm{S}_{3}+\mathrm{S}+2 \mathrm{e}^{-}$ & 14.07 & 13.12 & $9.6 \pm 0.2[98]$ \\
\hline & $\mathrm{S}_{2}^{+}+\mathrm{S}_{2}+2 \mathrm{~S}+2 \mathrm{e}^{-}$ & 16.54 & 15.53 & $12.8 \pm 1.0[114]$ \\
\hline $\mathrm{S}^{+}$ & $\mathrm{S}^{+}+2 \mathrm{~S}_{2}+\mathrm{S}+2 \mathrm{e}$ & 17.37 & 16.14 & $10.4 \pm 0.3[47] ; 10.40 \pm 0.1[98]$ \\
\hline & $\mathrm{S}^{+}+\mathrm{S}_{3}+\mathrm{S}_{2}+2 \mathrm{e}$ & 14.90 & 13.73 & $10.30 \pm 0.2($ IMMS $)$ \\
\hline & $\mathrm{S}^{+}+\mathrm{S}_{4}+\mathrm{S}+2 \mathrm{e}$ & 17.69 & 16.25 & $10.36 \pm 0.1($ IHES $)$ \\
\hline & $\mathrm{S}^{+}+\mathrm{S}_{5}+2 \mathrm{e}$ & 14.96 & & \\
\hline
\end{tabular}


Continuation of Table 16

\begin{tabular}{|c|c|c|c|c|}
\hline \multirow{2}{*}{ Ions } & \multirow{2}{*}{$\begin{array}{l}\text { Dissociative ionization } \\
\text { channel } \\
\mathrm{e}^{-}+\mathrm{S}_{n}(n=8,6,2) \rightarrow\end{array}$} & \multicolumn{2}{|c|}{$\begin{array}{c}\text { Calculated appearance } \\
\text { energy, eV }\end{array}$} & \multirow{2}{*}{ Experimental appearance energy, eV } \\
\hline & & B3PW91 & $\mathrm{HF} / \mathrm{MP} 2$ & \\
\hline \multicolumn{5}{|c|}{$E_{\mathrm{AP}}\left(\mathrm{S}_{k}^{+} / \mathrm{S}_{2}\right), k=1-2$} \\
\hline $\mathrm{S}_{2}^{+}$ & $\mathrm{S}_{2}^{+}+2 \mathrm{e}^{-}$ & 9.65 & 9.17 & $\begin{aligned} 9.6[47] ; 9.9[6] ; 9.36[48] ; \\
9.356 \pm 0.002[113] ; 9.6 \pm 0.2[98,113] ; 9.4[107] ; \\
\mathbf{9 . 6} \pm \mathbf{0 . 2}(\mathbf{I M M S})\end{aligned}$ \\
\hline $\mathrm{S}^{+}$ & $\mathrm{S}^{+}+\mathrm{S}+2 \mathrm{e}^{-}$ & 14.99 & 13.80 & $\begin{array}{c}10.4 \pm 0.3[47] ; \\
14.732 \pm 0.005[113] ; \\
13.5 \pm 0.5[106] ; \\
14.74 \pm 0.01[114] ; \\
\mathbf{1 0 . 3 0} \pm \mathbf{0 . 2} \text { (IMMS); } \\
\mathbf{1 0 . 3 6} \pm \mathbf{0 . 1} \text { (IHES); } \\
\mathbf{1 0 . 3 0} \pm \mathbf{0 . 2}[96]\end{array}$ \\
\hline
\end{tabular}

methods, respectively. Similar values are obtainedwhen considering the processes $\mathrm{S}_{8} \rightarrow \mathrm{S}_{4}^{+}+2 \mathrm{~S}_{2}+\mathrm{e}^{-}$ and $\mathrm{S}_{8} \rightarrow \mathrm{S}_{4}^{+}+\mathrm{S}_{4}+\mathrm{e}^{-}$.

The appearance energies calculated by us for the $\mathrm{S}_{8} \rightarrow \mathrm{S}_{3}^{+}+\mathrm{S}_{3}+\mathrm{S}_{2}+\mathrm{e}^{-}$and $\mathrm{S}_{8} \rightarrow \mathrm{S}_{3}^{+}+\mathrm{S}_{5}+\mathrm{e}^{-}$reactions are almost identical, although the formation of the $\mathrm{S}_{5}$ molecule in the latter reaction requires a low energy consumption. Probably, this fact may testify that it is very important to take interatomic vibrations into account when calculating the energy structure of polyatomic molecules [90]. It may point to some instability of the $\mathrm{S}_{5}$ molecule with respect to its decay into the $\mathrm{S}_{3}$ and $\mathrm{S}_{2}$ ones. In particular, according to our calculations (see Table 11), the dissociation of this molecule according to the reaction $\mathrm{S}_{5} \rightarrow \mathrm{S}_{2}+\mathrm{S}_{3}$ results in the energy release $D\left(\mathrm{~S}_{2}+\mathrm{S}_{3} / \mathrm{S}_{5}\right)-$ not energy absorption - which is equal to $-0.06 \mathrm{eV}$ in the B3PW91 approximation and $-0.03 \mathrm{eV}$ in the $\mathrm{HF} / \mathrm{MP} 2$ one.

All the data on the appearance energy of the $\mathrm{S}_{n}^{+}$ ( $n=1 \div 6$ ) sulfur ions, which are presented in Table 4 , correspond to the reactions presented in Table 16. In such a way, although with certain reservations, it is possible to identify the molecule in a gaseous mixture, from which a particular ionic fragment was formed through DI.

By analyzing the data given in Table 16, we can draw the following conclusion. The formation of the $\mathrm{S}_{n}^{+}(n=1 \div 6)$ ions may probably occur owing to the direct rather than dissociative ionization of the parent atoms and molecules, because the ionization poten- tials of those systems are almost equal to the appearance energies of their ions (see Tables 4 and 11). A small difference on either side between those values may result from shortcomings of theoretical approximations used in the calculation, in particular, the neglect of the energy of molecular vibrations.

Note that the presence of parent molecules in excited (electron or vibrational) states decreases the appearance energy of ionic fragments by the state excitation energy. Furthermore, the simultaneous formation of the corresponding cation and anion through the electron capture by a neutral fragment at DI of the molecule will result in a reduction of the fragment appearance energy by the electron affinity energy of this fragment.

The maximum and minimum values calculated forthe appearance energy of some sulfur ionic fragments using the DFT/B3PW91 method are shown in Figs. $17\left[E_{\mathrm{AP}}\left(\mathrm{S}_{k}^{+} / \mathrm{S}_{8}\right), k \leq 8\right], 18\left[E_{\mathrm{AP}}\left(\mathrm{S}^{+} / \mathrm{S}_{n}\right)\right.$, $1 \leq n \leq 8]$, and $19\left[E_{\mathrm{AP}}\left(\mathrm{S}_{2}^{+} / \mathrm{S}_{n}\right), 2 \leq n \leq 8\right]$. The appearance energy maximum corresponds to a complete separation of the residual neutral molecule into atomic fragments. The appearance energy minimum corresponds to the cases where the residual neutral part comprises a molecule, i.e., all its atoms are bound. The appearance energy can be lower than the indicated minimum value only for the formation of a negative molecular ion from the residual molecule.

From the dependences shown in Figs. 17 to 19, one can see that the minimum appearance energy is more sensitive to the energy parameters of the formed frag-

ISSN 2071-0194. Ukr. J. Phys. 2020. Vol. 65, No. 7 
ments in comparison with the maximum appearance energy. According to DFT/B3PW91 calculations, the maxima of the minimum appearance energies are as follows: $E_{\mathrm{AP}}\left(\mathrm{S}_{k}^{+}-\mathrm{S}_{8-k} / \mathrm{S}_{8}\right)=13.28 \mathrm{eV}$ at $k=4$, $E_{\mathrm{AP}}\left(\mathrm{S}^{+}-\mathrm{S}_{n-1} / \mathrm{S}_{n}\right)=14.96 \mathrm{eV}$ at $n=6$, and $E_{\mathrm{AP}}\left(\mathrm{S}_{2}^{+}-\mathrm{S}_{n-2} / \mathrm{S}_{n}\right)=12.37 \mathrm{eV}$ at $n=7$. At the same time, the minima of the minimum appearance energies are $E_{\mathrm{AP}}\left(\mathrm{S}_{k}^{+}-\mathrm{S}_{8-k} / \mathrm{S}_{8}\right)=9.5 \mathrm{eV}$ at $k=6, E_{\mathrm{AP}}\left(\mathrm{S}^{+}-\mathrm{S}_{n-1} / \mathrm{S}_{n}\right)=12.2 \mathrm{eV}$ at $n=4$, and $E_{\mathrm{AP}}\left(\mathrm{S}_{2}^{+}-\mathrm{S}_{n-2} / \mathrm{S}_{n}\right)=9.34 \mathrm{eV}$ at $n=4$.

Doubly charged ions of sulfur molecules. The maximum and minimum appearance energy values calculated for singly charged ionic fragments $\mathrm{S}_{k}^{+}$with $k=1 \div 8$ (see Figs. 17 to 19 ) can be used to determine the appearance energies for doubly charged ionic fragments $\mathrm{S}_{k}^{2+}$. For this purpose, in accordance with formulas (36) and (37), the ionization potentials of $\mathrm{S}_{k}^{+}$ ions have to be added to the corresponding energies.

Recall that Table 4 contains the appearance energies for doubly $\left(\mathrm{S}^{2+}\right.$ and $\left.\mathrm{S}_{2}^{2+}\right)$ and triply $\left(\mathrm{S}_{2}^{3+}\right)$ charged sulfur molecular ions, which were measured by us with the help of the MMS and HES methods; namely, $21.9 \pm 0.2,17.37 \pm 0.1$, and $29.40 \pm 0.1 \mathrm{eV}$, respectively. The values obtained are in good agreement with the data of work [65], which may testify to the observation of those ions in the same reactions.

Let us consider possible reactions giving rise to the formation of doubly charged ions. The formation of the $\mathrm{S}^{2+}$ ion from the $\mathrm{S}_{n}$ molecule in the process

$\mathrm{S}_{n}+\mathrm{e}^{-} \rightarrow \mathrm{S}^{2+}+\mathrm{S}_{n-1}+3 \mathrm{e}^{-}$

is characterized by the appearance energy which can be calculated from the formula

$E_{\mathrm{AP}}\left[\mathrm{S}^{2+}-\mathrm{S}_{n-1} / \mathrm{S}_{n}\right]=I(\mathrm{~S})+I\left(\mathrm{~S}^{+}\right)+D\left(\mathrm{~S}-\mathrm{S}_{n-1} / \mathrm{S}_{n}\right)$.

In particular, if the $\mathrm{S}^{2+}$ ion appears in the process $\mathrm{S}_{2}+\mathrm{e}^{-} \rightarrow \mathrm{S}^{2+}+\mathrm{S}+3 \mathrm{e}^{-}$, the appearance energy can be equal to $38.098 \mathrm{eV}$ (here, according to handbook data $[107,109]$, we put $I(S) \approx 10.360 \mathrm{eV}, I\left(S^{+}\right)=$ $=23.338 \mathrm{eV}$, and $\left.D\left(\mathrm{~S}-\mathrm{S} / \mathrm{S}_{2}\right)=4.4 \mathrm{eV}\right)$. The value of $E_{\mathrm{AP}}\left[\mathrm{S}^{2+}-\mathrm{S} / \mathrm{S}_{2}\right]$ calculated according to the data of Table 11 equals $38.406 \mathrm{eV}$ (B3PW91) or $37.019 \mathrm{eV}$ ( $\mathrm{HF} / \mathrm{MP} 2)$.

If the $\mathrm{S}^{2+}$ ion is formed from the molecular ion $\mathrm{S}_{n}^{+}$ in the process

$\mathrm{S}_{n}^{+}+\mathrm{e}^{-} \rightarrow \mathrm{S}^{2+}+\mathrm{S}_{n-1}+2 \mathrm{e}^{-}$,

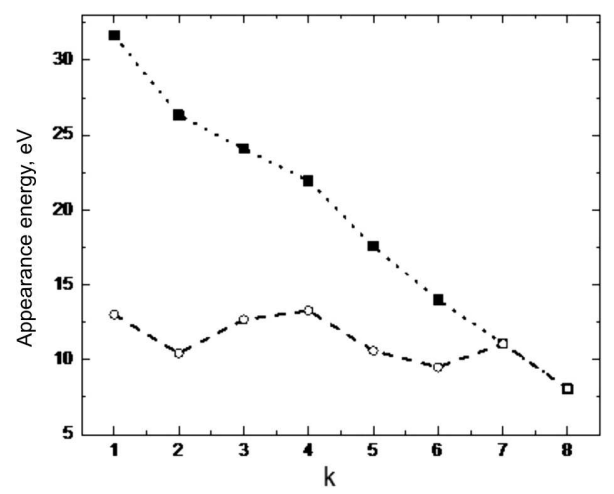

Fig. 17. Calculated maximum $\left(E_{\mathrm{AP}}\left[\mathrm{S}_{k}^{+}-(8-k) \mathrm{S} / \mathrm{S}_{8}\right]\right.$, and minimum $\left(E_{\mathrm{AP}} \mathrm{S}_{k}^{+}-\mathrm{S}_{8-k} / \mathrm{S}_{8}, \circ\right)$ appearance energies of the $\mathrm{S}_{k}^{+}$ionic fragments with $k \leq 8$. At $k=8$, the ionization energy of the $\mathrm{S}_{8}$ molecule was used

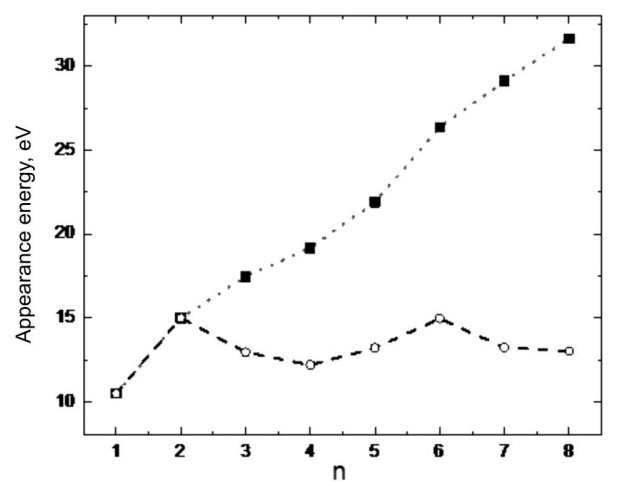

Fig. 18. Maximum $\left(E_{\mathrm{AP}}\left[\mathrm{S}^{+}-(n-1) \mathrm{S} / \mathrm{S}_{n}\right], \mathbf{\square}\right)$ and minimum $\left(E_{\mathrm{AP}}\left(\mathrm{S}^{+}-\mathrm{S}_{n-1} / \mathrm{S}_{n}\right), \circ\right)$ appearance energies of the $\mathrm{S}^{+}$ionic fragment calculated for $1 \leq n \leq 8$. At $n=1$, the ionization energy of the $\mathrm{S}$ atom was used

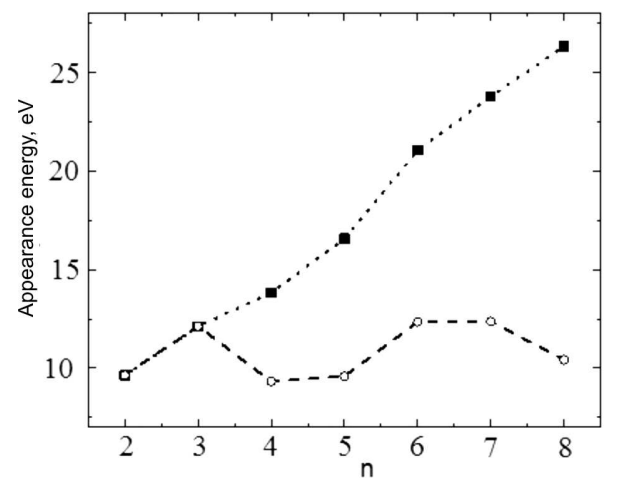

Fig. 19. Maximum $\left(E_{\mathrm{AP}}\left[\mathrm{S}_{2}^{+}-(n-2) \mathrm{S} / \mathrm{S}_{n}\right]\right.$, $)$ and minimum $\left(E_{\mathrm{AP}}\left(\mathrm{S}_{2}^{+}-\mathrm{S}_{n-2} / \mathrm{S}_{n}\right)\right.$, o $)$ appearance energies of the $\mathrm{S}_{2}^{+}$ionic fragment calculated for $2 \leq n \leq 8$. At $n=2$, the ionization energy of the $S_{2}$ molecule was used 
its appearance energy equals

$E_{\mathrm{AP}}\left[\mathrm{S}^{2+}-\mathrm{S}_{n-1} / \mathrm{S}_{n}^{+}\right]=I\left(\mathrm{~S}^{+}\right)+D\left(\mathrm{~S}^{+}-\mathrm{S}_{n-1} / \mathrm{S}_{n}^{+}\right)$.

This value is lower than the ion appearance energy in the previous process either by the magnitude of the ionization potential $I\left(\mathrm{~S}_{n}\right)$ of an $\mathrm{S}_{n}$ molecule or by the magnitude of the ionization potential of an $\mathrm{S}$ atom and the dissociation energy $D\left(\mathrm{~S}^{+}-\mathrm{S}_{n-1} / \mathrm{S}_{n}^{+}\right)$of the molecular ion. For instance, in the case of diatomic $(n=2)$ molecules, the appearance energy $E_{\mathrm{AP}}\left[\mathrm{S}^{2+}-\right.$ $\left.\mathrm{S} / \mathrm{S}_{2}^{+}\right]=28.698 \mathrm{eV}$; here, we used the ion dissociation energy [107]

$D\left(\mathrm{~S}^{+}-\mathrm{S} / \mathrm{S}_{2}^{+}\right)=$

$=D\left(\mathrm{~S}-\mathrm{S} / \mathrm{S}_{2}\right)-I\left(\mathrm{~S}_{2}\right)+I(\mathrm{~S})=5.36 \mathrm{eV}$.

The calculated value of $E_{\mathrm{AP}}\left[\mathrm{S}^{2+}-\mathrm{S} / \mathrm{S}_{2}^{+}\right]$equals 28.756 or $27.849 \mathrm{eV}$, if, according to Table 11, $I\left(\mathrm{~S}^{+}\right)==23.426$ or $23.209 \mathrm{eV}$, respectively. If the sulfur atom captures an electron in the course of this reaction, then the energy $E_{\mathrm{AP}}\left[\mathrm{S}^{2+}-\mathrm{S}^{-} / \mathrm{S}_{2}^{+}\right]$will be lower than $E_{\mathrm{AP}}\left[\mathrm{S}^{2+}-\mathrm{S} / \mathrm{S}_{2}^{+}\right]$by the magnitude of $E_{a}(\mathrm{~S})$, which was put equal to $2.0077 \mathrm{eV}$ [109] or $2.157 \mathrm{eV}$ in our calculations. So, in the case of DI of the $\mathrm{S}_{2}^{+}$ion, the appearance energy of the $\mathrm{S}^{2+}$ ion equals $26.6903 \mathrm{eV}$ [109], and the appearance energy of the $\mathrm{S}^{-}$ion equals 26.629 or $26.049 \mathrm{eV}$ depending on whether the DFT/B3PW91 or HF/MP2 method, respectively, was applied in calculations.

Finally, if the $\mathrm{S}^{2+}$ ion is formed through the direct ionization of the atomic $\mathrm{S}^{+}$ion,

$\mathrm{S}^{+}+\mathrm{e}^{-} \rightarrow \mathrm{S}^{2+}+2 \mathrm{e}^{-}$,

the corresponding appearance energy $E_{\mathrm{AP}}\left[\mathrm{S}^{2+} / \mathrm{S}^{+}\right]=$ $I\left(\mathrm{~S}^{+}\right)=23.338 \mathrm{eV}$ [109]. According to our calculations, $I\left(S^{+}\right)=23.426$ or $23.209 \mathrm{eV}$. Hence, even the presented appearance energies of the $\mathrm{S}^{2+}$ ion in this process exceed the experimental value of $21.9 \pm 0.2 \mathrm{eV}$ by $1.31-1.53 \mathrm{eV}$.

If $\mathrm{S}^{2+}$ ions are produced owing to DI of initial systems in excited states, then the energy of their appearance will be reduced by the state excitation energy. For example, ionic fragments can be formed from the excited states of parent molecules. The first electron-excited state $B^{3} \Sigma_{u}^{-}$of the $\mathrm{S}_{2}^{*}$ molecule has an energy of $3.91 \mathrm{eV}$ [107]. Hence, the energy of the ionic fragment appearance will be lower by the magnitude of this parent-molecule excitation energy. Analogously, $\mathrm{S}^{2+}$ ions can be formed from the excited state of either the molecular ion $\mathrm{S}_{2}^{+*}$ or the atomic ion $\mathrm{S}^{+*}$ [109]. In the latter case, the excitation energies from 1.8 to $3 \mathrm{eV}$ correspond to metastable terms of the $3 p^{3}$ configuration with lifetimes ranging from $50-80 \mathrm{~min}\left({ }^{2} D\right.$ terms $)$ to $5-3.5 \mathrm{~s}\left({ }^{2} P\right.$ terms). Configurations ranging from $3 s 3 p^{4}$ to $3 p^{2} 3 d$ with transition-allowed terms correspond to energies varying from 9.8 to $13 \mathrm{eV}$, but their lifetimes are about a few nanoseconds.

In the case of doubly or triply charged molecular ions, the energies of their appearance have to be lower. For instance, according to the results of our calculations, the formation of the doubly charged molecular ion $\mathrm{S}_{2}^{2+}$ in the process of direct ionization of the singly charged ion $\mathrm{S}_{2}^{+}$, i.e., $\mathrm{S}_{2}^{+}+\mathrm{e}^{-} \rightarrow \mathrm{S}_{2}^{2+}+2 \mathrm{e}^{-}$, is characterized by the value $I\left(\mathrm{~S}_{2}^{+}\right)=17.31 \mathrm{eV}$. It is lower than $I\left(\mathrm{~S}^{+}\right)$and very close to the experimental values. An analogous formation of the triply charged ion $\mathrm{S}_{2}^{3+}$ in the process of direct ionization of the doubly charged ion $\mathrm{S}_{2}^{2+}$, i.e., $\mathrm{S}_{2}^{2+}+\mathrm{e}^{-} \rightarrow \mathrm{S}_{2}^{3+}+2 \mathrm{e}^{-}$, is characterized by the value $I\left(\mathrm{~S}_{2}^{2+}\right)=29.22 \mathrm{eV}$. It is also very close to the experimental value. According to our calculations, the direct ionization of a neutral molecule $\mathrm{S}_{2}$ is characterized by the following total energies: $I\left(\mathrm{~S}_{2}\right)+I\left(\mathrm{~S}_{2}^{+}\right)=26.96 \mathrm{eV}$ for the double ionization and $I\left(\mathrm{~S}_{2}\right)+I\left(\mathrm{~S}_{2}^{+}\right)+I\left(\mathrm{~S}_{2}^{2+}\right)=56.18 \mathrm{eV}$ for the triple ionization.

Thus, our calculations brought us to a conclusion that the formation of the $\mathrm{S}_{2}^{2+}$ and $\mathrm{S}_{2}^{3+}$ ions occurs in the process of direct ionization of $\mathrm{S}_{2}^{+}$and $\mathrm{S}_{2}^{2+}$ ions, respectively. It can be a result of the single ionization of a diatomic sulfur molecule $\mathrm{S}_{2}$ and followed by the ionization processes of its singly and doubly charged ions that are already available or appear in the gas mixture.

The energy balance $E$ for three channels $-A_{n}^{2+} \rightarrow$ $\rightarrow A^{+}+A_{n-1}^{+}, A_{n}^{2+} \rightarrow A^{2+}+A_{n-1}$, and $A_{n}^{2+} \rightarrow$ $\rightarrow A+A_{n-1}^{2+}-$ describing the formation of pairs of ionic fragments from the $A_{n}^{2+}$ ions can be found using the following expressions:

$$
\begin{aligned}
& E\left(\mathrm{~A}^{+}-\mathrm{A}_{n-1}^{+} / \mathrm{A}_{n}^{2+}\right)=I\left(\mathrm{~A}_{n}\right)+I\left(\mathrm{~A}_{n}^{+}\right)- \\
& -I(\mathrm{~A})-I\left(\mathrm{~A}_{n-1}-E\left(\mathrm{~A}-\mathrm{A}_{n-1} / \mathrm{A}_{n}\right)\right. \\
& E\left(\mathrm{~A}^{2+}-\mathrm{A}_{n-1} / \mathrm{A}_{n}^{2+}\right)=I\left(\mathrm{~A}_{n}\right)+I\left(\mathrm{~A}_{n}^{+}\right)- \\
& -I(\mathrm{~A})-I\left(\mathrm{~A}^{+}\right)-D\left(\mathrm{~A}-\mathrm{A}_{n-1} / \mathrm{A}_{n}\right) \\
& E\left(\mathrm{~A}-\mathrm{A}_{n-1}^{2+} / \mathrm{A}_{n}^{2+}\right)=I\left(\mathrm{~A}_{n}\right)+I\left(\mathrm{~A}_{n}^{+}\right)- \\
& -I\left(\mathrm{~A}_{n-1}\right)-I\left(\mathrm{~A}_{n-1}^{+}\right)-E\left(\mathrm{~A}-\mathrm{A}_{n-1} / \mathrm{A}_{n}\right) .
\end{aligned}
$$


Only the first reaction corresponds to the Coulombic decay, because one of the fragments in two other reactions is neutral. These neutral fragments can be excited further: the atomic fragments into electronic excited states, and the molecular fragments into electronic, vibrational, or rotational excited ones.

As was already indicated above, if $E<0$, i.e., if the absolute value of the total energy of the initial ion $A_{n}^{2+}$ is larger than the sum of the absolute values of the total energies of the final components, then the molecular ion $A_{n}^{2+}$ is stable. In order to break it, the energy $E$ has to be supplied. If $E>0$, the ion is unstable and decays into the indicated fragments with the release of energy. In the case of sulfur with $n=2$, the energy balance calculated in the B3PW91 approximation for the above-indicated reactions with the $\mathrm{S}_{2}^{2+}$ ions equals $1.5 \mathrm{eV}$ in the $2 \mathrm{~S}^{+} / \mathrm{S}_{2}^{2+}$ channel and $-11.446 \mathrm{eV}$ in the $\mathrm{S}^{2+}-\mathrm{S} / \mathrm{S}_{2}^{2+}$ channel. Of course, the doubly charged $A_{n}^{2+}$ ion can also decay into other fragments preserving the total charge. From whence, it follows that the $\mathrm{S}_{2}^{2+}$ ion is unstable with respect to the decay into two $\mathrm{S}^{+}$ions, which fly apart with a total kinetic energy of $1.5 \mathrm{eV}$.

Figure 20 demonstrates the dependences of the energy balance in the reactions of the fragment pair formation from the $\mathrm{S}_{n}^{2+}$ ions on the the number of atoms $n$ in those ions calculated in the B3PW91 approximation for three reaction channels. One can see that the $\mathrm{S}_{n}^{2+}$ ions are unstable with respect to their decay into two ions, $\mathrm{S}^{+}$and $\mathrm{S}_{n-1}^{+}$, for all $n=2 \div 8$. The released energy is maximum $(12.55 \mathrm{eV})$ at $n=3$ and is spent for the kinetic energy of the $\mathrm{S}^{+}$and $\mathrm{S}_{2}^{+}$ions, and it is minimum $(1.5 \mathrm{eV})$ at $n=2$ and is spent for the appearance of two $\mathrm{S}^{+}$ions. Note that, in the cases where the $\mathrm{S}_{n}^{2+}$ ion decays into a doubly charged and a neutral fragment, $\left(\mathrm{S}^{2+}, \mathrm{S}_{2}\right)$ and $\left(\mathrm{S}_{2}^{2+}, \mathrm{S}\right)$, the calculated energy balance also reaches a maximum at $n=3$. In the latter case, the $\mathrm{S}$ and $\mathrm{S}_{2}^{2+}$ fragments appear owing to a real decay with a total energy release of $5.72 \mathrm{eV}$. But there is no decay at other $n$ in the indicated cases, and the $S_{n}^{2+}$ ions are stable.

\subsubsection{Ionic fragments of selenium molecules}

Singly charged ions of selenium molecules. In Table 17, the calculated appearance energies of the $\mathrm{Se}_{k}^{+}$ ionic fragments from the $\mathrm{Se}_{8}, \mathrm{Se}_{6}$, and $\mathrm{Se}_{2}$ molecules are given and compared with experimental data. Our results (cf. Table 5) are also presented in bold. An

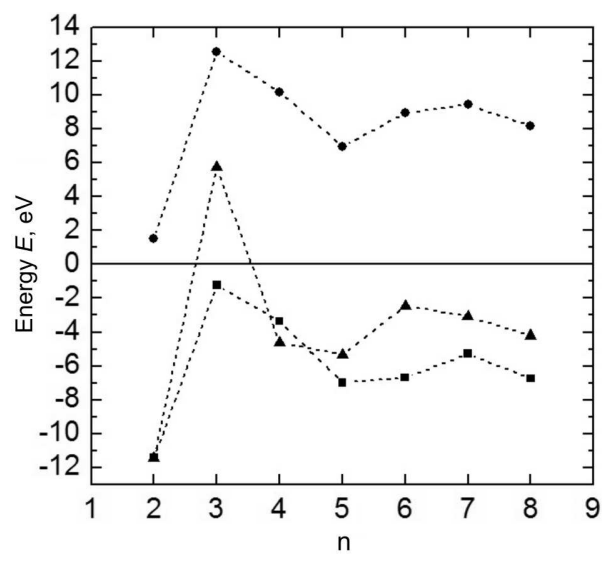

Fig. 20. Energy balance $E$ calculated for the formation reactions of fragment pairs from the $\mathrm{S}_{n}^{2+}$ ions with $n=2 \div 8$ through the channels $\mathrm{S}^{+}-\mathrm{S}_{n-1}^{+} / \mathrm{S}_{n}^{2+}(\bullet), \mathrm{S}^{2+}-\mathrm{S}_{n-1} / \mathrm{S}_{n}^{2+}$ (ם), and $\mathrm{S}-\mathrm{S}_{n-1}^{2+} / \mathrm{S}_{n}^{2+}(\mathbf{\Delta})$

analysis of the data allows us to assert that, in the majority of cases, the $\mathrm{Se}_{n}^{+}(n=1 \div 8)$ ions are formed in the process of direct rather than dissociative ionization from the parent atom or molecule, because the ionization potentials of those systems are almost identical to the appearance energies of their ions (see Tables 13 and 5). In other words, now the ion appearance energy is determined by the ionization potential of the parent system. Small deviations between those values may be induced by shortcomings of theoretical approximations used in calculations, in particular, by the neglect of vibrational energies in the initial and final states of the molecule.

In the case of DI process, the account for the dissociation energy will result in its addition to the corresponding molecular ionization potentials $\left.I \mathrm{Se}_{n}\right)$. This increment will substantially increase the appearance energy obtained in our calculations for $\mathrm{Se}_{2}(3.57 \mathrm{eV})$ and $\mathrm{Se}_{3}(1.75 \mathrm{eV})$ (see Table 13). The presence of excited electron or vibrational states in the initial molecules will decrease the appearance energy of ionic fragments by the state excitation energy. Analogously, the formation of a negative ion from a neutral fragment in the process of electron-impact DI of the molecule will reduce the appearance energy of this fragment by the magnitude of the electron affinity energy.

In Figs. 21 to 23, the calculated maximum and minimum values of the appearance energy are depicted for some selenium ionic fragments: $E_{\mathrm{AP}}\left(\mathrm{Se}_{k}^{+} / \mathrm{Se}_{8}\right)$ 
Table 17. Appearance energies of $\mathrm{Se}_{k}^{+}$ionic fragments from $\mathrm{Se}_{8}, \mathrm{Se}_{6}$, and $\mathrm{Se}_{2}$ molecules

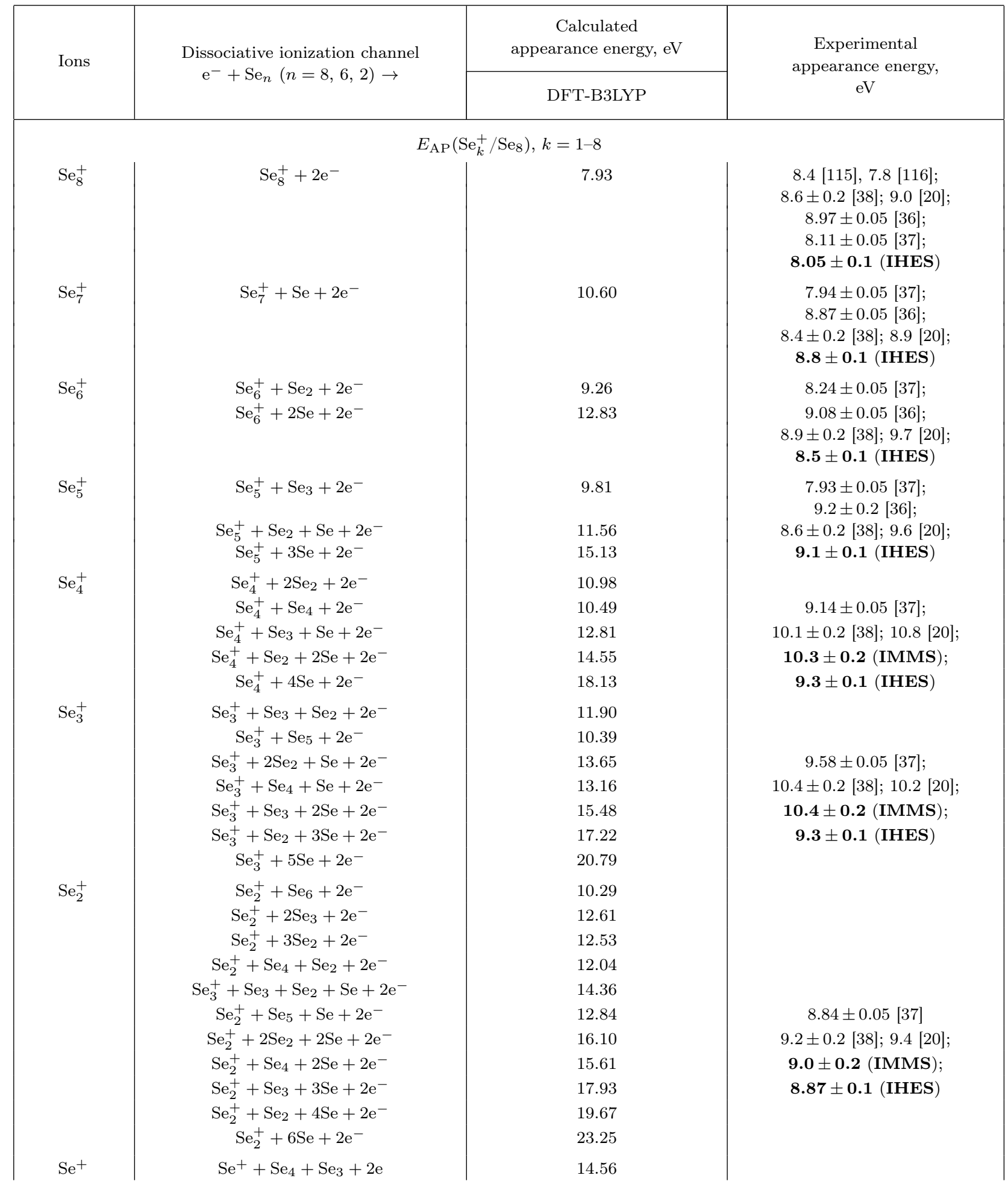


Continuation of Table 17

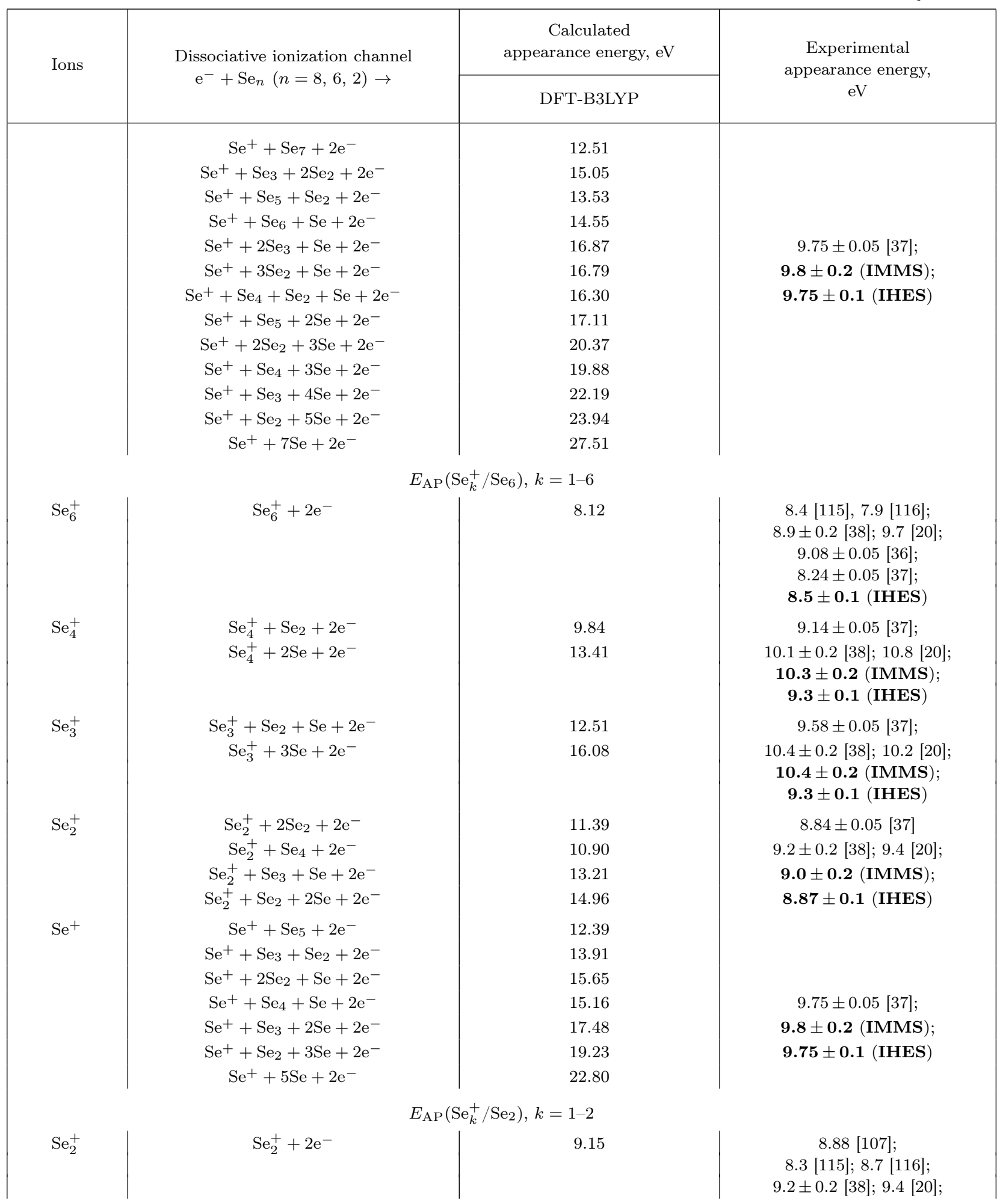


Continuation of Table 17

\begin{tabular}{|c|c|c|c|}
\hline \multirow{2}{*}{ Ions } & \multirow{2}{*}{$\begin{array}{l}\text { Dissociative ionization channel } \\
\quad \mathrm{e}^{-}+\mathrm{Se}_{n}(n=8,6,2) \rightarrow\end{array}$} & $\begin{array}{c}\text { Calculated } \\
\text { appearance energy, eV }\end{array}$ & \multirow{2}{*}{$\begin{array}{c}\text { Experimental } \\
\text { appearance energy, } \\
\mathrm{eV}\end{array}$} \\
\hline & & DFT-B3LYP & \\
\hline \multirow[b]{2}{*}{$\mathrm{Se}^{+}$} & \multirow[b]{2}{*}{$\mathrm{Se}^{+}+\mathrm{Se}+2 \mathrm{e}^{-}$} & \multirow[b]{2}{*}{13.41} & $\begin{array}{c}8.84 \pm 0.05[37] \\
\mathbf{9 . 0} \pm \mathbf{0 . 2}(\text { IMMS }) \\
\mathbf{8 . 8 7} \pm \mathbf{0 . 1}(\text { IHES })\end{array}$ \\
\hline & & & $\begin{array}{c}12.0 \pm 0.5[130] ; \\
12.6 \pm 0.5[131] ; \\
9.75 \pm 0.05[37] ; \\
\mathbf{9 . 8} \pm \mathbf{0 . 2} \text { (IMMS); } \\
\mathbf{9 . 7 5} \pm \mathbf{0 . 1} \text { (IHES) }\end{array}$ \\
\hline
\end{tabular}

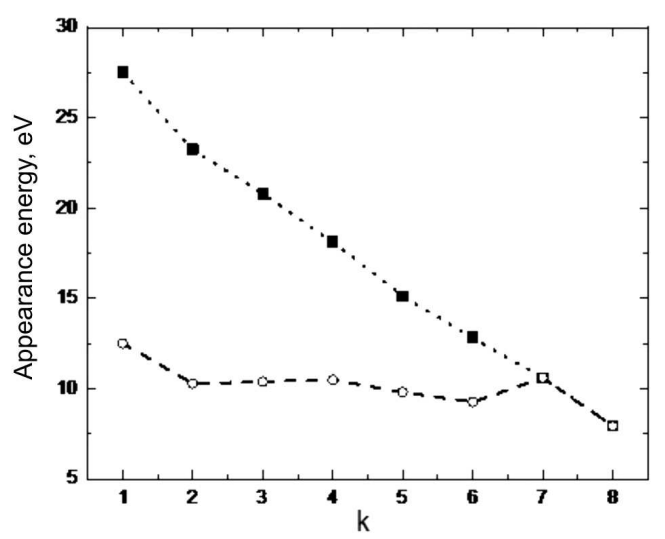

Fig. 21. Calculated maximum $\left(E_{\mathrm{AP}}\left[\mathrm{Se}_{k}^{+}-(8-k) \mathrm{Se} / \mathrm{Se}_{8}\right]\right.$, and minimum $\left(E_{\mathrm{AP}}\left(\mathrm{Se}_{k}^{+}-\mathrm{Se}_{8-k} / \mathrm{Se}_{8}\right), \circ\right)$ appearance energies of the $\mathrm{Se}_{k}^{+}$ionic fragments with $k \leq 8$. At $k=8$, the ionization energy of the $\mathrm{Se}_{8}$ molecule was used

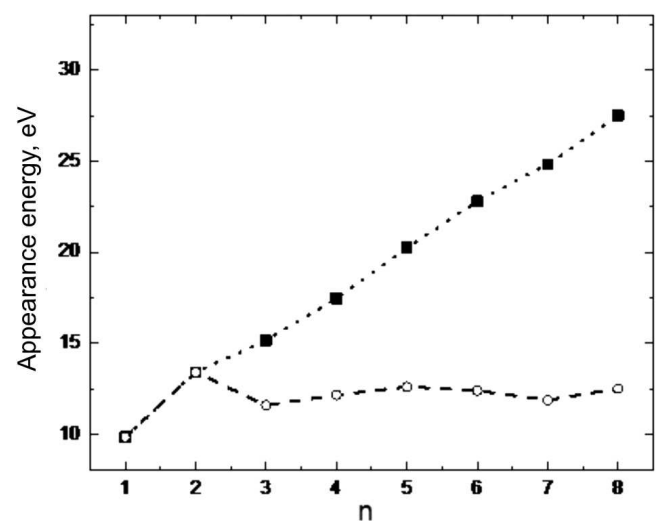

Fig. 22. Maximum $\left(E_{\mathrm{AP}}\left[\mathrm{Se}^{+}-(n-1) \mathrm{Se} / \mathrm{Se}_{n}\right], \mathbf{\square}\right)$ and minimum $\left(E_{\mathrm{AP}}\left(\mathrm{Se}^{+}-\mathrm{Se}_{n-1} / \mathrm{Se}_{n}\right), \circ\right)$ appearance energies of the $\mathrm{Se}^{+}$ionic fragment calculated for $1 \leq n \leq 8$. At $n=1$, the ionization energy of a Se atom was used with $k \leq 8, E_{\mathrm{AP}}\left(\mathrm{Se}^{+} / \mathrm{Se}_{n}\right)$ with $1 \leq n \leq 8$, and $E_{\mathrm{AP}}\left(\mathrm{Se}_{2}^{+} / \mathrm{Se}_{n}\right)$ with $2 \leq n \leq 8$, respectively. The figures demonstrate that the appearance energy minimum is also more sensitive to changes in the energy parameters of the formed fragments in comparison with the appearance energy maximum, as it was in the case of sulfur clusters, but to a less extent. The maximum values of the minimum appearance energies are as follows: $E_{\mathrm{AP}}\left(\mathrm{Se}_{k}^{+}-\mathrm{Se}_{8-k} / \mathrm{Se}_{8}\right)=12.51 \mathrm{eV}$ at $k=1, E_{\mathrm{AP}}\left(\mathrm{Se}^{+}-\mathrm{Se}_{n-1} / \mathrm{Se}_{n}\right)=13.41 \mathrm{eV}$ at $n=2$, and $E_{\mathrm{AP}}\left(\mathrm{Se}_{2}^{+}-\mathrm{Se}_{n-2} / \mathrm{Se}_{n}\right)=10.89 \mathrm{eV}$ at $n=3$. At the same time, the minimum values of the minimum appearance energies are $E_{\mathrm{AP}}\left(\mathrm{Se}_{k}^{+}-\mathrm{Se}_{8-k} / \mathrm{Se}_{8}\right)=$ $=9.81 \mathrm{eV}$ at $k=6, E_{\mathrm{AP}}\left(\mathrm{Se}^{+}-\mathrm{Se}_{n-1} / \mathrm{Se}_{n}\right)=9.84 \mathrm{eV}$ at $n=1$, and $E_{\mathrm{AP}}\left(\mathrm{Se}_{2}^{+}-\mathrm{Se}_{n-2} / \mathrm{Se}_{n}\right)=9.63 \mathrm{eV}$ at $n=4$. One can see that the presented appearance energies for the selenium clusters are somewhat lower in comparison with those obtained for the sulfur ones.

Doubly charged ions of selenium molecules. The value of the appearance energy experimentally measured by us for the $\mathrm{Se}^{2+}$ ion equals $21.2 \pm 0.2 \mathrm{eV}$ (see Table 5). Let us consider the possible formation reactions of doubly charged ions. For instance, the formation of the $\mathrm{Se}^{2+}$ ion from the $\mathrm{Se}_{n}$ molecule in the process

$\mathrm{Se}_{n}+\mathrm{e}^{-} \rightarrow \mathrm{Se}^{2+}+\mathrm{Se}_{n-1}+3 \mathrm{e}^{-}$

is characterized by the appearance energy, which can be calculated according to the formula

$E_{\mathrm{AP}}\left[\mathrm{Se}^{2+}-\mathrm{Se}_{n-1} / \mathrm{Se}_{n}\right]=$ $=I(\mathrm{Se})+I\left(\mathrm{Se}^{+}\right)+D\left(\mathrm{Se}-\mathrm{Se}_{n-1} / \mathrm{Se}_{n}\right)$.

In particular, if the $\mathrm{Se}^{2+}$ ion is formed in the process $\mathrm{Se}_{2}+\mathrm{e}^{-} \rightarrow \mathrm{Se}^{2+}+\mathrm{Se}+3 \mathrm{e}^{-}$

ISSN 2071-0194. Ukr. J. Phys. 2020. Vol. 65, No. 7 
this energy can achieve the value of $E_{\mathrm{AP}}\left[\mathrm{Se}^{2+}-\right.$ $\left.-\mathrm{Se} / \mathrm{Se}_{2}\right]=34.076 \mathrm{eV}$ (here, we used the handbook data $I(\mathrm{Se})=9.752 \mathrm{eV}, I\left(\mathrm{Se}^{+}\right)=21.16 \mathrm{eV}$, and $\left.D\left(2 \mathrm{Se} / \mathrm{Se}_{2}\right)=3.164 \mathrm{eV}[107,109]\right)$. The value calculated by us according to the data quoted in Table 13 equals $E_{\mathrm{AP}}\left[\mathrm{Se}^{2+}-\mathrm{Se} / \mathrm{Se}_{2}\right]=34.73 \mathrm{eV}$.

If the $\mathrm{Se}^{2+}$ ion is formed from a $\mathrm{Se}_{n}^{+}$molecular ion in the process

$\mathrm{Se}_{n}^{+}+\mathrm{e}^{-} \rightarrow \mathrm{Se}^{2+}+\mathrm{Se}_{n-1}+2 \mathrm{e}^{-}$,

its appearance energy equals

$$
\begin{aligned}
& E_{\mathrm{AP}}\left[\mathrm{Se}^{2+}-\mathrm{Se}_{n-1} / \mathrm{Se}_{n}^{+}\right]= \\
& =I\left(\mathrm{Se}^{+}\right)+D\left(\mathrm{Se}^{+}-\mathrm{Se}_{n-1} / \mathrm{Se}_{n}^{+}\right) .
\end{aligned}
$$

This value is lower than the $\mathrm{Se}^{2+}$ appearance energy in the previous process by the magnitude of the ionization potential of a $\mathrm{Se}_{2}$ molecule. In particular, in the case of diatomic molecules $(n=2)$, it equals $E_{\mathrm{AP}}\left[\mathrm{Se}^{2+}-\mathrm{Se} / \mathrm{Se}_{2}^{+}\right]=25.26 \mathrm{eV}$ (here, we put $D\left(\mathrm{Se}^{+}-\mathrm{Se} / \mathrm{Se}_{2}^{+}\right)=4.1 \mathrm{eV}$ [107]). Our calculated value is $E_{\mathrm{AP}}\left[\mathrm{Se}^{2+}-\mathrm{Se} / \mathrm{Se}_{2}^{+}\right]=25.58 \mathrm{eV}$.

Finally, if the formation of the $\mathrm{Se}^{2+}$ ion occurs through the direct ionization of the $\mathrm{Se}^{+}$atomic ion,

$\mathrm{Se}^{+}+\mathrm{e}^{-} \rightarrow \mathrm{Se}^{2+}+2 \mathrm{e}^{-}$,

it is characterized by the appearance energy $E_{\mathrm{AP}}\left[\mathrm{Se}^{2+} / \mathrm{Se}^{+}\right]=I\left(\mathrm{Se}^{+}\right)=21.16 \mathrm{eV}$ [109]. This value is close to our experimental result of $21.2 \pm$ $\pm 0.2 \mathrm{eV}$ (see Table 5) and to our calculated value $I\left(\mathrm{Se}^{+}\right)=21.32 \mathrm{eV}$. Hence, a conclusion can be drawn that the $\mathrm{Se}^{2+}$ ions emerge owing to the direct ionization of $\mathrm{Se}^{+}$atomic ions that are available or appear in the gaseous mixture.

In the case of direct ionization of the diatomic molecular ion $\mathrm{Se}_{2}^{+}$,

$\mathrm{Se}_{2}^{+}+\mathrm{e}^{-} \rightarrow \mathrm{Se}_{2}^{2+}+2 \mathrm{e}^{-}$,

the calculated appearance energy equals $E_{\mathrm{AP}}\left[\mathrm{Se}_{2}^{2+} / \mathrm{Se}_{2}^{+}\right]=I\left(\mathrm{Se}_{2}^{+}\right)=16.02 \mathrm{eV}$. This is about $5 \mathrm{eV}$ lower than the indicated above appearance energy of the $\mathrm{Se}^{2+}$ atomic ion at the direct ionization of the $\mathrm{Se}^{+}$ion.

The values calculated by us for the maximum and minimum appearance energies of the ionic fragments $\mathrm{Se}_{k}^{+}$with $k=1 \div 8$ and presented in Figs. 21 to 23 can also be used to determine the analogous appearance

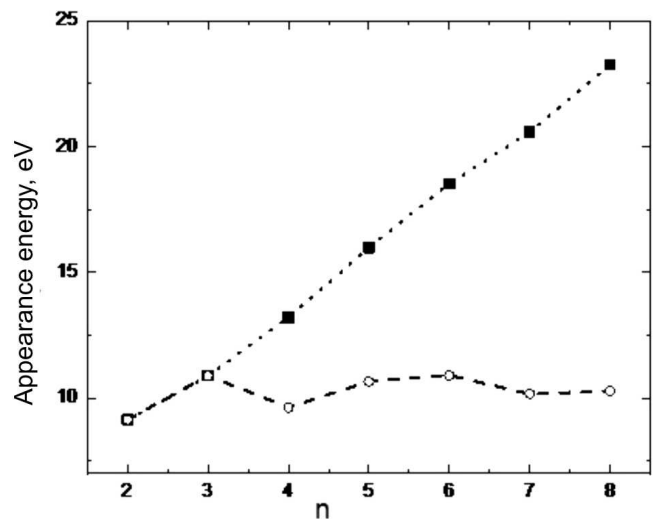

Fig. 23. Maximum $\left(E_{\mathrm{AP}}\left[\mathrm{Se}_{2}^{+}-(n-2) \mathrm{Se} / \mathrm{Se}_{n}\right], \mathbf{\square}\right)$ and minimum $\left(E_{\mathrm{AP}}\left(\mathrm{Se}_{2}^{+}-\mathrm{Se}_{n-2} / \mathrm{Se}_{n}\right), \circ\right)$ appearance energies of the $\mathrm{Se}_{2}^{+}$ionic fragment calculated for $2 \leq n \leq 8$. At $n=2$, the ionization energy of a $\mathrm{Se}_{2}$ molecule was used

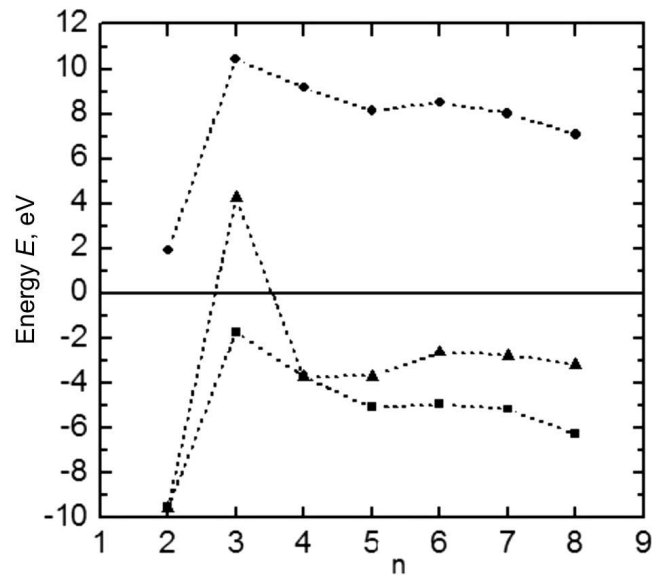

Fig. 24. Energy balance $E$ calculated for the formation reactions of fragment pairs from the $\mathrm{Se}_{n}^{2+}$ ions with $n=2 \div 8$ through the channels $\mathrm{Se}^{+}-\mathrm{Se}_{n-1}^{+}(\bullet), \mathrm{Se}^{2+}-\mathrm{Se}_{n-1}(\boldsymbol{\square})$, and $\mathrm{Se}-\mathrm{Se}_{n-1}^{2+}$

energies for doubly charged ionic fragments $\mathrm{Se}_{k}^{2+}$. For this purpose, in accordance with the formulas given above, the corresponding energies should be summed up with the ionization potentials of $\mathrm{Se}_{k}^{+}$ions.

The energy balance for reactions (43) with $\mathrm{Se}_{2}^{2+}$ ions calculated in the DFT/B3LYP approximation equals $1.92 \mathrm{eV}$ for $2 \mathrm{Se}^{+} / \mathrm{Se}_{2}^{2+}$ and $-9.56 \mathrm{eV}$ for $\mathrm{Se}^{2+}-\mathrm{Se} / \mathrm{Se}_{2}^{2+}$. From whence, it follows that the $\mathrm{Se}_{2}^{2+}$ ion is unstable with respect to its decay into two $\mathrm{Se}^{+}$ ions, which fly apart with a total kinetic energy of $1.92 \mathrm{eV}$. Figure 24 illustrates the dependences of the energy balance on the number of atoms $n$ calculated in the DFT/B3LYP approximation for three chan- 
nels of the reaction giving rise to the formation of fragment pairs from the $\mathrm{Se}_{n}^{2+}$ ion. One can see that the $\mathrm{Se}_{n}^{2+}$ ions are unstable with respect to their decay into two ions, $\mathrm{Se}^{+}$and $\mathrm{Se}_{n-1}^{+}$, for all $n=2 \div 8$. The maximum energy $(10.43 \mathrm{eV})$ is released at $n=3$ as the kinetic energy of the $\mathrm{Se}^{+}$and $\mathrm{Se}_{2}^{+}$ions, and the minimum energy $(1.92 \mathrm{eV})$ is released at $n=2$ as the kinetic energy of two $\mathrm{Se}^{+}$ions.

Note that, in the case of the $\mathrm{Se}_{n}^{2+}$ ion decay into doubly charged ionic and neutral fragments $-\mathrm{Se}^{2+}$, $\left.\mathrm{Se}_{2}\right)$ or $\left(\mathrm{Se}_{2}^{2+}, \mathrm{Se}\right)$ - the calculated energy balance also reaches a maximum at $n=3$. In the latter case, the appearance of the Se atom and the $\mathrm{Se}_{2}^{2+}$ ion is a real decay with a total released energy of $4.25 \mathrm{eV}$. For other $n$ values, there are no decays in the indicated cases, i.e., the $\mathrm{Se}_{n}^{2+}$ ions are stable.

\subsubsection{Ionic fragments of tellurium molecules}

Singly charged ions of tellurium molecules. Table 18 contains the appearance energies for the ionic fragments of tellurium molecules calculated by us in the DFT/B3LYP approximation. Table 6 contains our experimental values for the appearance energies of some tellurium ions and the ionization energies of the tellurium atom and some tellurium molecules, which we used in Table 18.

The calculated ionization energy of a Te atom is equal to $8.71 \mathrm{eV}$, and this value is close to the experimental ones given in Table 15 . If the $\mathrm{Te}^{+}$ion is formed in the DI process

$\mathrm{e}^{-}+\mathrm{Te}_{2} \rightarrow \mathrm{Te}^{+}+\mathrm{Te}+2 \mathrm{e}^{-}$

(see Table 18), then the calculated appearance energy $E_{\mathrm{AP}}\left[\mathrm{Te}^{+}-\mathrm{Te} / \mathrm{Te}_{2}\right]=10.91 \mathrm{eV}$ [see the energies $I(\mathrm{Te})$ and $D\left(2 \mathrm{Te} / \mathrm{Te}_{2}\right)$ in Table 15]. A value of $10.97 \mathrm{eV}$, which is obtained for the process

$\mathrm{e}^{-}+\mathrm{Te}_{5} \rightarrow \mathrm{Te}^{+}+\mathrm{Te}_{4}+2 \mathrm{e}^{-}$,

is also close to it. As one can see, those values are in good agreement with an experimental value of $10.9 \pm$ $\pm 0.25 \mathrm{eV}$ given above. For other processes

$\mathrm{e}^{-}+\mathrm{Te}_{n} \rightarrow \mathrm{Te}^{+}+\mathrm{Te}_{n-1}+2 \mathrm{e}^{-}$,

where $n=1$ (ionization of the atom), 3, 4, 6, 7, and 8 , the appearance energies are slightly lower in magnitude owing to lower dissociation energy values $D\left(\mathrm{Te}-\mathrm{Te}_{n-1} / \mathrm{Te}_{n}\right)$. According to the estimates made in Section 3, the concentration of $\mathrm{Te}_{2}$ molecules in the gas is high. Therefore, we may assume that it is DI of the $\mathrm{Te}_{2}$ molecule that gives rise to the formation of the $\mathrm{Te}^{+}$ion.

For the direct ionization of a $\mathrm{Te}_{2}$ molecule $(n=2)$, an energy of $8.57 \mathrm{eV}$ is required, which is lower than the appearance energy $(9.2 \pm 0.25 \mathrm{eV})$ and close to the ionization energy $(8.3 \pm 0.25 \mathrm{eV})$, the both being measured by us. In the case where the $\mathrm{Te}_{2}^{+}$ion is formed in the DI process

$\mathrm{e}^{-}+\mathrm{Te}_{3} \rightarrow \mathrm{Te}_{2}^{+}+\mathrm{Te}+2 \mathrm{e}$,

the appearance energy calculated by us $E_{\mathrm{AP}}\left[\mathrm{Te}_{2}^{+}-\right.$ $\left.-\mathrm{Te} / \mathrm{Te}_{3}\right]=9.50 \mathrm{eV}$ [according to Table 15, the energies $I\left(\mathrm{Te}_{2}\right)=8.57 \mathrm{eV}$ and $D\left(\mathrm{Te}_{2}-\mathrm{Te} / \mathrm{Te}_{3}\right)=$ $=0.93 \mathrm{eV}]$. This value is $0.3 \mathrm{eV}$ higher than the experimental appearance energy given above. Using the experimental value $I\left(\mathrm{Te}_{2}\right)=8.3 \pm 0.25 \mathrm{eV}$ and our calculated value $D\left(\mathrm{Te}_{2}-\mathrm{Te} / \mathrm{Te}_{3}\right)=0.93 \mathrm{eV}$, we obtain $E_{\mathrm{AP}}\left(\mathrm{Te}_{2}^{+}-\mathrm{Te} / \mathrm{Te}_{3}\right)=9.23 \mathrm{eV}$. Thus, we may assume that the $\mathrm{Te}_{2}^{+}$ion is formed due to DI of a $\mathrm{Te}_{3}$ molecule.

In the cases $n=7$ and 8 , the appearance energies of the $\mathrm{Te}_{2}^{+}$ion will also be close to the corresponding experimental values because of the small values for $D\left(\mathrm{Te}_{2}-\mathrm{Te}_{5} / \mathrm{Te}_{7}\right)$ and $D\left(\mathrm{Te}_{2}-\mathrm{Te}_{6} / \mathrm{Te}_{8}\right)$. In the DI processes

$\mathrm{e}^{-}+\mathrm{Te}_{n} \rightarrow \mathrm{Te}_{2}^{+}+\mathrm{Te}_{n-2}+2 \mathrm{e}^{-}$

with $n=5$ and 6 , the appearance energies of the $\mathrm{Te}_{2}^{+}$ ion are larger due to the larger values of $D\left(\mathrm{Te}_{2}-\right.$ $\left.-\mathrm{Te}_{n-2} / \mathrm{Te}_{n}\right)$. The dissociation energy $D\left(2 \mathrm{Te}_{2} / \mathrm{Te}_{4}\right)$ obtained by us is negative, i.e., this cluster must decay through such a channel, which increases the number of diatomic tellurium molecules.

For the direct ionization of a $\mathrm{Te}_{3}$ molecule $(n=3)$, an energy of $7.90 \mathrm{eV}$ is required, which is slightly lower than our experimental ionization energy of $8.1 \pm 0.25 \mathrm{eV}$ and an ionization energy of $8.2 \pm 0.6 \mathrm{eV}$ measured in work [52]. If the $\mathrm{Te}_{3}^{+}$ion is formed in the DI process

$\mathrm{e}^{-}+\mathrm{Te}_{4} \rightarrow \mathrm{Te}_{3}^{+}+\mathrm{Te}+2 \mathrm{e}^{-}$,

the appearance energy calculated by us $E_{\mathrm{AP}}\left[\mathrm{Te}_{3}^{+}-\right.$ $\left.-\mathrm{Te} / \mathrm{Te}_{4}\right]=9.07 \mathrm{eV}\left[I\left(\mathrm{Te}_{3}\right)=7.90 \mathrm{eV}\right.$ and $D\left(\mathrm{Te}_{3}-\right.$ $\left.-\mathrm{Te} / \mathrm{Te}_{4}\right)=1.17 \mathrm{eV}$, see Table 15]. This value is also close to $9.3 \mathrm{eV}$ from work [18]. The appearance

ISSN 2071-0194. Ukr. J. Phys. 2020. Vol. 65, No. 7 
Table 18. Appearance energies of $\mathrm{Te}_{k}^{+}$ionic fragments from $\mathrm{Te}_{8}, \mathrm{Te}_{6}$, and $\mathrm{Te}_{2}$ molecules

\begin{tabular}{|c|c|c|c|}
\hline \multirow{2}{*}{ Ions } & \multirow{2}{*}{$\begin{array}{l}\text { Dissociative ionization channel } \\
\quad \mathrm{e}^{-}+\mathrm{Te}_{n}(n=8,6,2) \rightarrow\end{array}$} & $\begin{array}{c}\text { Calculated } \\
\text { appearance energy, eV }\end{array}$ & \multirow{2}{*}{$\begin{array}{l}\text { Experimental } \\
\text { appearance energy, } \\
\mathrm{eV}\end{array}$} \\
\hline & & DFT/B3LYP & \\
\hline \multicolumn{4}{|c|}{$E_{\mathrm{AP}}\left(\mathrm{Te}_{k}^{+} / \mathrm{Te}_{8}\right), k=1-8$} \\
\hline $\mathrm{Te}_{8}^{+}$ & $\mathrm{Te}_{8}^{+}+2 \mathrm{e}^{-}$ & 7.67 & $\begin{array}{l}\sim 7.3 \pm 0.2[126] \\
\quad \sim 7.55[129]\end{array}$ \\
\hline $\mathrm{Te}_{6}^{+}$ & $\begin{array}{l}\mathrm{Te}_{6}^{+}+\mathrm{Te}_{2}+2 \mathrm{e}^{-} \\
\mathrm{Te}_{6}^{+}+2 \mathrm{Te}+2 \mathrm{e}^{-}\end{array}$ & $\begin{array}{c}8.52 \\
10.73\end{array}$ & \\
\hline $\mathrm{Te}_{5}^{+}$ & $\mathrm{Te}_{5}^{+}+\mathrm{Te}_{3}+2 \mathrm{e}^{-}$ & 9.15 & \\
\hline $\mathrm{Te}_{4}^{+}$ & $\begin{array}{l}\mathrm{Te}_{4}^{+}+2 \mathrm{Te}_{2}+2 \mathrm{e}^{-} \\
\mathrm{Te}_{4}^{+}+\mathrm{Te}_{4}+2 \mathrm{e}^{-}\end{array}$ & $\begin{array}{l}9.78 \\
9.88\end{array}$ & \\
\hline $\mathrm{Te}_{3}^{+}$ & $\begin{array}{c}\mathrm{Te}_{3}^{+}+\mathrm{Te}_{3}+\mathrm{Te}_{2}+2 \mathrm{e}^{-} \\
\mathrm{Te}_{3}^{+}+\mathrm{Te}_{5}+2 \mathrm{e}^{-}\end{array}$ & $\begin{array}{c}10.79 \\
9.57\end{array}$ & $\begin{array}{c}\text { Ionization energy } \\
8.2 \pm 0.6[52] ; 9.3[18] \\
8.1 \pm 0.25\end{array}$ \\
\hline $\mathrm{Te}_{2}^{+}$ & $\mathrm{Te}_{2}^{+}+\mathrm{Te}_{6}+2 \mathrm{e}^{-}$ & 9.48 & $\begin{array}{c}\text { Ionization energy } \\
8.4 \pm 0.6[52] ; \\
8.3 \pm 0.2[18] ; \\
11.71 \pm 0.01[38] ; \\
8.3 \pm 0.25 \\
\text { Appearance energy } \\
9.00[20] ; 8.26[46] ; \\
9.0 \pm 0.2[51] ; 9.2 \pm 0.25\end{array}$ \\
\hline $\mathrm{Te}^{+}$ & $\mathrm{Te}^{+}+\mathrm{Te}_{4}+\mathrm{Te}_{3}+2 \mathrm{e}^{-}$ & 12.46 & $\begin{array}{c}\text { Ionization energy } \\
9.5 \pm 1.0[52] ; 8.9[18] \\
8.96[46] ; 9.009[53] ; \\
8.8 \pm 0.25\end{array}$ \\
\hline & & & $\begin{array}{c}\text { Appearance energy } \\
12.20[20] ; \\
10.8 \pm 0.5[18] ; \\
8.8 \pm 0.2[51] ; 10.9 \pm 0.25\end{array}$ \\
\hline \multicolumn{4}{|c|}{$E_{\mathrm{AP}}\left(\mathrm{Te}_{k}^{+} / \mathrm{Te}_{6}\right), k=1-6$} \\
\hline $\mathrm{Te}_{6}^{+}$ & $\mathrm{Te}_{6}^{+}+2 \mathrm{e}^{-}$ & 7.62 & $\begin{array}{c}\sim 7.33[126] ; 6.29[123] \\
\sim 7.5[129]\end{array}$ \\
\hline $\mathrm{Te}_{4}^{+}$ & $\begin{array}{l}\mathrm{Te}_{4}^{+}+\mathrm{Te}_{2}+2 \mathrm{e}^{-} \\
\mathrm{Te}_{4}^{+}+2 \mathrm{Te}+2 \mathrm{e}^{-}\end{array}$ & $\begin{array}{c}8.87 \\
11.08\end{array}$ & \\
\hline $\mathrm{Te}_{3}^{+}$ & $\begin{array}{c}\mathrm{Te}_{3}^{+}+\mathrm{Te}_{2}+\mathrm{Te}+2 \mathrm{e}^{-} \\
\mathrm{Te}_{3}^{+}+3 \mathrm{Te}+2 \mathrm{e}^{-}\end{array}$ & $\begin{array}{l}10.82 \\
13.02\end{array}$ & $\begin{array}{l}8.2 \pm 0.6[52] ; 9.3[18] \\
8.1 \pm 0.25\end{array}$ \\
\hline \multirow[t]{3}{*}{$\mathrm{Te}_{2}^{+}$} & $\mathrm{Te}_{2}^{+}+2 \mathrm{Te}_{2}+2 \mathrm{e}^{-}$ & 10.22 & Ionization energy \\
\hline & $\begin{array}{c}\mathrm{Te}_{2}^{+}+\mathrm{Te}_{4}+2 \mathrm{e}^{-} \\
\mathrm{Te}_{2}^{+}+\mathrm{Te}_{3}+\mathrm{Te}+2 \mathrm{e}^{-}\end{array}$ & $\begin{array}{l}10.32 \\
11.49\end{array}$ & $\begin{array}{c}8.4 \pm 0.6[52] ; \\
8.3 \pm 0.2[18] ; \\
11.71 \pm 0.01[38] \\
8.3 \pm 0.25\end{array}$ \\
\hline & $\mathrm{Te}_{2}^{+}+\mathrm{Te}_{2}+2 \mathrm{Te}+2 \mathrm{e}^{-}$ & 12.42 & $\begin{array}{c}\text { Appearance energy } \\
9.00[20] ; 8.26[46] ; \\
9.0 \pm 0.2[51] ; 9.2 \pm 0.25\end{array}$ \\
\hline
\end{tabular}


Continuation of Table 18

\begin{tabular}{|c|c|c|c|}
\hline \multirow{2}{*}{ Ions } & \multirow{2}{*}{$\begin{array}{l}\text { Dissociative ionization channel } \\
\quad \mathrm{e}^{-}+\mathrm{Te}_{n}(n=8,6,2) \rightarrow\end{array}$} & $\begin{array}{c}\text { Calculated } \\
\text { appearance energy, eV }\end{array}$ & \multirow{2}{*}{$\begin{array}{c}\text { Experimental } \\
\text { appearance energy, } \\
\mathrm{eV}\end{array}$} \\
\hline & & DFT/B3LYP & \\
\hline $\mathrm{Te}^{+}$ & $\begin{array}{c}\mathrm{Te}^{+}+\mathrm{Te}_{5}+2 \mathrm{e}^{-} \\
\mathrm{Te}^{+}+\mathrm{Te}_{3}+\mathrm{Te}_{2}+2 \mathrm{e}^{-} \\
\mathrm{Te}^{+}+2 \mathrm{Te}_{2}+\mathrm{Te}+2 \mathrm{e}^{-} \\
\mathrm{Te}^{+}+\mathrm{Te}_{4}+\mathrm{Te}+2 \mathrm{e}^{-} \\
\mathrm{Te}^{+}+\mathrm{Te}_{3}+2 \mathrm{Te}+2 \mathrm{e}^{-} \\
\mathrm{Te}^{+}+\mathrm{Te}_{2}+3 \mathrm{Te}+2 \mathrm{e}^{-} \\
\mathrm{Te}^{+}+5 \mathrm{Te}+2 \mathrm{e}^{-}\end{array}$ & $\begin{array}{l}10,40 \\
11.63 \\
12.56 \\
12.66 \\
13.83 \\
14.76 \\
\\
16.96\end{array}$ & $\begin{array}{c}\text { Ionization energy } \\
9.5 \pm 1.0[52] ; 8.9[18] ; \\
8.96[46] ; 9.009[53] ; \\
8.8 \pm 0.25 \\
\text { Appearance energy } \\
12.20[20] ; \\
10.8 \pm 0.5[18] ; \\
8.8 \pm 0.2[51] ; 10.9 \pm 0.25\end{array}$ \\
\hline \multicolumn{4}{|c|}{$E_{\mathrm{AP}}\left(\mathrm{Te}_{k}^{+} / \mathrm{Te}_{2}\right), k=1-2$} \\
\hline $\mathrm{Te}_{2}^{+}$ & $\mathrm{Te}_{2}^{+}+2 \mathrm{e}^{-}$ & 8.57 & $\begin{array}{c}\text { Ionization energy } \\
8.4 \pm 0.6[52] ; \\
8.3 \pm 0.2[18] ; \\
11.71 \pm 0.01[38] ; \\
8.3 \pm 0.25 \\
\text { Appearance energy } \\
9.00[20] ; 8.26[46] ; \\
9.0 \pm 0.2[51] ; 9.2 \pm 0.25 \\
\sim 7.9[126], 7.87[123], \\
\sim 7.95[129] ; 8.29[107]\end{array}$ \\
\hline $\mathrm{Te}^{+}$ & $\mathrm{Te}^{+}+\mathrm{Te}+2 \mathrm{e}^{-}$ & 10.91 & $\begin{array}{c}\text { Ionization energy } \\
9.5 \pm 1.0[52] ; 8.9[18] ; \\
8.96[46] ; 9.009[53] ; \\
8.8 \pm 0.25 \\
\text { Appearance energy } \\
10.8 \pm 0.5[120] ; \\
11.71 \pm 0.01[38] ; \\
12.20[20] ; \\
10.8 \pm 0.5[18] ; \\
8.8 \pm 0.2[51] ; 10.9 \pm 0.25\end{array}$ \\
\hline
\end{tabular}

energies of the $\mathrm{Te}_{3}^{+}$ion from $\mathrm{Te}_{n}$ molecules with $n=5 \div 8$ are larger than the presented calculated values because of the larger corresponding values of $D\left(\mathrm{Te}_{3}-\mathrm{Te}_{n-3} / \mathrm{Te}_{n}\right)$. Therefore, we may assume that, in our experiment, the $\mathrm{Te}_{3}^{+}$ion is formed in the process of direct ionization of a $\mathrm{Te}_{3}$ molecule, whereas the process of DI of a $\mathrm{Te}_{4}$ molecule was considered in work [18].

In Figs. 25 to 27, the calculated maximum and minimum values of the appearance energy are shown for some tellurium ionic fragments: $E_{\mathrm{AP}}\left(\mathrm{Te}_{k}^{+} / \mathrm{Te}_{8}\right)$ at $k \leq 8, E_{\mathrm{AP}}\left(\mathrm{Te}^{+} / \mathrm{Te}_{n}\right)$ at $1 \leq n \leq 8$, and $E_{\mathrm{AP}}\left(\mathrm{Te}_{2}^{+} / \mathrm{Te}_{n}\right)$ at $2 \leq n \leq 8$. From those figures, one can see that, as was in the cases of sulfur and selenium, the minimum appearance energy is more sensitive to the changes in the energy characteristics of the formed fragments than the maximum one. The maximum values of the minimum appearance energies are as follows: $E_{\mathrm{AP}}\left(\mathrm{Te}_{k}^{+}-\mathrm{Te}_{8-k} / \mathrm{Te}_{8}\right)=10.49 \mathrm{eV}$ at $k=1, E_{\mathrm{AP}}\left(\mathrm{Te}^{+}-\mathrm{Te}_{n-1} / \mathrm{Te}_{n}\right)=10.97 \mathrm{eV}$ at $n=5$, and $E_{\mathrm{AP}}\left(\mathrm{Te}_{2}^{+}-\mathrm{Te}_{n-2} / \mathrm{Te}_{n}\right)=10.32 \mathrm{eV}$ at $n=6$. At the same time, the minimum values of the minimum appearance energies are as follows: $E_{\mathrm{AP}}\left(\mathrm{Te}_{k}^{+}-\mathrm{Te}_{8-k} / \mathrm{Te}_{8}\right)=7.67 \mathrm{eV}$ at $k=8$, $E_{\mathrm{AP}}\left(\mathrm{Te}^{+}-\mathrm{Te}_{n-1} / \mathrm{Te}_{n}\right)=8.71 \mathrm{eV}$ at $n=1$, and $E_{\mathrm{AP}}\left(\mathrm{Te}_{2}^{+}-\mathrm{Te}_{n-2} / \mathrm{Te}_{n}\right)=8.46 \mathrm{eV}$ at $n=4$. By comparing those appearance energies with their counterparts for the sulfur and selenium clusters, one can see 
that, in general, the appearance energy becomes some smaller, when going from sulfur to tellurium. Furthermore, the locations of the minima remain almost the same at the corresponding $k$ and $n$ in the clusters of those elements, whereas the number and locations of some maxima change.

Doubly charged ions of a tellurium molecule. In Figs. 25 to 27, the calculated maximum and minimum appearance energies for singly charged $\mathrm{Te}_{k}^{+}$ionic fragments with $k=1 \div 8$ are illustrated. As was in the cases of sulfur and selenium, they can be used to determine the appearance energies for the doubly charged $\mathrm{Te}_{k}^{2+}$ ionic fragments. For this purpose, according to the formulas given above, the ionization potentials of $\mathrm{Te}_{k}^{+}$ions have to be added to the corresponding energies.

According to our measurements, the ionization energy giving rise to the appearance of a doubly charged $\mathrm{Te}^{2+}$ ion equals $20.6 \pm 0.25 \mathrm{eV}$, whereas the literature data give $27.3 \mathrm{eV} \mathrm{[46]} \mathrm{and} 18.6 \mathrm{eV}$ [53] (see Table 6). A discrepancy among the presented values testifies that, in those and our works, the $\mathrm{Te}^{2+}$ ion was formed following different reactions. If the $\mathrm{Te}^{2+}$ ion is formed in the DI process of a $\mathrm{Te}_{2}$ molecule, the calculated energy of its appearance equals $29.78 \mathrm{eV}$. But if it is formed in the DI process of a molecular $\mathrm{Te}_{2}^{+}$ ion, the calculated energy of its appearance will be lower by the magnitude of the $\mathrm{Te}_{2}$ molecule ionization potential and equal to $21.21 \mathrm{eV}$. However, if this process runs with the formation of a negative $\mathrm{Te}^{-}$ion, the appearance energy of the $\left(\mathrm{Te}^{2+}, \mathrm{Te}\right)$ pair amounts to $19.37 \mathrm{eV}$, i.e., it is lower by the electron affinity energy of a tellurium atom (the calculated value is $1.84 \mathrm{eV})$.

If the $\mathrm{Te}^{2+}$ ion is formed through the direct ionization of a atomic $\mathrm{Te}^{+}$ion, then, as was in the case of the doubly charged selenium ion, its appearance energy is equal to the ionization potential of this ion, $I\left(\mathrm{Te}^{+}\right)=18.6 \mathrm{eV}[109]$. The value calculated by us equals $I\left(\mathrm{Te}^{+}\right)=18.87 \mathrm{eV}$ (see Table 15$)$. As one can see, those data are in good agreement with the results of work [53], but they are lower than the experimental values: by $2 \mathrm{eV}$ in comparison with the data of work [109] and by $1.73 \mathrm{eV}$ in comparison with our results. Note also that they are much lower than the data of work [46]. The direct ionization of a $\mathrm{Te}_{2}^{+}$molecular ion requires the energy that is lower than $I\left(\mathrm{Te}^{+}\right)$, and the corresponding value equals $I\left(\mathrm{Te}_{2}^{+}\right)=14.61 \mathrm{eV}$.

ISSN 2071-0194. Ukr. J. Phys. 2020. Vol. 65, No. 7

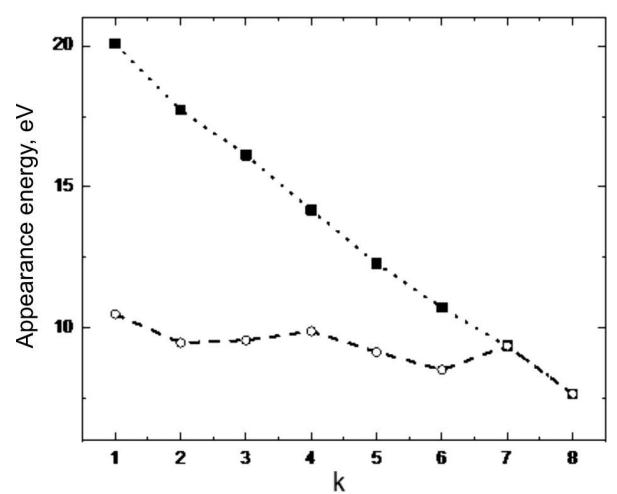

Fig. 25. Calculated maximum $\left(E_{\mathrm{AP}}\left[\mathrm{Te}_{k}^{+}-(8-k) \mathrm{Te} / \mathrm{Te}_{8}\right]\right.$, and minimum $\left(E_{\mathrm{AP}}\left(\mathrm{Te}_{k}^{+}-\mathrm{Te}_{8-k} / \mathrm{Te}_{8}\right), \circ\right)$ appearance energies of the $\mathrm{Te}_{k}^{+}$ionic fragments with $k \leq 8$. At $k=8$, the ionization energy of a $\mathrm{Te}_{8}$ molecule was used

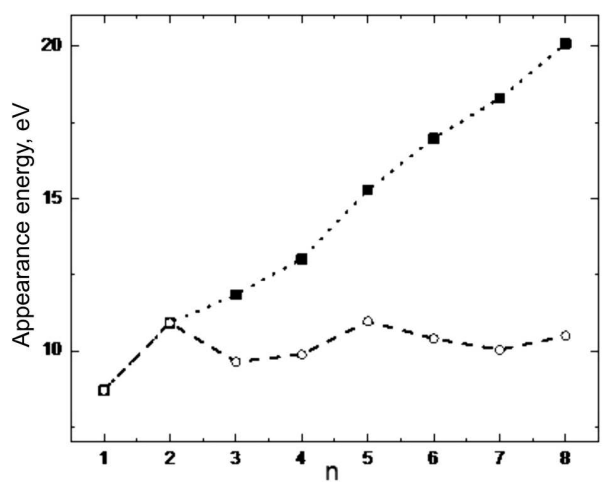

Fig. 26. Maximum $\left(E_{\mathrm{AP}}\left[\mathrm{Te}^{+}-(n-1) \mathrm{Te} / \mathrm{Te}_{n}\right]\right.$, $\left.\mathbf{a}\right)$ and minimum $\left(E_{\mathrm{AP}}\left(\mathrm{Te}^{+}-\mathrm{Te}_{n-1} / \mathrm{Te}_{n}\right), \circ\right)$ appearance energies of the $\mathrm{Te}^{+}$ionic fragment calculated for $1 \leq n \leq 8$. At $n=1$, the ionization energy of a Te atom was used

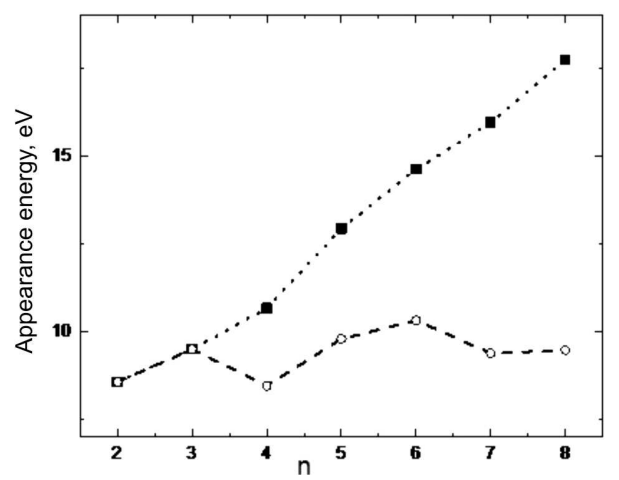

Fig. 27. Maximum $\left(E_{\mathrm{AP}}\left[\mathrm{Te}_{2}^{+}-(n-2) \mathrm{Te} / \mathrm{Te}_{n}\right]\right.$, 口) and min$\operatorname{imum}\left(E_{\mathrm{AP}}\left(\mathrm{Te}_{2}^{+}-\mathrm{Te}_{n-2} / \mathrm{Te}_{n}\right), \circ\right)$ appearance energies of the $\mathrm{Te}_{2}^{+}$ionic fragment calculated for $2 \leq n \leq 8$. At $n=2$, the ionization energy of a $\mathrm{Te}_{2}$ molecule was used 


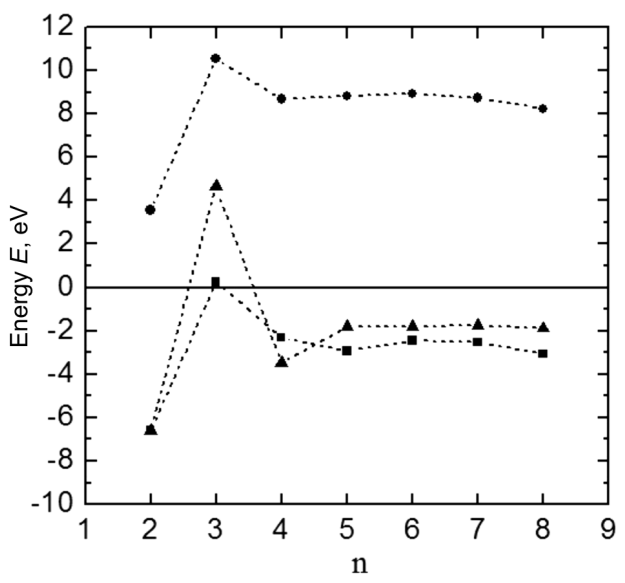

Fig. 28. Energy balance $E$ calculated for the formation reactions of fragment pairs from $\mathrm{Te}_{n}^{2+}$ ions with $n=2 \div 8$ through the channels $\mathrm{Te}^{+}-\mathrm{Te}_{n-1}^{+}(\bullet), \mathrm{Te}^{2+}-\mathrm{Te}_{n-1}$ and $\mathrm{Te}-\mathrm{Te}_{n-1}^{2+}$

Hence, the $\mathrm{Te}^{2+}$ ion detected by us is most likely formed owing to the DI process of a $\mathrm{Te}_{2}^{+}$molecular ion. The $\mathrm{Te}_{2}^{+}$ion observed in work [53] might be formed through the direct ionization of a $\mathrm{Te}^{+}$atomic ion. In work [46], the $\mathrm{Te}^{2+}$ ion [with an ionization energy of $27.3 \mathrm{eV}$ (see Table 6)] might possibly be formed in the process of direct two-electron ionization of a Te atom; the corresponding value calculated by us equals $I(\mathrm{Te})+I\left(\mathrm{Te}^{+}\right)=27.58 \mathrm{eV}$.

Note that the formation of $\mathrm{Te}^{2+}$ ions in the processes

$\mathrm{e}^{-}+\mathrm{Te}_{n} \rightarrow \mathrm{Te}^{2+}+\mathrm{Te}_{n-1}+3 \mathrm{e}^{-}$

with $n=3 \div 8$ requires energies of $27.58 \mathrm{eV}+D(\mathrm{Te}-$ $\left.-\mathrm{Te}_{n-1} / \mathrm{Te}_{n}\right)$, which are higher than the value observed by us. The formation of negative $\mathrm{Te}_{n-1}^{-}$ions in those processes will reduce this energy by the magnitude of the affinity energy $E_{a}\left(\mathrm{Te}_{n-1}\right)$ of the molecule. The formation of the $\mathrm{Te}^{2+}$ ion in the processes

$\mathrm{e}^{-}+\mathrm{Te}_{n}^{+} \rightarrow \mathrm{Te}^{2+}+\mathrm{Te}_{n-1}+2 \mathrm{e}^{-}$

with $n=3 \div 8$ requires energies of $27.58 \mathrm{eV}+D(\mathrm{Te}-$ $\left.-\mathrm{Te}_{n-1} / \mathrm{Te}_{n}\right)-I\left(\mathrm{Te}_{n}\right)$, which are also larger than our experimental value (see Table 15). However, the formation of the negative $\mathrm{Te}_{n-1}^{-}$ions in those processes brings about the following calculated values for the appearance energies: $18.52 \mathrm{eV}$ at $n=3,19.52 \mathrm{eV}$ at $n=4,19.49 \mathrm{eV}$ at $n=5,19.13 \mathrm{eV}$ at $n=6,18.71 \mathrm{eV}$ at $n=7$, and $19.02 \mathrm{eV}$ at $n=8$. One can see that, at $n=3$ and 7 , i.e., in the cases of $\mathrm{Te}_{3}^{+}$and $\mathrm{Te}_{7}^{+}$ ions, the energy is close to the values determined in work [53].

The energy balance calculated in the DFT/B3LYP approximation for the reactions with doubly charged diatomic $\mathrm{Te}_{2}^{2+}$ ions indicated above amounts to $3.56 \mathrm{eV}$ for the $2 \mathrm{Te}^{+} / \mathrm{Te}_{2}^{2+}$ reaction channel and to $-6.6 \mathrm{eV}$ for the $\left(\mathrm{Te}^{2+}-\mathrm{Te}\right) / \mathrm{Te}_{2}^{2+}$ one. From whence, it follows that the $\mathrm{Te}_{2}^{2+}$ ion is unstable with respect to its decay into two $\mathrm{Te}^{+}$ions, which fly apart with a total kinetic energy of $3.56 \mathrm{eV}$. Figure 28 shows the dependences of the energy balance in the reactions of the $\mathrm{Te}_{n}^{2+}$ ionic fragment pair formation on the number of atoms $n$ in the fragments calculated in the DFT/B3LYP approximation for three reaction channels. The figure testifies that, as was in the case of selenium ions, the $\mathrm{Te}_{n}^{2+}$ ions are unstable with respect to their decay into two ions, $\mathrm{Te}^{+}$and $\mathrm{Te}_{n-1}^{+}$, for all $n=2 \div 8$. The maximum energy $(10.55 \mathrm{eV})$ is released at $n=3$ as the kinetic energy of the $\mathrm{Te}^{+}$and $\mathrm{Te}_{2}^{+}$ ions, and the minimum energy $(3.56 \mathrm{eV})$ is released at $n=2$ as the kinetic energy of two $\mathrm{Te}^{+}$ions.

As was in the cases of sulfur and selenium, at $n=3$, the calculated energy balance for diatomic doubly charged tellurium ions has the maximum magnitude in the cases of their decay into a doubly charged ionic fragment and a neutral one, $\left(\mathrm{Te}^{2+}, \mathrm{Te}_{2}\right)$ and $\left(\mathrm{Te}_{2}^{2+}, \mathrm{Te}\right)$. Furthermore, in the cases $n=2$ and 3, these are real decays with low $(0.25 \mathrm{eV})$ and high $(4.65 \mathrm{eV})$ released energies, respectively. In the cases of other $n$, no decays take place: the $\mathrm{Te}_{n}^{2+}$ ions are stable, but the binding energy is somewhat lower than in the case of selenium ions.

\section{Conclusions}

A complex research of elementary processes - the excitation and ionization (the formation of positive and negative ions at $0-70 \mathrm{eV}$ ) of atoms and molecules - occurring at the interaction of controlledenergy electrons with chalcogens (sulfur, selenium and tellurium) in the gaseous phase has been carried out. The following results were obtained:

- the sulfur, selenium, and tellurium vapors mainly contain di- and polyatomic molecules $M_{n}$ with $n=$ $2 \div 8$, whereas the atomic component concentration does not exceed a few percent;

- atomic ions are mainly formed through the dissociative ionization of molecules;

ISSN 2071-0194. Ukr. J. Phys. 2020. Vol. 65, No. 7 
- for the first time, the total (integral) ionization cross-sections for positive and negative ions were measured and the corresponding appearance energy thresholds were determined;

- negative ions are effectively formed within the electron energy interval $0-10 \mathrm{eV}$, and the probability of their appearance is much lower than the probability of the formation of positive ions;

- the intensity ratios between the isotope peaks and the main one are preserved for both atomic and molecular components;

- doubly charged ions $\mathrm{S}^{2+}, \mathrm{Se}^{2+}$ and $\mathrm{Te}^{2+}$ were detected for the first time in the chalcogen vapors; the energy dependences of the intensities of their electron-impact formations were measured;

- in the case of low-energy electrons (3-15 eV), the molecular bands of diatomic molecules dominate in the optical spectra of researched elements in the spectral interval 200-600 nm;

- it was unambiguously shown for selenium and tellurium that the resonance atomic lines in the nearthreshold region are excited owing to the dissociative excitation of diatomic molecules.

The combination of mass spectrometry and optical research methods, when studying atoms and complex molecules in the gaseous phase using monochrome controlled-energy electrons, makes it possible to simplify the identification procedure of atomic and molecular states and obtain a valuable information about the course of elementary processes.

The energy characteristics of the clusters of chalcogen atoms - such as the ionization potentials, the electron affinity energies, and the dissociation energies! - have been studied theoretically. The corresponding results were applied to analyze the mechanisms of cluster fragmentation in the course of dissociative ionization processes. The obtained values were compared with the experimental data, and, in most cases, a satisfactory agreement was achieved. Insignificant discrepancies between the experimental and the calculated data may arise owing to the neglect of the vibrational degrees of freedom in the initial and final molecular systems. When analyzing the magnitudes of the appearance energy, as well as the possible channels of fragmentation processes, the excitation states of parent molecules and the formation of negative atomic and molecular ions (anions) have be taken into account.
The appearance energies of positive ionic fragments from the indicated clusters through various reaction channels have been calculated. The channels of the ionic fragment formation were identified for some available experimental data. The calculation results obtained for the appearance energies in various fragmentation channels of the dissociative ionization of homoatomic molecular targets - sulfur, $\mathrm{S}_{n}$, selenium, $\mathrm{Se}_{n}$. and tellurium, $\mathrm{Te}_{n}$, clusters with $n=2 \div 8$ - testify that the applied theoretical methods are rather successful.

Singly charged ions of sulfur and selenium clusters, $\mathrm{S}_{n}^{+}$and $\mathrm{Se}_{n}^{+}$, are formed, as a rule, through the direct, rather than dissociative, ionization of the parent molecules, $\mathrm{S}_{n}$ and $\mathrm{Se}_{n}$, respectively. The tellurium ions $\mathrm{Te}^{+}$and $\mathrm{Te}_{2}^{+}$are formed in the process of dissociative ionization of $\mathrm{Te}_{2}$ and $\mathrm{Te}_{3}$ molecules, whereas the $\mathrm{Te}_{3}^{+}$ion through the direct ionization of a $\mathrm{Te}_{3}$ molecule. The possibility of the $\mathrm{Te}_{3}^{+}$ion formation from the $\mathrm{Te}_{4}$ molecule in the process of dissociative ionization is pointed out.

The processes giving rise to the formation of doubly charged ions have been analyzed. In particular, the $\mathrm{S}_{2}^{2+}$ and $\mathrm{S}_{2}^{3+}$ ions are formed in the gas mixture in the process of direct ionization of $\mathrm{S}_{2}^{+}$and $\mathrm{S}_{2}^{2+}$ ions. The doubly charged $\mathrm{Se}^{2+}$ ion is formed as a result of the direct ionization of an atomic $\mathrm{Se}^{+}$ion, and the doubly charged $\mathrm{Te}^{2+}$ ion appears in the process of dissociative ionization of a $\mathrm{Te}_{2}^{+}$molecular ion. As was shown in the cited papers, the $\mathrm{Te}^{2+}$ ion is a product of the direct ionization: the two-electron ionization of a tellurium atom or the one-electron ionization of a $\mathrm{Te}^{+}$atomic ion. The calculations showed that the doubly charged $\mathrm{S}_{n}^{2+}, \mathrm{Se}_{n}^{2+}$, and $\mathrm{Te}_{n}^{2+}$ ions are energetically unstable with respect to their decay into corresponding singly charged ions, for example, into $\mathrm{Te}^{+}$and $\mathrm{Te}_{n-1}^{+}$. However, they are stable in general with respect to their decay into fragment pairs like $\left(\mathrm{Te}^{2+}, \mathrm{Te}_{n-1}\right)$ or $\left(\mathrm{Te}, \mathrm{Te}_{n-1}^{2+}\right)$.

The applied theoretical method can be successfully used to consistently describe the energy parameters of the dissociative ionization process. It can serve as a basis, while analyzing the possible reaction channels, even in the case of dissociative ionization with the formation of positive multiply charged ions.

The work was partially sponsored in the framework of the Target Research Program of the NAS of Ukraine "Perspective Studies in Plasma Physics, 
Controlled Fusion, and Plasma Technologies" for 2017-2019 and the Target Research Program of the Department of Physics and Astronomy of the NAS of Ukraine "Competitive performance of the researches and developments the most important for the state, including those with a high readiness level".

The authors thank E.E. Kontrosh, P.P. Markush, and T.Yu. Popyk for their help in the preparation of this work. We are also grateful to our colleagues for fruitful collaboration: to N. Aguirre and S. DiazTendero (Madrid, Spain) for the sulfur cluster research, and to S.T.S. Kovács, P. Herczku, Z. Juhász, E. Bene, B. Sulik, L. Gulyás, L. Sarkadi, and S. Ricz (Debrecen, ATOMICS, Hungary) for the analysis of the products of collisions between molecules and highenergy particles.

1. J.H. Gross. Mass Spectrometry: A Textbook (Springer, 2011).

2. A.N. Zavilopulo, A.S. Agafonova, A.V. Snegurskii. Electron impact-induced ionization and dissociation of the freon-12 molecule. Techn. Phys. 55, 1735 (2010).

3. A.N. Zavilopulo, O.B. Shpenik, O.V. Pilipchinets. Mass spectrometry of a xylitol molecule. Techn. Phys. 64, 8 (2019).

4. A.N. Zavilopulo, F.F. Chipev, O.B. Shpenik. Ionization of nitrogen, oxygen, water, and carbon dioxide molecules by near-threshold electron impact. Techn. Phys. 50, 402 (2005).

5. L.M. Feaga, M.A. McGrath, P.D. Feldman. The abundance of atomic sulfur in the atmosphere of Io, Astrophys. J. 570, 439 (2002).

6. J. Berkovitz, J.R. Marquart. Equilibrium composition of sulfur vapor. J. Chem. Phys. 39, 275 (1963).

7. M. Harnisch, N. Weinberger, S. Denifl, P. Scheier, O. Echt. Helium droplets doped with sulfur and $\mathrm{C}_{60} . J$. Phys. Chem. C 119, 10919 (2015).

8. E. Rühl. Core level excitation, ionization, relaxation, and fragmentation of free clusters. Int. J. Mass Spectrom. Ion Phys. 229, 117 (2003).

9. W. Rosinger, M. Grade, W. Hirschwald. Electron impact induced excitation processes involving the sulfur clusters $\mathrm{S}_{2}$ to $\mathrm{S}_{8}$. Ber. Bunsen. Phys. Chem. 87, 536 (1983).

10. H.P. Saha, D. Lin. Ab initio calculation for low-energy elastic scattering of electrons from sulfur atoms. Phys. Rev. A 56, 1897 (1997)

11. O. Zatsarinny, S.S. Tayal. Low-energy electron collisions with atomic sulfur: $R$-matrix calculation with nonorthogonal orbitals. J. Phys. B 34, 3383 (2001).

12. H. Murai, Y. Ishijima, T. Mitsumura, Y. Sakamoto, H. Kato, M. Hoshino, F. Blanco, G. García, P. LimãoVieira, M.J. Brunger, S.J. Buckman, H. Tanaka. A comprehensive and comparative study of elastic electron scat- tering from OCS and $\mathrm{CS}_{2}$ in the energy region from 1.2 to $200 \mathrm{eV}$. J. Chem. Phys. 138, 054302 (2013).

13. C. Winstead, P.G. Hipes, M.A.P. Lima, V. McKoy. Studies of electron collisions with polyatomic molecules using distributed-memory parallel computers. J. Chem. Phys. 94, 5455 (1991).

14. S. Kaur, A. Bharadvaja, K.L. Baluja. Electron-impact study of $\mathrm{S}_{3}$ using the $R$-matrix method. Phys. Rev. A 83, 062707 (2011).

15. N. Greenwood, A. Earnshaw. Chemistry of the Elements (Butterworth-Heinemann, 1997).

16. Z.J. Becker. Elemental Selenium. In Chemical Thermodynamics of Selenium. Edited by F.J. Mompean, J. Perrone, M. Illemassène (Elsevier, 2010), ch. V.1.

17. L.G. Johansson, E. Gafvelin, J. Amér. Selenocysteine in proteins-properties and biotechnological use. Biochim. Biophys. Acta 1726, 1 (2005).

18. NIST Standard Reference Database. http:// www.webbook.nist.gov.

19. G. Audi, A.H. Wapstra, C. Thibault. The AME2003 (NUBASE) atomic mass evaluation (II). Tables, graphs, and references. Nucl. Phys. A 729, 3 (2003).

20. R. Viswanathan, R. Balasubramanian, D. Raj, D. Albert, B.M. Sai, N.T.S. Lakshmi. Vaporization studies on elemental tellurium and selenium by Knudsen effusion mass spectrometry. J. Alloy. Compd. 603, 75 (2014).

21. E. Illenberger, J. Momigny. Gaseous Molecular Ions. An Introduction to Elementary Processes Induced by Ionization (Springer, 1992).

22. Advanced Topics in Theoretical Chemical Physics. Edited by J. Maruani, R. Lefebvre, E.J. Brändas (Kluwer, 2003).

23. J.H. Gross. Principles of ionization and ion dissociation. In J.H. Gross. Mass Spectrometry (Springer, 2011), p. 21.

24. Z.J. Becker, K. Rademann, F. Hensel. Ultraviolet photoelectron studies of the molecules $\mathrm{Se}_{5}, \mathrm{Se}_{6}, \mathrm{Se}_{7}$ and $\mathrm{Se}_{8}$ with relevance to their geometrical structure. Z. Phys. D 19, 229 (1991).

25. A.N. Zavilopulo, O.B. Shpenik, A.M. Mylymko. Examination of a molecular Se beam by mass spectrometry with electron ionization. Techn. Phys. 62, 359 (2017).

26. G. Ganteför, S. Hunsicker, R.O. Jones. Prediction and observation of ring and chain isomers in $\mathrm{Sn}^{-}$ions. Chem. Phys. Lett. 236, 43 (1995).

27. O.B. Shpenik, A.N. Zavilopulo, O.V. Pylypchynets. Electron impact ionization of tellurium in the gas phase. Dopov. Nat. Akad. Nauk Ukr. No. 5, 44 (2018) (in Ukrainian).

28. A.N. Zavilopulo, M.I. Mykyta, A.N. Mylymko, O.B. Shpenik. Ionization and dissociative ionization of methane molecules. Techn. Phys. 58, 1251 (2013).

29. A.N. Zavilopulo, O.B. Shpenik, A.S. Agafonova. Electron impact ionization of gas-phase guanine near the threshold. J. Phys. B 42, 1 (2009).

30. J.E. Kontros, L. Szótér, I.V. Chernyshova O.B. Shpenik. Cross-sections of slow electron scattering by cadmium atoms. J. Phys. B 35, 2195 (2002).

ISSN 2071-0194. Ukr. J. Phys. 2020. Vol. 65, No. 7 
31. N.M. Erdevdy, O.B. Shpenik, P.P. Markush. Electronimpact excitation of gas-phase sulfur. J. Appl. Spectrosc. 82, 19 (2015).

32. A.N. Zavilopulo, E.A. Mironets, A.S. Agafonova. An upgraded ion source for a mass spectrometer. Instrum. Experim. Techn. 55, 65 (2012).

33. G. Dudek, E.P. Dudek. The mass spectrum of sulfur. J. Chem. Educ. 66, 304 (1989).

34. P. Bradt, F.L. Mohler, V.H. Dibeler. Mass spectrum of sulfur vapor. J. Res. Nat. Bur. Stand. 57, No. 4, 223 (1956).

35. H. Rau. Vapour composition and critical constants of selenium. J. Chem. Thermodyn. 6, 525 (1974).

36. H. Fujisaki, J.B. Westmore, A.W. Tickner. Mass spectrometric study of subliming selenium. Can. J. Chem. 44, 3063 (1966).

37. K. Kooser, D.T. Ha, E. Itälä, J. Laksman, S. Urpelainen, E. Kukk. Size selective spectroscopy of Se microclusters. J. Chem. Phys. 137, 044304 (2012).

38. J. Berkowitz, W.A. Chupka. Photoionization of hightemperature vapors. VI. $\mathrm{S}_{2}, \mathrm{Se}_{2}$, and $\mathrm{Te}_{2}$. J. Chem. Phys. 50, 4245 (1969).

39. R. Yamdagni, R.F. Porter. Mass spectrometric and torsion effusion studies of the evaporation of liquid selenium. J. Electrochem. Soc. 115, 601 (1968).

40. A.K. Hearley, B.F.G. Johnson, J.S. McIndoe, D.G. Tuck. Mass spectrometric identification of singly-charged anionic and cationic sulfur, selenium, tellurium and phosphorus species produced by laser ablation. Inorg. Chim. Acta 334, 105 (2002).

41. G.M. Minchev, M. Eddrief, L.M. Trendafilov, H.M. Naradikian, K.L. Trendafilov. Investigation of Se molecular beams used for MBE. Vacuum 47, 157 (1996).

42. M. Albeck, S. Shaik. Identification of tellurium-containing compounds by means of mass spectrometry. J. Organomet. Chem. 91, 307 (1975).

43. Proceedings of the Workshop on Knudsen Effusion Mass Spectrometry (April 23-25, 2012. Juelich, Germany). Edited by N. Jacobson, T. Markus. ECS Trans. 46 (2013).

44. R. Viswanathan, M. Sai Baba, D. Darwin, A. Raj, R. Balasubramanian, C.K. Mathews. A high temperature mass spectrometric study of tellurium and selenium clusters. In Advance in Mass Spectrometry. Edited by J.F.J. Todd (Wiley, 1985), p. 1087.

45. J.T. Snodgrass, J.V. Coe, K.M. McHugh, C.B. Freidhoff, K.H. Bowen. Photoelectron spectroscopy of selenium and tellurium containing negative ions: $\mathrm{SeO}_{2}^{-}, \mathrm{Se}_{2}^{-}$, and $\mathrm{Te}_{2}^{-}$. J. Phys. Chem. 93. 1249 (1989)

46. K.F. Willey, P.Y. Cheng, T.G. Taylor, M.B. Bishop, M.A. Duncan. Photoionization and mass selected photodlssociation of tellurium clusters. J. Phys. Chem. 94, 1545 (1990).

47. D. Hohl, R.O. Jones. Structure of sulfur clusters using simulated annealing: $\mathrm{S}_{2}$ to $\mathrm{S}_{13}$. J. Chem. Phys. 89, 6823 (1988).
48. J. Berkowitz, C. Lifshitz. Photoionization of high temperature vapors. II. Sulfur molecular species. J. Chem. Phys. 48, 4346 (1968).

49. Sh.Sh. Demesh, A.N. Zavilopulo, O.B. Shpenik, E.Yu. Remeta. Fragment appearance energies in dissociative ionization of a sulfur hexafluoride molecule by electron impact. Techn. Phys. 60, 830 (2015).

50. S.R. Freund, C.R. Wetzel, J.Sh. Randy, R.T. Hayes. Cross section measurements for electron impact ionization of atoms. Phys. Rev. A 41, 3575 (1990).

51. J. McFarlane, J.C. LeBlanc. Whiteshell Laboratories Pinawa. Manitoba ROE 1L0 AECL-11333. COG-95-276I, 51 (1996).

52. J. L. Franklin, J.G. Dillard, H.M. Rosenstock, J.T. Herron, K. Draxl, F.H. Field. Ionization potentials, appearance potentials, and heats of formation of gaseous positive ions. Nat. Stand. Ref. Data Ser. 26. 289 (1969).

53. C.E. Moore. Ionization potentials and ionization limits derived from the analysis of optical spectra. Nat. Stand. Ref. Data Ser. 34, 22 (1970).

54. G.J. Schulz. Resonances in electron impact on diatomic molecules. Rev. Mod. Phys. 45, 423 (1973).

55. H. Feshbach. A unified theory of nuclear reactions. Ann. Phys. 19, 287 (1962).

56. H.S. Taylor. Qualitative aspects of resonances in electronatom and electron-molecule scattering, excitation, and reactions. J. Chem. Phys. 45, 2872 (1966).

57. Y. Le Coat, L. Bouby, J.P. Guillotin, J.P. Ziesel. Negative ion formation by electron attachment in $\mathrm{S}_{2}$ and in the sulphur vapour. J. Phys. B 29, 545 (1996).

58. J. Berkowitz. Photoabsorption, Photoionization, and Photoelectron Spectroscopy (Academic Press, 1979).

59. M. Schmidt, W. Siebert, K.W. Bagnall. Photoelectron spectroscopy of small tellurium clusters. J. Non-Cryst. Solids 312-314, 337 (2002).

60. V. Kaufman, W.C. Martin. Wavelengths and energy level classifications for the spectra of sulfur (S I through S XVI). J. Phys. Chem. Ref. Data 22, 279 (1993).

61. D.A. Peterson, L.A. Schlie. Stable pure sulfur discharges and associated spectra. J. Chem. Phys. 73, 1551 (1980).

62. J.E. Ruedy, R.C. Gibbs. The arc spectrum of selenium. Phys. Rev. 46, 880 (1934)

63. 63. A.N. Zavilopulo, P.P. Markush, O.B. Shpenik. Electron impact ionization and dissociative ionization of sulfur in the gas phase. Techn. Phys. 59, 951 (2014).

64. D.C. Martin. Analysis of the spectrum of Se II. Phys. Rev. 48, 938 (1935).

65. M. Urban, H.F.G. Diercksen, M. Jurek. Metastability in the sulphur molecule $\mathrm{S}_{2}^{2+}$ and $\mathrm{S}_{2}^{3+}$ cations. A theoretical study. Mol. Phys. 94, 199 (1988).

66. A. Benamar, D. Rayane, P. Melinon, B. Tribollet, M. Broyer. Comparison between selenium and tellurium clusters. Z. Phys. D 19, 237 (1991).

67. T.D. Märk. Fundamental aspects of electron impact ionization. Int. J. Mass Spectr. Ion Phys. 45, 125 (1982). 
68. A.N. Zavilopulo, O.B. Shpenik, A.V. Snegursky, F.F. Chipev, V.S. Vukstich. Threshold electron impact ionization of $\mathrm{SF}_{6}$ molecule. Tech. Phys. Lett. 31, 785 (2005).

69. J.H. Gross, P.J. Todd. Mass Spectrometry. A Textbook (Springer, 2004).

70. L.G. Christophorou, J.K. Olthoff. Fundamental Electron Interactions with Plasma Processing Ga, Se, S (Springer, 2004).

71. K. Levsen. Fundamental Aspects in Organic Mass Spectrometry (Chemie, 1978).

72. Sh.Sh. Demesh, E.Yu. Remeta. Ion appearance energies at electron-impact dissociative ionization of sulfur hexafluoride molecule and its fragments. Eur. Phys. J. D 69, 168 (2015).

73. Sh.Sh. Demesh, A.N. Zavilopulo, O.B. Shpenik, E.Yu. Remeta. The energy of the appearance of sulfur hexafluoride fragments by electron impact. Zh. Tekhn. Fiz. 85, No. 6, 44 (2015) (in Russian).

74. Electron Impact Ionization. Edited by T.D. Märk, G.H. Dunn (Springer, 1985).

75. Sh.Sh. Demesh, E.Yu. Remeta. Appearance energies of the $\mathrm{SF}_{6}$ molecule ionic fragments studied $a b$ initio. In Proceedings of the 6th Conference on Elementary Processes in Atomic Systems. (Comenius University, 2014), p. 67 .

76. K.J. Laidler, J.H. Meiser. Physical Chemistry (Benjamin/Cummings, 1982).

77. S.T.S. Kovács, P. Herczku, Z. Juhász, B. Sulik. Fragmentation of $\mathrm{H}_{2} \mathrm{O}$ molecules induced by singly charged projectiles. J. Phys.: Conf. Ser. 635, 032115 (2015).

78. S.T.S. Kovács, P. Herczku, Z. Juhász, L. Sarkadi, L. Gulyás, B. Sulik. Ionization of small molecules induced by $\mathrm{H}^{+}, \mathrm{He}^{+}$, and $\mathrm{N}^{+}$projectiles: Comparison of experiment with quantum and classical calculations. Phys. Rev. A 94, 012704 (2016).

79. S.T.S. Kovács, P. Herczku, Z. Juhász, L. Sarkadi, L. Gulyás, B. Sulik. Dissociative ionization of the $\mathrm{H}_{2} \mathrm{O}$ molecule induced by medium-energy singly charged projectiles. Phys. Rev. A 96, 032704 (2017).

80. M.W. Schmidt, K.K. Baldridge, J.A. Boatz, S.T. Elbert, M.S. Gordon, J.H. Jensen, S. Koseki, N. Matsunaga, K.A. Nguyen, S. Su, T.L. Windus, M. Dupuis, J.A. Montgomery. General atomic and molecular electronic structure system. J. Comput. Chem. 14, 1347 (1993).

81. W. Kohn, L.J. Sham. Self-consistent equations including exchange and correlation effects. Phys. Rev. 140, A1133 (1965).

82. A.D. Becke. Density-functional thermochemistry. V. Systematic optimization of exchange-correlation functionals. J. Chem. Phys. 107, 8554 (1997).

83. T. Helgaker, W. Klopper, A. Halkier, K.L. Bak, P. Jørgensen, J. Olsen. Highly accurate $a b$ initio computation of thermochemical data. In: Quantum-Mechanical Prediction of Thermochemical Data (Kluwer, 2001), Ch. 1.
84. R.O. Jones, P. Ballone. Density functional and MonteCarlo studies of sulfur. I. Structure and bonding in $\mathrm{S}_{n}$ rings and chains $(n=2-18)$. J. Chem. Phys. 118, 9257 (2003).

85. S. Kohara, A. Goldbach, N. Koura, M.-L. Saboungi, L.A. Curtiss. Vibrational frequencies of small selenium molecules. Chem. Phys. Lett. 287, 282 (1998).

86. T. Arion, R. Flesch, T. Schlatholter, F. Alvarado, R. Hoekstra, R. Morgenstern, E. Rühl. Collision induced fragmentation of free sulfur clusters. Int. J. Mass Spectrom. 277, 197 (2008).

87. P. Ghosh, J. Bhattacharjee, U.V. Waghmare. The origin of stability of helical structure of tellurium. J. Phys. Chem. C 112, 983 (2008).

88. Sh.Sh. Demesh, E.Yu. Remeta. Appearance energies of $\mathrm{S}_{k}^{+}$ions from $\mathrm{S}_{n}$ molecules studied $a b$ initio. In: Proceedings of the $3 r d X U V / X$-Ray Light and Fast Ions for Ultrafast Chemistry General Meeting. Edited by K. Tőkési (ATOMKI/ DE/ ELFT, Debrecen, 2015), p. 33.

89. Sh.Sh. Demesh. Appearance energies of sulfur fluoride ions and molecular orbital ionization energies. Nauk. Visn. Uzhgorod. Nat. Univ. Ser. Fiz. 38, 110 (2015) (in Ukrainian).

90. Sh. Demesh, E. Remeta. Theoretical study of sulphur cluster fragmentation. In: Proceedings of the 12th European Conference on Atoms, Molecules and Photons (Goethe-Universität, 2016), p. 137.

91. Sh. Demes, V. Kelemen, E. Remeta. Theoretical study of elastic electron scattering by sulphur clusters. In Proceedings of the 50th Anniversary EGAS conference. (Jagiellonian University, 2018), p. 83.

92. Sh.Sh. Demesh, V.I. Kelemen, E.Yu, Remeta. Potential electron scattering by the phosphorous systems $\mathrm{P}_{n}(n=$ =1-3). J. Phys.: Conf. Ser. 635, 072020 (2015).

93. Sh.Sh. Demesh, V.I. Kelemen, E.Yu, Remeta. Potential electron scattering by molecule. Zh. Fiz. Dosl. 19, 4301 (2016) (in Ukrainian).

94. Sh.Sh. Demesh, V.I. Kelemen, E.Yu. Remeta. Potential electron scattering by $\mathrm{P}_{2}$ and $\mathrm{P}_{3}$ phosphorus molecules. Ukr. J. Phys. 61, 291 (2016).

95. S. Demesh, V. Kelemen, E. Remeta. Elastic electron scattering by the $\mathrm{CF}_{3}$ radical in the $1-1000 \mathrm{eV}$ energy range. J. Phys. B 50, 135201 (2017).

96. A.N. Zavilopulo, O.B. Shpenik, P.P. Markush, M.I. Mykyta. Electron-impact ionization of sulfur in the gas phase. Tech. Phys. Lett. 40, 13 (2014).

97. E. Rühl. Core level excitation, ionization, relaxation, and fragmentation of free clusters. Int. J. Mass Spectrom. Ion Phys. 229, 117 (2003).

98. P.F. Kelly. Oxygen, sulfur, selenium and tellurium. Annu. Rep. Prog. Chem., Sect. A 97, 95. (2001).

99. S.J. Brotton, J.W. McConkey. Dissociative excitation and fragmentation of $\mathrm{S}_{8}$ by electron impact. J. Chem. Phys. 134, 204301 (2011).

ISSN 2071-0194. Ukr. J. Phys. 2020. Vol. 65, No. 7 
100. S. Millefiori, A. Alparone. Ab initio study of the structure and polarizability of sulfur clusters, $\mathrm{S}_{n}(n=2-12)$. J. Phys. Chem. A 105, 9489 (2001).

101. I.N. Levine. Quantum Chemistry (Prentice-Hall, 2000).

102. A. Szabo, N.S. Ostlund. Modern Quantum Chemistry: Introduction to Advanced Electronic Structure Theory (Dover, 1996).

103. Computational Chemistry Comparison and Benchmark Data Base Release. NIST Standard Reference Database, No. 101 (2018).

104. F.A. Cotton, G. Wilkinson. Advanced Inorganic Chemistry: A Comprehensive Text (Interscience, 1972).

105. K.P. Huber. G. Herzberg. Molecular Spectra and Molecular Structure. IV. Constants of Diatomic Molecules (Van Nostrand Reinhold, 1979).

106. J.A. Kerr. Bond dissociation energies by kinetic methods. Chem. Rev. 66, 465 (1966).

107. A.A. Radtsig, B.M. Smirnov. Handbook on Atomic and Molecular Physics (Atomizdat, 1980) (in Russian).

108. A.A. Radzig, B.M. Smirnov. Reference Data on Atoms, Molecules, and Ions (Springer, 1985).

109. A.A. Radzig, B.M. Smirnov. Parameters of Atoms and Atomic Ions. A Handbook (Energoatomizdat, 1986) (in Russian).

110. A.N. Zavilopulo, O.B. Shpenik, P.P. Markush, M.I. Mykyta. Electron-impact ionization and dissociative ionization of sulfur in the gas phase. Tech. Phys. 59, 951 (2014).

111. S. Hunsicker, R.O. Jones, G. Ganteför. Rings and chains in sulfur cluster anions $\mathrm{S}^{-}$to $\mathrm{S}_{9}$ : Theory (simulated annealing) and experiment (photoelectron detachment). J. Chem. Phys. 102, 5917 (1995)

112. J.E. Bartmess. Negative ion energetics data. In: NIST Reference Database, No. 69 (2018).

113. S.G. Lias, J.E. Bartmess, J.F. Liebman, J.L. Holmes, R.D. Levin, W.G. Mallard. Ion energetics data. In: NIST Standard Reference Database, No. 69 (2018).

114. H.M. Rosenstock, K. Draxl, B.W. Steiner, J.T. Herron. Ion energetics data. In: NIST Standard Reference Database, No. 69 (2018).

115. B. Tribollet, A. Benamar, D. Rayane, P. Melinon, M. Broyer. Experimental studies on selenium cluster structures. Z. Phys. D 26, 352 (1993).v

116. J. Becker, K. Rademann, F. Hensel. Electronic structure of selenium- and tellurium-clusters. Z. Phys. D 19, 233 (1991).

117. X. Yang, Y. Hu, S. Yang, M.M.T. Loy. Photofragmentation studies of small selenium cluster cations $\mathrm{Se}_{n}^{+}(n=3-$ 8). J. Chem. Phys. 111, 7837 (1999).

118. C. Bréchignac, Ph. Cahuzac, N. Kébaïli, J. Leygnier. Photothermodissociation of selenium clusters. J. Chem. Phys. 112, 10197 (2000)

119. P.P. Markush. Selenium vapor ionization by slow electrons. Nauk. Visn. Uzhgorod. Nat. Univ. Ser. Fiz. 34, 149 (2013) (in Ukrainian).
120. O.B. Shpenik, M.M. Erdevdy, P.P.Markush, J.E.Kontros, I.V. Chernyshova. Electron impact excitation and ionization of sulfur, selenium, and tellurium vapors. $U k r . J$. Phys. 60, 217 (2015).

121. W. Xu, W. Bai. The selenium clusters $\operatorname{Se}_{n}(n=1-5)$ and their anions: Structures and electron affinities. J. Mol. Struct. THEOCHEM. 854, 89 (2008).

122. A. Alparone. Structural, energetic and response electric properties of cyclic selenium clusters: an ab initio and density functional theory study. Theor. Chem. Acc. 131, 1239 (2012).

123. G. Igel-Mann, H. Stoll, H. Preuss. Structure and ionization potentials of clusters containing heavy elements. II. Homonuclear group VI clusters up to hexamers. Mol. Phys. 80, 341 (1993).

124. B.C. Pan, J.G. Han, J. Yang, S. Yang. Theoretical studies of neutral and cationic selenium clusters. Phys. Rev. B 62, 17026 (2000).

125. Wen Yang, Ren-Bao Liu. Quantum many-body theory of qubit decoherence in a finite-size spin bath. Phys. Rev. B 78, 085315 (2002)

126. K. Nagaya, A. Oohata, I. Yamamoto, M. Yao. Photoelectron spectroscopy of small tellurium clusters. J. NonCryst. Solids 312-314, 337 (2002).

127. C. Bréchignac, Ph. Cahuzac, M. de Frutos, P. Garnier, N. Kebaili. Dissociation energies of tellurium cluster ions from thermoevaporation experiments. J. Chem. Phys. 103, 6631 (1995).

128. J. Akola, R.O. Jones. Structure and dynamics in amorphous tellurium and $\mathrm{Te}_{n}$ clusters: A density functional study. Phys. Rev. B 85, 134103 (2012).

129. B.C. Pan. Geometric structures, electronic properties, and vibrational frequencies of small tellurium clusters. Phys. Rev. B 65, 085407 (2002).

130. O.M. Uy, J. Drowart. Mass spectrometric determination of the dissociation energies of the molecules $\mathrm{BiO}, \mathrm{BiS}$, BiSe and BiTe. Trans. Faraday Soc. 65, 3221 (1969).

131. O.M. Uy, D.W.Muenow, P.J. Ficalora, J.L. Margrave. Mass spectrometric studies at high temperatures. Part 30. Vaporization of $\mathrm{Ga}_{2} \mathrm{~S}_{3}, \mathrm{Ga}_{2} \mathrm{Se}_{3}$ and $\mathrm{Ga}_{2} \mathrm{Te}_{3}$, and stabilities of the gaseous gallium chalcogenides. Trans. Faraday Soc. 64, 2998 (1968)

Received 10.10.19

Translated from Ukrainian by O.I. Voitenko

О. Шиеник, А. Завілопуло,

Є. Ремета, Ш. Демеш, М. Ердевді

НЕПРУЖНІ ПРОЦЕСИ ВЗАЕМОДІЇ

ЕЛЕКТРОНІВ 3 ХАЛЬКОГЕНАМИ В ГАЗОВІЙ ФАЗІ

$\mathrm{P}$ е $з$ ю м е

Проведено комплексні дослідження елементарних процесів парних зіткнень у випадку проходження електронів низьких (0-70 eB) енергій через пару халькогенів ( $\mathrm{S}, \mathrm{Se}, \mathrm{Te}) . \mathrm{Y}$ діапазоні температур випаровування $(T=320-700 \mathrm{~K}$ для сірки, $T=420-490 \mathrm{~K}-$ селену і $T=400-600 \mathrm{~K}-$ телуру) 
в рамках мас-спектроскопічного методу досліджено склад пари цих елементів, за допомоги методу оптичної спектроскопії вивчено спектри випромінювання в діапазоні довжин хвиль від 200 до 600 нм і, використовуючи електронні струмені високої енергетичної однорідності, виміряно повні (інтегральні) перерізи утворення позитивних і негативних йонів S, Se i Te. Знайдено, що в умовах проведених досліджень у парі халькогенів основними компонентами є молекули 3 кількістю атомів $n$ від 2 до 8 . У спектрах випромінювання за енергій бомбардувальних електронів нижче 10 еВ спостерігаються в основному смуги двоатомних молекул, а за вищих енергій $(E>15 \mathrm{eB})$ з'являються окремі атомні та йонні лінії, до того ж за $E=50$ еВ найінтенсивнішими серед них є лінії однозарядних йонів. Показано, що найефективнішим каналом реакції є взаємодія електронів з двоатомними молекулами цих елементів, а інші процеси в основному пов'язані з розпадом багатоатомних молекул. 3 аналізу енергетичних залежностей характеристик процесів знайдено пороги збудження і йонізації продуктів взаємодії. Ви- явлено особливості на енергетичних залежностях функцій збудження і йонізаціі. Вперше в цих дослідженнях виявлено двозарядні йони двоатомних молекул сірки та атомів селену і телуру, а також зареєстровано появу тризарядних йонів двоатомних молекул сірки. Доведено, що основний внесок в повний (інтегральний) ефективний переріз йонізації як позитивних, так і негативних йонів вносять процеси взаємодії електронів з двоатомними молекулами $\mathrm{S}_{2}, \mathrm{Se}_{2}$ i $\mathrm{Te}_{2}$. Окрім експериментальних досліджень проведено детальні теоретичні дослідження. Виконано розрахунки та зроблено теоретичний аналіз характеристик структури гомоатомних молекул сірки $\mathrm{S}_{n}$, селену $\mathrm{Se}_{n}$, телуру $\mathrm{Te}_{n}(n=2-8)-$ міжатомних відстаней, потенціалів йонізації, енергій спорідненості до електрона, енергій дисоціації. Енергетичні характеристики використано для розрахунку енергій появи однозарядних та двозарядних йонних фрагментів вказаних молекул в процесі дисоціативної йонізації. Проведено ретельне порівняння отриманих даних з наявними експериментальними та теоретичними даними. 